\title{
Mechanical Systems for Energy Storage - Scale and Environmental Issues. Pumped Hydroelectric and Compressed Air Energy Storage
}

David J. Evans*, British Geological Survey, Keyworth, Nottingham, England, Gideon Carpenter, Evidence, Policy and Permitting Directorate, Natural Resources Wales, Pembrokeshire, Wales, and Gareth Farr, British Geological Survey, Cardiff, Wales.

Corresponding contributor. Email: dje@bgs.ac.uk

\section{Abstract}

This chapter introduces large-scale utility (bulk) energy storage in the form of pumped hydroelectric (PHS) and compressed air energy storage (CAES). Both are mechanical energy storage technologies, converting electrical energy into potential energy and both fall into the category of grid-scale, energy management. Brief reviews and discussions relating to the general operational aspects, legislative and environmental aspects of the two storage types are provided in the context of UK development. Both storage technologies offer the potential for better integration and penetration of renewable electricity sources and the reduction of greenhouse gas (GHG) emissions.

\section{Introduction}

International, national and regional energy policies aim to promote the use of renewablebased electricity (RES-E) to reduce carbon emissions and secure local power supplies. The European Union has set ambitious greenhouse gas (GHG) emission reduction targets of $20 \%$ by 2020 and $80 \%$ by $2050 .{ }^{1}$ In addition, the United Nations set a target of doubling the renewables share in the global energy mix by 2030 , from the $18 \%$ seen in 2010 , to $36 \%$ in $2030 .^{2}$ The transition to and increasing the use of renewable energies such as wind and solar, which are by nature intermittent, will therefore introduce increased natural variability 
into electricity generation and capacity. To meet patterns of demand that do not follow such variations in generation, there will be a need for fast-ramping, back-up generation, supported by reliable forecasting and, importantly, increased bulk, grid-scale storage capacity for electricity generated from renewables.

The United Kingdom (UK) has made considerable progress in decarbonising electricity generation as it moves towards a low-carbon energy system to meet climate change targets. This process has involved increased deployment of renewable energy technologies and changes in electricity consumption, alongside decommissioning of ageing coal, nuclear and gas-fired power stations. ${ }^{3-5}$

These rapid changes are presenting challenges for the future of the UK's electricity system. The increase in renewables is leading to an increasingly decentralised generating system and higher amounts of generation intermittency from natural energy sources. The increase in intermittency requires flexible generation to balance the system. In the past, fast-response thermal generation has largely met this need. The UK National Infrastructure Commission has set out priorities for a future energy system identifying the role of interconnectors, energy storage and flexible demand as being key innovations that will enable a smart power system to secure supply and meet carbon targets. ${ }^{6}$ Importantly, it has been calculated that these innovations would save consumers up to $f 8$ billion in system operating costs that would otherwise have been required for conventional investment in the energy system.

Whilst interconnectors will play an important role, increased energy storage will not only balance existing flexible generation, but will enable greater amounts of renewables to be integrated into the system in the future. Technology developments and falling costs mean that battery storage is becoming increasingly common at a range of scales, although collectively their energy storage capacity remains small.

Energy storage involves converting energy from forms that are difficult to store, to more convenient or economically viable storage forms. The energy can be stored in various ways, including chemical, electrochemical, thermal and mechanical storage. Some technologies provide short-term, small-scale energy storage options, whilst others represent grid- 
support, load levelling and longer-term mechanical bulk (utility scale) energy storage options (see Figure 1). The two largest sources of mechanical energy storage are Pumpedhydroelectric storage (PHS) and compressed air energy storage (CAES) ${ }^{7}$ :

1. PHS - this is a type of hydroelectric energy storage used by electric power systems for load balancing. Energy is stored in the form of gravitational potential energy of water, pumped from a lower to a higher elevation reservoir. Typically, pumps are run by low-cost surplus off-peak electric power. During periods of high or peak electrical demand, release of the stored water through turbines generates electric power. Pumped hydroelectric storage is, however, a proven technology that can reliably deliver a large-scale and fast-responding storage capacity. ${ }^{8}$ Globally it is the most common form of energy storage, with a capacity of 188 gigawatts (GW), representing $96 \%$ of total global energy storage capacity. ${ }^{7}$ Geography, however, constrains the ultimate capacity for PHS and as such, in most developed countries only limited prospects exist for further development, including in the UK, ${ }^{9,10}$ although significant potential for hydro-storage capacity may still exist in many other areas around the world. ${ }^{11}$

\section{Conventional (diabatic) CAES, or adiabatic compressed air energy storage (ACAES)}

- this is essentially equivalent to PHS in terms of applications, output and storage capacity. CAES is the second commercially proven, large-scale electrical energy storage (EES) after PHS, but instead of pumping water from a lower to a higher reservoir during periods (generally off peak) of excess power or energy produced by base gas, oil, nuclear or coal-fired units, air is compressed and stored in an air store 'reservoir' (currently salt caverns). As with pumped storage, release of power can be very quick and at peak times, as the air is withdrawn and used in the generation of electricity. CAES is viewed increasingly as offering bulk storage potential and a solution to levelling intermittent renewables generation (wind-power and solar photovoltaic plants [PV]) and maintaining a system balance. ${ }^{12,13}$ CAES technology is based on the principle of traditional gas-turbine plants and has some advantages over pumped storage, including the fact that its visible impact on the landscape is lower and there is more scope for building CAES facilities nearer the centres of wind- 
power production, especially in Germany and areas of the US. Worldwide CAES capacity is 431 megawatts (MW). ${ }^{7}$

CAES is not, however, an independent system, as it requires gas for heating of air and has to be associated with a gas-turbine plant during electricity generation: it cannot be used in other types of power plant during generation. ${ }^{14}$ More importantly, the requirement of combusting fossil fuels and the associated emissions make CAES less attractive compared to other EES technologies. ${ }^{15-17}$ However, advances in CAES technologies and linking to renewables generation (including offshore wind) offer the prospect of improved cycle efficiencies, with the reduction and possibly elimination of emissions.

(insert Figure 1 around here)

The smaller contribution of grid-scale energy storage from CAES, with only two commercial facilities constructed and currently operational using solution-mined salt caverns, does not reflect physical or environmental limitations, more the lack of policy and economic drivers for energy storage in general and CAES in particular. ${ }^{18}$

This chapter considers the two main types of bulk, grid-scale, mechanical energy storage in PHS and underground (geological storage) CAES. Underground geological storage offers potentially very large volumes and is of five main types: salt caverns (solution mined or conventional mining), porous rock (aquifer or depleted hydrocarbon field), hard rock mined void, abandoned non-salt mine and lined-rock cavern.

In the UK, four PHS sites are operational and a further six planned, whilst only one CAES plant is planned in Northern Ireland, although others are being considered in Cheshire, all using salt cavern storage (see Figure 2).

(insert Figure 2 around here)

Non-geological CAES options not considered here include above ground, or shallowly buried containers or pipes. ${ }^{19}$ Whilst such systems are attractive in that they permit the siting of CAES plants almost anywhere as no underground geological storage formation is required, such systems are estimated to be about five times more expensive than salt-based air storage caverns and porous aquifer based air storage systems. ${ }^{20}$ Other novel systems 
include energy bags secured to the sea bed, ${ }^{21}$ schemes linking wind turbines with energy storage in supporting legs, ${ }^{22-24}$ or where power is converted directly from the rotor by means of gas/air compression within the rotor blades. ${ }^{25}$

\section{Pumped Hydroelectric Storage - introduction to the technology, geology and environmental aspects}

PHS is a well-established form of storage used by electric power companies in many countries for load balancing, utility scale electricity storage. Plants that do not use pumped storage are classified as conventional hydroelectric plants. Essentially, in PHS water pumped from a lower to a higher elevation reservoir during off-peak periods stores energy in the form of the gravitational potential energy of water. In comparison to conventional hydroelectric dams and power generation, the reservoirs used with PHS are smaller and generating periods are much shorter, being measured in hours to parts of days. Pumped storage is the largest-capacity form of grid energy storage available, with more than 300 facilities worldwide. ${ }^{26}$ However, the relatively low energy density of PHS/PHES systems requires either a very large body of water or a large variation in height between the reservoir and turbines. ${ }^{27}$

PHS was first deployed at sites in the Swiss and Italian mountains in the $1890 \mathrm{~s}^{28}$ and the first sites in Germany date back to the $1920 \mathrm{~s}^{29}$. The first use of PHS in the US was by the Connecticut Electric and Power Company in 1930, using a large reservoir located near New Milford, Connecticut. The water was pumped to the storage reservoir from the Housatonic River c. $70 \mathrm{~m}$ below. ${ }^{30}$ In the UK, the first PHS facility commissioned was at Ffestiniog in North Wales during the 1960s. Dinorwig was the first hydropower development built, using an old slate quarry in Elidir Mountain in the 1970s, with the modern Dinorwig plant having opened in 1984 and which has provided over 30 years of storage and supply. ${ }^{31}$

A number of PHS system configurations are possible, including open- and closed-loop, underground and pump-back systems (see Figure 3). Open-loop systems generally comprise an upper reservoir with no real natural inflow (inflowing river), which delivers water through tunnelling to the turbines underground and discharges to a river or lower reservoir. In some cases, the lower reservoir is the ocean, with the system using seawater. The upper reservoir 
may be an open natural or engineered body of water anywhere at the surface, as long as there is sufficient topography to provide the 'head' of water required for operation. This could be in mountain sites, or along coasts with sufficiently high cliffs. The reservoir could be manmade, or make use of an existing depression or mined void such as a former quarry, as at operational Dinorwig and the proposed Glyn Rhonwy plant in North Wales. ${ }^{31,32}$ Such sites tend to be located in areas of massive, homogenous, hard rock types such as igneous and crystalline metamorphic rocks like granites and gneisses, or some hard sedimentary rock types like dolomites. These rock types are more likely to contain fewer fractures and be impermeable, preventing leakage. However, grouting and lining of the storage and any dam structure may be required. Thus, sites are likely to be in mountainous areas and potentially in areas of outstanding natural beauty, introducing social and ecological issues to proposed developments. There are examples where delay or abandonment of pumped hydro construction has occurred because of environmental concerns. ${ }^{33}$

Underground PHS operates in a similar fashion to conventional PHS (see Figure 3), with the exception that, whilst involving a surface reservoir and an underground powerhouse, the lower reservoir is underground and mined from hard rock. ${ }^{34}$ It converts the energy of a water column flowing from a surface reservoir to the underground reservoir and then pumps the same water mass back to the surface. The system eliminates dependence upon natural topography and enables design for higher head operation. In this sense, it carries a lesser environmental impact in comparison to conventional PHS.

(Insert Figure 3 around here)

Closed-loop systems not involving connection to surface waters involve both reservoirs being excavated underground, with a number of projects considered in old mines, including a $1500 \mathrm{MW}$ project at Norton, Ohio and a $1300 \mathrm{MW}$ project in California. ${ }^{35,36}$ Pump-back plants operate as a hybrid combination of pumped storage and conventional hydroelectric plants, with an upper reservoir that is replenished in part by natural inflows from a stream or river. There has been modification of some standard hydroelectric power plants to operate with a pump-back system, such as the Grand Coulee Dam in the US. This was expanded in 1973 with water pumped back up from below the dam ${ }^{37}$ and similar conversions of other such plants are under consideration in other countries. 
The design of almost every PHS/PHES power plant is highly dependent on the site characteristics: there needs to be sufficient water available and both the topography and geology of the area must be favourable. Suitable sites are, therefore, likely to be in hilly or mountainous regions, which are potentially in areas of natural beauty and which would pose additional social and ecological issues. All schemes will require very site-specific investigations to determine rock mass qualities and if major permeable zones, such as faults or fractures in the rock, exist. Most reservoirs will require some sort of engineered lining (often clay) to reduce leakage rates and risk. Evaporation may be a problem in some areas.

In the US, a growing number of proposed projects are avoiding highly sensitive or scenic areas, with some proposing to take advantage of 'brownfield' industrial sites such as old mines, using different mined levels as the reservoirs. One such $1300 \mathrm{MW}$ scheme is being considered by Eagle Crest Energy in California, which would reduce environmental impacts to a minimum. ${ }^{36}$ Although additional challenges exist when compared to using fresh water, PHS plants can operate with seawater, with the world's first demonstration of seawater PHS at the $30 \mathrm{MW}$ Yanbaru project in Okinawa, Japan, commissioned in $1999 .{ }^{38}$ Built atop a cliff, it used seawater; however, due to lack of anticipated local electricity demand the plant was dismantled in 2016. ${ }^{39}$

\subsection{Efficiencies and Economics}

PHS presents a number of benefits ${ }^{7}$ :

- It is a mature technology where installations have a long design life enabling it to play an important role in the long-term planning and management of energy supply systems;

- Its large scale of storage allows it to deliver for long discharge periods contributing to security of supply;

- Provision of frequency response and short-term operating reserve services;

- Energy arbitrage or the time-shifting of electrical energy by consuming the surplus from renewables at times of high availability or use of lower cost, baseload 
electricity power to pump into storage and delivering fast response discharge at higher-value periods of peak or system demand;

- High-flexibility response of absorbing and generating electricity smooths the demand profile between highly variable renewable electricity source (VRES) generation and the response by conventional thermal plants, enabling them to operate with improved efficiency and at lower cost.

Although PHS stations are net consumers of energy they remain an important component of an integrated, renewable energy system. They have system efficiencies of 70 to $85 \%$, which compares favourably with other mechanical energy storage systems such as compressed air energy storage (CAES) which has efficiencies in a similar range. In contrast, hydrogen fuel cells have an efficiency of just 20 to $50 \%$ and lithium ion batteries an efficiency of nearly $100 \% \cdot{ }^{14,40}$

The construction and installation costs of PHS are estimated to be twice that of conventional hydropower plants with similar capacity while operating costs are almost equal. ${ }^{41}$ With capital costs estimated between $£ 500$ and $£ 2000$ per kilowatt of installed capacity, $^{7,42}$ it has been shown to be the most cost-efficient storage technology, with a levelised cost of delivered electricity of $£ 105$ per megawatt/hour $(\mathrm{MW} / \mathrm{h}){ }^{42}$

Despite the storage benefits that PHS schemes can deliver for energy systems, they currently face a number of economic challenges where the greatest risk is uncertainty in long-term revenue. PHS schemes are complex infrastructure projects requiring extended periods for development and construction, high capital expenditures and have a long design life of 40 to 80 years. ${ }^{43}$ This type of investment is, therefore, not ideal for cost recovery in market-driven energy systems.

Most historical PHS has developed where electricity markets have a degree of public ownership. Analysis has shown that a reduction in the global development of PHS coincided with large-scale deregulation of electricity markets during the 1990 s. $^{14}$ The technology requires long-term investment and some certainty on return, where a stable regulatory and financial environment will, therefore, be a pre-condition to attract private funding. Modern 
liberalised energy markets tend not to provide this certainty where they are difficult to forecast, contracts are short-term and future policy decisions can be unpredictable, leading to increased risks associated with developing this type of hydropower scheme. ${ }^{44}$

Revenue streams for PHS will, therefore, need to come from the range of services that the technology can deliver, although each of these streams is subject to considerable uncertainty. Although the technology also delivers a number of external benefits, such as reduced carbon emissions, lower systems costs and energy security, there is currently no mechanism to internalise their value.

The UK National Infrastructure Commission concludes that current regulatory conditions unintentionally disadvantage storage providers, preventing them from participating across the various electricity markets, but that much greater use could be made of the technology where better regulation creates a level business environment between generation and storage. ${ }^{6}$

The UK government has developed interventions in the energy market to provide greater certainty for investors in some sectors, although these are either not currently viewed to favour PHS or actively favour other technologies. The Capacity Mechanism was introduced to provide support for backup generators to help balance the energy system, but the timescale on which it operates is considered too short to attract investment in PHS. ${ }^{45,46}$ Development of the Cap and Floor mechanism was specifically to support investment in interconnectors to the UK. ${ }^{47}$

Although a number of PHS developments are currently at advanced stages of planning, there remains some uncertainty as to whether they will progress to construction unless appropriate measures are put in place to provide favourable investment conditions for private finance. ${ }^{7}$

\subsection{UK Deployment of PHS}

\subsubsection{Existing Facilities}


There are currently four PHS schemes operating in the UK (see Figure 2) and with a capacity of $2828 \mathrm{MW}$ they represent $1.5 \%$ of global capacity. These are Dinorwig ${ }^{48}$ (Gwynedd, North Wales) at $1728 \mathrm{MW}$, Ffestiniog $^{49}$ (Gwynedd, North Wales) at $360 \mathrm{MW}$, Cruachan $^{50}$ (Dalmally, Scotland) at $440 \mathrm{MW}$ and Foyers ${ }^{51}$ (Highlands, Scotland) with a capacity of $300 \mathrm{MW}$. The Ffestiniog, Cruachan and Foyers schemes were commissioned in 1963, 1965 and 1975, respectively. The Dinorwig power station, commissioned in 1984 and having taken 10 years to complete, is one of the largest PHS schemes in the world, where the flow of $60 \mathrm{~m}^{3} \mathrm{~s}^{-1}$ is released from the upper Marchlyn Mawr reservoir, through turbines set in the former Dinorwig quarry and discharging into Llyn Peris.

\subsubsection{Potential for Future PHS}

The increasingly important role of storage in our energy systems has led to a renewed interest in new PHS schemes. Whilst topography, water resource availability, environmental and landscape protection are principle constraints to the development of new schemes, a Geographic Information System (GIS) based study concluded there is still considerable potential for development of more pumped-storage sites in the UK. ${ }^{52} \mathrm{~A} 2010$ study for the Scottish Government identified there being a role for $7000 \mathrm{MW}$ of new pumped-storage hydropower to meet Scotland's energy system storage needs by $2030 .{ }^{53}$ Based on a typical scheme capacity of $400 \mathrm{MW}$, this means a requirement for 17 new schemes, and the study concluded that it is unlikely this number of sites is available. In reality the number of potential sites for the construction of large, new PHS schemes is likely to be limited and more comprehensive, site-level studies will be required to increase confidence in estimates of future UK capacity.

There is, however, interest in developing a small number of new sites in the UK and upgrades to existing sites to increase capacity. Collectively they could more than double the UK's current PHS capacity. A summary of these is given below:

- Coire Glas (Scotland) - consents secured for a new $600 \mathrm{MW}$ scheme although studies are being carried out to increase this to $1500 \mathrm{MW} ;{ }^{54}$

- Balmacaan (Scotland) - proposals to develop a new site for a $600 \mathrm{MW}$ scheme;

- Glenmuckloch (Scotland) - proposals to develop a new $400 \mathrm{MW}$ scheme; ${ }^{55}$ 
- Glyn Rhonwy (Wales) - consents secured for a $50 \mathrm{MW}$ scheme although applications are being made to increase this to $100 \mathrm{MW}^{32}$

- Cruachan (Scotland) - proposals to upgrade the current scheme to add up to 600 MW of additional capacity; ${ }^{56}$

- Sloy (Scotland) - Conversion of existing 152.5 MW hydropower scheme through addition of $60 \mathrm{MW}$ pumping capacity; ${ }^{57}$

- Muaitheabhal (Isle of Lewis) - proposals for a new $300 \mathrm{MW}$ scheme.

\subsubsection{Traditional Sites and Potential Problems}

Historically, PHS schemes were constructed in mountainous or upland areas utilising existing but modified natural lakes for upper and lower reservoirs. This type of scheme, described as an open-loop system, has the reservoirs in hydrological continuity with existing water catchments. Enlargement of an existing natural lake generally creates the reservoirs through construction of an impoundment to provide the increased storage volume required for power generation. Hydraulic controls are established on the lower lake (reservoir) to regulate outflows and retain necessary storage volumes for pumped-hydropower operation. The Dinorwig scheme is typical of this arrangement. The connectivity of open-loop schemes with natural hydrological systems means that their operation is likely to have impacts on the wider water environment. Conversely a closed-loop PHS scheme is one in which there is limited hydrological connectivity beyond the boundary of the engineered scheme and operates, from a water resources perspective, largely independently of its hydrological setting. The proposed 100 MW Glyn Rhonwy scheme, near Llanberis in North Wales, is a good example of a closed-loop scheme that would utilise two redundant slate quarries to create the upper and lower reservoirs, each with a storage volume of 1.1 million $\mathrm{m}^{3}$. The mountainous topography is necessary to provide not only the landform suitable for dam construction and reservoir storage, but also the hydraulic head necessary for power generation. To illustrate, the Cruachan scheme has a reservoir storage volume of 10 million $\mathrm{m}^{3}$ whilst the hydraulic head for the four UK pumped-storage schemes ranges between 300 and $500 \mathrm{~m}$. 
Given the scale of conventional PHS schemes in upland areas, they are typically constructed using tunnels and chambers to convey flow, house turbines and provide access and service routes instead of using buried or overground infrastructure. There are risks associated with extensive use of tunnels in such schemes and tunnel collapses have occurred in many developments, both in the UK and internationally. Although a conventional hydropower development, the tunnel collapse on the newly constructed Glendoe scheme in Scotland put the scheme out of action for three years at an overall cost of $£ 100$ million (see Figure 2). ${ }^{58}$ Numerous other collapses have been recorded in countries with major hydropower development programmes, such as in Ethiopia, ${ }^{59}$ Vietnam $^{60}$ and China. ${ }^{61}$ Causes have been attributed to poor construction practices, poor or inadequate geological assessment and unfavourable geological conditions.

\subsubsection{Cliff-top Sites}

Recognising the many constraints of typical inland, mountain settings for PHS, there is increasing interest in the use of seawater and cliff-top sites. These types of scheme would operate in the same way as traditional PHS schemes but would require construction of only the upper reservoir on land at elevation and use of seawater for power generation, discharging into the sea, which acts as the lower reservoir. As described above, the first experimental seawater scheme was on Okinawa Island, Japan, in 1999. ${ }^{38,39,62}$ There were a number of challenges in using seawater for the scheme. To prevent leakage of salt water into the terrestrial environment, the upper reservoir was lined, whilst the quality of the water created difficulties in operation and maintenance due to its corrosive nature. To reduce the impact of the scheme on the marine environment, environmental mitigation measures were installed. ${ }^{63}$ Increasingly, cliff-top sites are seen as potential alternatives in places with limited scope for conventional upland schemes and with less impact on lake and river ecosystems. Investigations into the feasibility of new cliff-top schemes are ongoing in a number of countries, including Australia ${ }^{64}$ and Hawaii ${ }^{65}$. Use of seawater is also under consideration in a low-head context, with the conclusion that it is a technically and economically feasible option ${ }^{66}$.

\subsection{Environmental and Regulatory Factors in PHS}




\subsubsection{Overview of Environmental Regulation for PHS}

PHS schemes are large, complex civil engineering projects that are likely to have significant impacts on their local environment during the construction, operation and decommissioning stages of their design life. Although the general design principles of PHS schemes are similar, their environmental impacts will vary according to where they are located, how they are arranged and are operated.

Extensive legislation is in place in the UK to protect the natural environment. This ranges from targeted conservation of high biodiversity value habitats and rare species of flora and fauna, to protecting the quality of our wider environment, including soils, air, water and landscapes. In some cases, such as water, a key purpose of the law is for the proper and equitable use of a common natural resource.

Regulation of activities affecting the environment is achieved through a system of permits, licences and consents issued and enforced by range of public sector agencies and authorities across the UK. The principal environmental regulators are Natural England (NE) and the Environment Agency (EA) in England, Natural Resources Wales (NRW), Scottish Environment Protection Agency (SEPA), Scottish Natural Heritage (SNH) and Department of Agriculture, Environment and Rural Affairs in Northern Ireland (DAERA). Local Planning Authorities also have a statutory duty to consider the environmental impacts of development in decision making for Town and Country Planning.

The underlying approach for environmental regulation requires that development activities are assessed for their impacts, leading to the issue of a consent or assumed permission, authorising an activity where the impact of that activity on the environment can be controlled to meet standards of protection set out in legislation. The consent will include specific conditions on how that activity must be carried out, where failure to comply with these conditions is an offence and can lead to enforcement action.

The level of regulation of controlled activities generally varies according to environmental risk. Some activities meet low risk criteria, which, although controlled in law, may be 
undertaken without the need for a specific consent if, when undertaking that activity, a set of generic rules are followed. Conversely, bespoke licences may be required for high-risk activities where extensive analysis of potential environmental impacts must be submitted to the regulator to inform a licensing decision.

It should be noted that differences exist in environmental legislation between the devolved administrations in the UK. Whilst the overall objectives of national legislation remain similar, the processes involved in obtaining authorisations and conditions associated with them may vary, although much of our domestic environmental legislation has developed in response to European Commission directives with duties transposed into UK law.

Environmental regulation covers an expansive range of complex subject areas, from impacts to internationally rare bryophytes or invertebrates, to effects on noise, landscape and management of wastewater. The aim of the following sections in this chapter is not to provide complete and exhaustive detail on all aspects of environmental regulation but to provide a brief introduction and overview of some key areas relevant to the development of PHS, with a focus on ecological impacts. Although there are engineering and operational differences between PHS, storage reservoir and run-of-river hydropower schemes, they pose common environmental risks where the development of any large hydropower scheme should follow a standard process of environmental assessment and will need to meet similar regulatory requirements. Any assessment is required to consider a range of regulations and legislation as illustrated in Figure 4.

(insert Figure 4 around here)

These sections are presented with the caveat that if they wish to further their understanding of any subject areas described in this chapter, then readers should seek detailed advice and guidance from the relevant environmental regulator. Finally, this text was written prior to the UK having left the European Union and some uncertainty remains over the long-term impacts of Brexit on environmental regulation. 


\subsubsection{Environmental Assessment Process}

An Environmental Impact Assessment (EIA) is the core tool enabling a consistent and structured approach to be taken when assessing how a development will affect the environment, the significance of potential impacts and the options available for mitigating those impacts. It is likely that a statutory Environmental Impact Assessment (EIA) will be required for all PHS schemes where generation capacity is greater than $0.5 \mathrm{MW}$ and/or the development is located fully, or partly, in an environmentally sensitive area. ${ }^{67-74}$ The process can lead to improved environmental design and provides decision makers with the information they need for Town and Country Planning and environmental regulation (see Figure 5).

(insert Figure 5 around here)

\subsubsection{Abstraction and Impoundment Licensing}

Water resources are managed across the UK using a regulatory system of abstraction and impoundment licensing, which is central to the development and operation of pumpedstorage hydropower schemes. ${ }^{75-78}$ It is highly likely that these licences will be required for future PHS, although actual requirement will be dependent on the specific arrangements of individual schemes. The licensing system is in place to ensure the sustainable use of water resources for society at a national scale where this includes, for example, public water supply, industrial, navigation and amenity purposes. The licensing system also protects the ecology of our lakes and rivers by controlling the amount of water available for abstraction and governs construction of impoundments in watercourses where there is an obstruction, impedance or diversion of flow.

Whilst Water Resources legislation or Controlled Activities Regulations are the principal legal tools used to implement abstraction and impoundment licensing, a raft of wider environmental law exists that is specific to the protection of certain sites, habitats and species. These must be considered within the licensing process and be fully addressed before a license can be issued. ${ }^{79-82}$ One of the most important of these is the Water Framework Directive (WFD). 
The WFD targets protection of inland surface waters (rivers and lakes), transitional waters (estuaries), coastal waters and groundwater. It is based on a spatial structure of River Basin Districts, each of which is sub-divided into water bodies representing the water environment at catchment and sub-catchment levels. The WFD has introduced a cyclical process of river basin planning, involving the characterisation and assessment of impacts on river basin districts, environmental monitoring, setting environmental objectives and the design and implementation of a programme of measures needed to achieve them.

Environmental regulators must take the WFD into consideration when determining abstraction and impoundment licenses, ensuring authorisations meet environmental standards and don't compromise environmental objectives.

Article 4.7 of the WFD does, however, include provision for derogation of its objectives in certain circumstances. This recognises that some impact to the water environment may be necessary for society, but only where a development meets the criteria of providing benefit to human health, human safety, for sustainable development or other overriding public interest. In such cases, it must be demonstrated that all steps will have been taken to mitigate the adverse impacts of the activity on the status of the water body and that it cannot be achieved by a significantly better environmental option for reasons of technical infeasibility or disproportionate cost. ${ }^{83}$ Compliance with objectives and standards of other European Community legislation such as the Habitats Directive will still be required.

Environmental legislation is more extensive now than in the 1960 s and 1970 s when the Dinorwig and Cruachan schemes were constructed and, as described earlier, our water environment is now expected to meet the environmental standards of the WFD as well as there being more protection for designated sites, habitats and species. The implications of this are that open-loop schemes that have hydrological connectivity beyond the development boundaries will present a risk of wider ecological impact and face greater challenges in meeting the regulatory requirements for abstraction and impoundment licensing than a closed-loop scheme that has a higher level of hydrological independence from its surrounding drainage network. 
Any raised dam structure or engineering works proposed to enhance storage capacity of a natural lake will require an impoundment licence. Where a natural lake is utilised for a lower reservoir there may be less need to increase storage volume, although it is likely it would be necessary to install some form of hydraulic control on its outflow to manage levels for hydropower scheme operation. Like the upper reservoir in an open-loop system, a lower reservoir utilising an existing lake would have its own natural upstream catchment and pattern of inflows, with subsequent outflows reflecting the storage and attenuation characteristics of the lake. Impoundment licensing would be required to permit construction of outflow control structures from the lower reservoir, as their operation would impede natural outflow and alter the hydrological regime in the downstream watercourse.

Legislation recognises these storage reservoirs as inland waters or sources of supply, where any water taken from them would require authorisation via an abstraction licence. It is, therefore, likely that for any new scheme a licence would be required for the release of water from the upper reservoir for power generation and conversely to allow water to be pumped from the lower reservoir back into the upper storage. Abstraction from one reservoir to another within a closed-loop system such as the quarry-based Glyn Rhonwy scheme, probably would, however, be exempt from licensing, with the exception of the need to abstract from a source of supply outside the system to import 'infill' and 'top-up water'. It is also likely that closed-loop, quarry-based schemes using existing voids would be exempt from the need for impoundment licencing if their engineering works were not creating a raised structure that obstructs or impedes surface water flows within an open hydrological system.

Where storage reservoir catchments are small and have limited inflows, it might be necessary to augment the water resource in the pumped storage system with a transfer from an adjacent catchment, which in turn would require a transfer licence. Like an abstraction licence, a transfer licence authorises abstraction of flow from one source of supply with subsequent discharge to another source of supply without intervening use.

Inter-catchment transfer of water for operational purposes, or to increase water resource availability for PHS, presents several environmental risks that require careful assessment. Of primary concern is the risk of spreading invasive, non-native species. ${ }^{84}$ There is also a risk of 
distributing existing native species of fish, macrophytes and invertebrates between catchments via mass water movement, with the potentially undesirable consequence of introducing them into an ecosystem in which they may currently be absent. Bio-security risk assessments are, therefore, essential components of the EIA. Inter-catchment transfer should also be assessed in the context of water quality in order to avoid introduction of flow into a riverine or lake ecosystem that disrupts the natural nutrient, chemical and quality balance in which that catchment's aquatic organisms have evolved. Fish screening will be required on abstraction intakes where fish populations are present in the open-system reservoirs but are less likely to be needed in closed-systems if fish are absent, preventing their ingress to the penstock and turbines.

Natural lakes used as reservoirs and actively managed for power generation will have a significant impact on both lake and stream hydrology and where potential changes will require analysis to inform the licensing process. Changes to natural outflows might include an overall reduction in flow volumes within the downstream channel and loss of flow variability, particularly in the low- and medium-flow ranges. This will affect the timing, frequency, magnitude and duration of components of the natural flow regime. Alterations to these ecological flow components change the hydrological, hydraulic and geomorphological parameters of the river and riparian environment, modifying the condition of the habitat upon which river biota are dependent to progress through their life cycles. $^{85}$

Fluctuations in lake water levels (where the lake is an actively managed reservoir as part of a hydropower scheme) have also been shown to adversely affect littoral invertebrate and macrophyte communities. ${ }^{86-88}$ Whilst the flora and fauna of the littoral zone of lakes is dependent on a range of physical characteristics of the shoreline, including slope, substrate and exposure to wave action, studies have shown that the degree of control and consequent duration, frequency and extent of water-level changes are of fundamental importance to littoral communities. ${ }^{89,90}$ In upper reservoirs of pumped-storage schemes large fluctuations in water levels occur on a frequent basis and have a significant impact on littoral flora and fauna, ${ }^{88}$ whilst lower reservoirs experience fluctuations within naturally occurring ranges that are less likely to adversely affect lake ecology. ${ }^{87}$ 
It is likely, however, that to meet current regulatory requirements, particularly the WFD, future open-system schemes would need to mitigate their impacts in the form of more dynamic operating regimes and greater complexity in compensation-flow releases from storage reservoirs than in the big hydropower schemes of the past. ${ }^{85}$ The detail of mitigation measures would be dependent on the ecological and geomorphological sensitivity of the downstream watercourse to changes in flows and of the effects of fluctuations in water levels on lake-flora and fauna. ${ }^{89-91}$ They could, for example, take the form of seasonally varying compensation flows, actively managed, periodic reservoir releases and seasonal restrictions on timing, volume and frequency of abstractions to retain lake water levels within natural ranges. Such operational controls would be incorporated into abstraction and impoundment licence conditions, or set out within a formal operating agreement, against which assessment of regulatory compliance can be made.

Potential changes to surface water flows and groundwater levels resulting from scheme development should be analysed for their connection with other existing water features such as springs, flushes and mechanisms of water supply to wetland areas. Dewatering is likely to be a key component of construction works. An abstraction licence may now be required for this activity in England and Wales. There are, however, exemptions for temporary, small-scale, low-risk dewatering activities from both surface and groundwaters, subject to their meeting restrictions based on duration, site sensitivity and volumes. An application for an abstraction licence in this situation will require support from a Hydrogeological Impact Appraisal. ${ }^{92}$ It may be necessary to apply for a Consent to Investigate a Groundwater Source, which authorises test-pumping and enables monitoring of the effect of any drawdown on local surface water features, the results of which should inform the hydrogeological impact appraisal. In Scotland, abstraction of water from quarries or dewatering is a controlled activity covered by General Binding Rules or licensing, depending on the nature of the operation. ${ }^{93}$

\subsubsection{Regulation of Dam and Reservoir Safety}

In the UK, reservoirs created by structures designed to hold water above natural ground level are controlled by legislation. The roots of the legislation date to early 20th Century 
dam failures and the loss of life caused by dam failure, and the subsequent catastrophic flooding that can occur. The laws vary between England, Northern Ireland, Scotland and Wales, ${ }^{93-96}$ but revolve around the common principle that the design, construction, alteration, maintenance and eventual removal of raised reservoirs is done under the scrutiny of qualified civil engineers. The point at which regulation applies is identified by the capacity of water retained above natural ground level, which is either $10000 \mathrm{~m}^{3}$ or another figure provided by specific regulations. The required civil engineers are specialists within the field of reservoir construction and may only act as reservoir panel engineers if appointed by government on recommendation by the Institution of Civil Engineers. Before construction of any reservoir, advice should be sought from the relevant regulator regarding specific laws applicable and the steps to be taken to comply with this.

\subsubsection{Water quality}

Open-loop system pumped-storage hydropower schemes have the potential to affect water quality through the principal mechanisms of:

- Increasing reservoir storage capacity through enhancement of natural lakes by dam construction or increased hydraulic control of outflows;

- Introduction of regulated/compensation flows into watercourses downstream of impoundments;

- Mixing of reservoir water during pumped storage operation.

Changes to water quality can adversely affect the conditions for aquatic flora and fauna in reservoirs and downstream rivers and streams. Lake water bodies naturally become thermally stratified where solar heating warms the surface water layer, known as the epilimnion, while water at the bottom becomes cooler and denser, known as the hypolimnion. Surface water will heat up and cool down more rapidly and over a greater temperature range than deeper water. In natural lakes, the extent to which the water layers become mixed is caused principally by disturbance of the surface by wind and other local factors such as tributary inflows. 
When the surface water cools to below the temperature of the water below it, it becomes denser and sinks, causing the water column to mix towards an isothermal state in which the water temperature is the same from surface to bed. During winter months lakes, therefore, tend to be isothermal, whereas during summer months they tend to be stably-stratified, with warm water at the surface and cooler water beneath ${ }^{97}$.

Enhancements to natural lakes to increase storage capacity will alter the physical characteristics of the water body and potentially lead to changes in thermal stratification, particularly where there is a low surface area to volume ratio, rendering it less responsive to fluctuations in solar radiation. ${ }^{98}$

Changes in water temperature are significant to aquatic ecology, not only through the direct effect on biological processes and metabolic rates of aquatic organisms, but indirectly, where it affects other parameters of water quality and chemistry such as dissolved oxygen, conductivity, $\mathrm{pH}$ and density. Ecological impacts may occur where the quality of water is substantially altered from that naturally occuring. Whilst outflows from natural lakes occur from the lake surface, discharges from impoundments are frequently released from depth, leading to cold-water compensation flows or reservoir releases that affecting the thermal and chemical characteristics of the downstream watercourse..$^{98,99}$ In summer months where thermal stratification has occurred in upper reservoirs, degasification of cold water can occur as flow passes through the turbine leading to low dissolved-oxygen levels in discharge water. ${ }^{100,101}$ Regular operation of a PHS scheme can, however, disrupt natural patterns of circulation within both upper and lower reservoirs, leading to increased vertical mixing and disturbance to natural thermoclines and processes of stratification with potential consequences for lake ecology.

From a regulatory perspective, a full assessment of how any new PHS scheme would affect water quality in connected water bodies would need to be undertaken to meet the requirements of the WFD.

\subsubsection{Designated Sites, Protected Species and Habitats}


The Environmental Impact Assessment for any proposed PHS development should identify the risk and significance of any likely impact on protected sites, habitats and species. Several European- and UK-level designations provide statutory protection for sites of high conservation importance across the UK. The principal designations are Special Areas of Conservation (SACs), Special Protection Areas (SPAs), Ramsar wetland sites and Sites of Special Scientific Interest (SSSIs). The Joint Nature Conservation Committee website provides comprehensive information about these designations. ${ }^{102}$

SACs are designated under the commonly termed EC Habitats Directive. ${ }^{99}$ The Directive lists habitats, plant and animal species of international importance within its Annexes. It is the duty of competent authorities (CAs) across the UK, including but not limited to environmental regulators and Local Authorities, to maintain these features at, or restore them to favourable condition status.

The Birds Directive ${ }^{105}$ sits parallel to the Habitats Directive, with the objective of specifically protecting wild birds and associated habitat. Similar to the Habitats Directive, there is a requirement to designate and maintain sites of importance for the conservation of the rare and vulnerable species within SPAs. SACs, together with SPAs, form the Natura 2000 network of areas protected for nature conservation across member states of the European Union.

Ramsar sites are specific areas of marsh, fen, peatland or water habitats of high conservation value designated under the Convention on Wetlands of International Importance. ${ }^{106}$ They include onshore, transitional water and coastal sites and, with relevance to hydropower developments, many upland lochs/lakes and wetlands.

SSSIs (ASSIs in Northern Ireland), are protected by law to prevent operations and activities from being carried out that might damage or destroy the scientific interest of part or all of the site. ${ }^{107-113}$ Consent must be sought from the relevant environmental regulator to carry out any controlled activity from which there may be risk of damage to SSSI features. Undertaking controlled activities without consent is an offence, which could lead to an unlimited fine and payment of costs necessary to repair any damage to the site. 
The Habitats Directive and 1981 Wildlife and Countryside Act largely protect individual species. The Act lists protected plants and animals under various schedules to which varying degrees of protection apply. The local regulating authority can grant licences under the Act to allow certain activities to be carried out that would otherwise be offences under the legislation, providing that the activities being undertaken are for non-developmental purposes such as scientific, research, education and conservation.

Lists of priority species and habitats identified as being threatened and requiring action for their conservation have also been drawn-up under the UK Biodiversity Action Plan (UK BAP). ${ }^{114}$ UK BAP priority species and habitats are incorporated into statutory lists for domestic or UK legislation. ${ }^{110,115-118}$ Following devolution of many environmental duties, individual UK nations have developed their own biodiversity strategies. These reflect national priorities, requirements and responsibilities, although the principal underlying objective remains to halt the loss of biodiversity and continue to reverse previous losses through targeted measures to conserve species and habitats. ${ }^{119,120}$

The network of internationally important SACs was chosen to best represent the features requiring protection under the Habitats Directive where many of those features are found in riverine, lakes/lochs and upland environments. Given that sites suitable for future PHS developments are likely to be in similar remote upland areas, there is a high likelihood that the construction or operation of any new PHS scheme would affect a Natura 2000 site and would need to address the requirements of the Habitats Directive as a central part of the development process.

The Habitats Regulations require that CAs, which in the case of hydropower developments will principally be the Local Planning Authorities and environmental regulators, must carry out a formal assessment of the implications of any proposals. This will be individually or in combination with other plans and projects that may affect the designated interest features of European Sites before deciding whether to permit or authorise any such proposals. These plans and projects in the case of PHS might refer to Town and Country Planning Consents, abstraction and impoundment licences or other environmental permits associated with 
specific construction activities. The assessment process is usually termed the Habitats Regulations Assessment (HRA), which requires a precautionary approach to be taken in any assessment as to whether a proposal is likely to have an adverse effect on the integrity of a site and thereby compromise the ability of the site to meet its conservation objectives. ${ }^{121}$ If it cannot be concluded beyond reasonable scientific doubt that a plan or project will not result in an adverse effect on the integrity of a European site, then the permission or consent being sought should be refused by the CA.

There is, however, provision within the Habitats Directive for a derogation that under certain circumstances would allow a plan or project to be approved, even though the HRA has shown that there is potential for it to have an adverse impact on site integrity. ${ }^{122}$

Significant long-term impacts on designated sites or protected species are more likely to be associated with open system type PHS schemes than closed ones, where both their construction and operation risks have more geographically extensive impacts due to their high connectivity with adjacent terrestrial, wetland and riverine ecosystems.

A key component of the overall EIA process is the Ecological Impact Assessment (EcIA), which provides a framework through which designated sites and protected species that may be affected by a proposal can be identified, and assessment of development impacts completed. The Chartered Institute of Ecology and Environmental Management (CIEEM) has produced comprehensive guidance on this. ${ }^{123}$

Protected habitats may also form a component of protected landscapes, including those in National Parks, Areas of Outstanding Natural Beauty (AONBs), Special Landscape Areas (SLAs), National Scenic Areas (NSAs) and Areas of Great Landscape Value (AGLVs) in Scotland. An assessment of projects, such as large pumped hydropower on landscapes, will form a key part of any Town and Country planning application and may be included in the EIA.

\subsubsection{Managing Construction to Protect the Environment}


Construction of a PHS scheme will involve key activities including the construction of temporary access tracks, working and lay-down areas, construction of permanent access roads, tunnelling, trenching, site dewatering and land drainage, and use of construction plant. Translocation of species and habitats is often considered as an option to mitigate impacts to ecology although in-situ conservation is preferred by environmental regulators. ${ }^{124,125}$ Reduced impact on the environment can be achieved through comprehensive planning and sensitively managed site operations, which can substantially reduce the impact of construction activities on the environment. This can be achieved through the development of, and adherence to site-scale Environmental Management Plans (EMPs) and activity-specific method statements. ${ }^{126}$ The underlying principles within an EMP involve understanding the risks from construction activities, identifying the environmental receptors and the potential pathways in which they are connected. The EMP and method statements must have regard for industry best practice and any regulatory requirements that apply to a given construction activity. ${ }^{127,128}$

These documents can have a high level of importance where their development, and the operational procedures set out within them, can be secured as conditions in licences or consents by a Regulating Authority and used to demonstrate compliance with environmental legislation. Failure to comply with them may lead to a breach of consent and an environmental offence with potential for enforcement action. The EMP should include a programme for environmental monitoring pre-, during- and post-construction. Associated with this should be an ongoing audit during construction activities in which checks are made to ensure that environmental mitigation measures and sensitive work practices are being implemented. It is usual, and often a condition of licence on large civil engineering projects, that an Ecological Clerk of Works (ECoW) is employed with specific responsibility for site environmental management.

Preventing pollution of the water environment is central to good site environmental management, where the water environment includes both surface and groundwater. Potential causes of pollution from construction sites include leakage/spillage of fuels, oils and fluids associated with machinery, use of construction materials, i.e. concrete, and uncontrolled discharge of site run-off that is high in sediment. A range of rules, consents 
and permits apply to activities in which there is a risk of pollution and a detailed assessment of consenting requirements should be included within the EMP. ${ }^{87,129-134}$

Regulations covering waste management are complex and are best addressed through the development and application of a Waste Management Plan. The plan should detail who is responsible for managing waste on site, what types of waste will be generated, how it will be stored and handled, the options for recycling and disposal, which contractors will be used to legally recycle or dispose of the waste and how waste generated will be measured. Advice should be sought from national regulators in developing the plan and securing waste management consents or permits. ${ }^{135,137}$

The construction of access roads and trenches for pipes and cabling need careful planning to minimise the risk to site hydrology. Access roads should be sited to avoid sensitive habitats such as peatland or wetland areas and maintain natural pathways for surface water drainage. ${ }^{138}$ Construction of trenches risks introducing preferential flow pathways that intercept or disrupt natural sub-surface drainage patterns and risks either reducing the availability of flow for existing wetland features, or increasing discharge into an alternative site. Risks and measures to mitigate the impact of construction activities on site hydrology should be included in the site drainage plan described earlier.

The importance of a Biosecurity Risk Assessment has already been described in the context of PHS design and operation. The Risk Assessment should extend to the construction phase to establish construction site biosecurity control measures, preventing the spread of invasive non-native species and diseases from site operations. ${ }^{139,140}$

Whilst the principal aim should be to avoid impact on habitats during construction of infrastructure, it is likely that some loss of habitat will occur in large projects. This loss might be short-term due to the need, for example, for construction of temporary access tracks, lay-down and working areas, or permanent for roads or where increases in reservoir or lake capacity inundates terrestrial habitat. A Habitat Management and Restoration Plan allows for sensitive habitats to be identified and enables careful planning and design of infrastructure, using techniques such as micro siting to minimise impact on them. 
Environmentally considerate construction practices and restoration techniques can be set out in method statements to support the plan. Post-construction reinstatement aims to reverse the impacts of temporary disturbance and recover the original condition and functioning of the habitat. ${ }^{141,142}$

\section{Compressed Air Energy Storage - Introduction to the Technologies, Geology and Environmental Aspects}

Compressed air energy systems have been in wide use since the late 19th century, with tanks often used for storage. Various cities including Paris, Birmingham, Dresden and Buenos Aires, had systems where the delivered power was used in homes, industry and transport (e.g. trams). The mining industry utilised rock caverns for small-scale compressed air storages utilising them to power mine trains, pumps, pneumatic drills and hammers. ${ }^{143}$

The use of the underground to store fluids and gases under pressure is also not new, with patents issued dating back to the turn of the $20^{\text {th }}$ Century. One of the first applications in the use of compressed air was for mining operations, as illustrated by the Ragged Chute Compressed Air Plant in Northern Ontario, Canada. Built in 1910, at the peak of the Cobalt silver boom, it was the world's only water-powered compressed air plant. ${ }^{144,145}$ With only two brief maintenance interludes, the plant ran continuously for just over 70 years until destroyed by fire in the 1980s, after which it was converted to a $7 \mathrm{MW}$ hydroelectric power station in $1991 .{ }^{145}$ The first references to electrical energy storage by means of compressed air storage for utility application were included in patents issued in the United States, ${ }^{146}$ the turbine manufacturer Stal Laval in Sweden and Great Britain (1952), and to Djordjevic in Yugoslavia (1950). ${ }^{143}$ Since the first patents, reviews and assessments of large-scale CAES potential have taken place since the 1960s, with small air-storage chambers developed alongside power stations in Scandinavia (see Figures $6 \& 7$ ). The technologies behind current and future electrical energy storages based on compressed air, $\mathrm{H}_{2}$ or synthetic methane (SNG) storages are derived from proven storage technologies developed for underground natural gas storage, dating back as far as 1915. e.g.147 
The value of CAES was recognised in the early 1980s and the US Department of Energy initiated a broad CAES research programme with efforts directed at evaluating the potential for grid-scale CAES in many configurations, including caverns in bedded and domed salt, excavated openings in hard rock environments (using water-column pressure compensation or not) and aquifers. ${ }^{148}$ Expectations then and at times since were high that CAES would gain utility acceptance ${ }^{149,150}$ but there has not been the take-up expected, with only two commercial projects operating, both hosted in salt caverns. Commissioned in 1978, Huntorf in Germany was the world's first commercial CAES plant, driving a generator to contribute $290 \mathrm{MW}$ for three hours every day to meet local peak-electricity demand. It remains operational almost 40 years later. ${ }^{151,152}$ The $110 \mathrm{MW}$ plant at McIntosh in Alabama, USA, was the second commercial CAES facility, which also is operational today. ${ }^{153}$ Since then, other tests and demonstration plants have appeared briefly, but nothing has progressed to commercial operation. These have included aquifer storages (Sesta, Italy, and Pittsfield, USA, in the 1980s and lowa in 2010), a salt cavern storage (Gaines, Texas, USA in late 2012) and the world's first pilot 1 MWh test plant with thermal storage in 2016, using the abandoned unlined Pollegio-Loderia tunnel, north of Biasca in the Swiss Alps. ${ }^{148,154,155}$

In the late 1990s concerns grew surrounding GHG emissions from fossil fuel use and interest turned to the large-scale deployment of renewable energy sources such as wind and solar. The intermittency of these energy sources and other factors, including the high price of natural gas fuel for peaking plants, and increased concerns about grid reliability, has resulted in renewed interest in this technology. ${ }^{17,156}$. From the early 2000 s, a number of active proposals for CAES development in the US were under consideration, including a $260 \mathrm{MW}$ aquifer storage facility in lowa and a $2700 \mathrm{MW}$ CAES plant in an abandoned limestone mine at Norton in Ohio (see Figures $6 \& 7^{157,158}$ ). Comprehensive reviews of early and subsequent CAES R\&D efforts can be found in the literature. ${ }^{143,148,156,159,160}$ This interest in CAES has continued in the USA, with a number of projects supported by the Electric Power Research Institute (EPRI) and funding from the American Recovery and Reinvestment Act of 2009 (ARRA). Many US states have over the years, looked into CAES potential, e.g. the PG\&E/EPRI 300 MW CAES aquifer assessment in southern California, linking storage to the large Tehachapi Wind Project ${ }^{161}$ (see Figure 7). The timeline summarises compressed air usage and CAES development to the present day. 
Current operational CAES facilities at Huntorf and McIntosh prove CAES as a commercially viable and mature, cost-competitive technology to meet grid-scale storage requirements (see Table 1). However, there are geological and geographical limitations on the distribution of these rocks and the ultimate volumes available to support salt cavern CAES. It is widely accepted that the potential exists to advance CAES technology beyond caverns to use pore space in aquifers and depleted hydrocarbon reservoirs as the storage volume. This section outlines the basics of CAES in terms of the applications, geological storage options, potential regulatory requirements and the environmental impacts and considerations, when considering CAES technology.

(insert Table 1 around here)

\subsection{Applications of CAES}

Increasingly, the applications and potential of CAES are recognised in terms of supporting power system operation and CAES will play an ever-growing and important role in energy management between generation and consumption. Potential applications and benefits of CAES include ${ }^{164}$ :

- Price arbitrage

- Peak shaving and demand-side management - using CAES to manage the demandside energy by storing at the lower price and releasing the stored electrical energy during peak-demand times

- Integration of more renewable power generation plants - enabling the seamless integration of renewable power generation plants into the existing power network to provide stable power grids whilst solving the problems of the inherent intermittence and instability of renewable power generation

- Applications to Smart Grids and wind energy networks - playing a role in both supply and consumption

- Applications to compressed air engines - compressed air energy being converted into other forms of mechanical energy through compressed air engines 
- Applications in other fields - including in the event of power supply failure, CAES acting in black-start capacity, rapidly providing power to important users

\subsection{CAES Configurations - DCAES, ACAES/AACAES, ICAES}

CAES is a form of mechanical storage, the basic concept of which is simple: electrically driven compressors convert electric energy into potential energy (more precisely, exergy) of pressurised air, which charges a storage that can be of many potential types. During compression from atmospheric pressure to a storage pressure of $c .1015$ psia (70 bar), the air temperature rises to $\mathrm{c} .600{ }^{\circ} \mathrm{C}$ (the heat of compression). Processing and geological storage of compressed air at such high temperatures is not possible and the heat must be reduced to around $110 / 120^{\circ} \mathrm{F}\left(43 / 49^{\circ} \mathrm{C}\right)$ prior to storage, which is achieved by a series of intercoolers. The handling of the heat during compression and prior to expansion provides the main CAES configurations, which can be in the form of conventional, diabatic CAES (DCAES), (advanced) adiabatic (ACAES/AA-CAES), or near isothermal CAES (ICAES, see Figure 8).

(insert Figure 8 around here)

When electricity generation is required (e.g. when power generation cannot meet load demand), the stored pressurised air is withdrawn (and expanded) in the turbine/generator unit. However, during expansion the air cools and prior to entering high pressure turbines must be heated, either by the combustion of fossil fuels, or the heat recovered from the compression process.

In the current operational (D)CAES plants the heat of compression is lost to the atmosphere as waste (reducing system efficiencies), and there is a need for additional fuel in the expansion process (see Figure 8a). The air then passes through a series of high- and lowpressure turbines, where it is mixed with fuel and combusted, with the exhaust expanded through low-pressure turbines. The high-pressure turbines capture some of the energy in the compressed air (see Figure $8 a$ and b)..$^{\text {e.g.14 }}$. Both the high- and low-pressure turbines are connected to a generator to produce electricity (see Figure 8). The exhaust is hot and, prior 
to release, waste heat may be captured via a recuperator and used during the air withdrawal phase, as at the McIntosh plant (see Figure 8b). At the Huntorf facility, reheating occurs in combustors using natural gas fuel. The overall efficiency of (D)CAES is approximately $42 \%$, as for the Huntorf power plant, ${ }^{151}$ which is low in comparison to other EES technologies (see Table 1). Following 28 years of operation, the retrofitting of the whole expansion train at Huntorf provided an increase in the output power from $290 \mathrm{MW}$ to $321 \mathrm{MW} \cdot{ }^{152}$ However, the exergy of the exhaust is still not utilised. The addition of a recuperator to recover the waste heat from the gas-fired expansion process provides improved efficiencies (c. 54\%) at the McIntosh CAES plant. ${ }^{157}$

The burning of fossil fuel produces $\mathrm{CO}_{2}$ emissions, reducing the efficiency of the storagerecovery cycle and adding to the cost of the recovered electrical energy. This compromises the ecological benefits that most would associate with renewable energy sources and technologies. The current focus of research is mainly on the so-called 'second generation' ACAES/AACAES, the design of which is to deliver higher efficiencies via a zero-carbon process that eliminates the supplemental gas-firing process. In an adiabatic (or advanced adiabatic, ACAES/AA-CAES) process, the heat of compression is captured and stored in a thermal energy storage (TES). It is later used to heat the air during withdrawal and expansion, increasing round-trip efficiencies. During withdrawal operations, the air leaves the storage cavern and passes through the TES before being applied to an expansion turbine coupled to a generator, without the need for any co-firing of fuel. Improved round-trip efficiencies of $>70 \%$ are expected, ${ }^{40}$ with $70 \%$ reported in RWE's 'ADELE' AACAES test project. ${ }^{165}$ Predicted system efficiencies at the ALACAES AACAES tunnel test facility, commissioned in 2016, are expected to approach 90\%. ${ }^{154}$ Emerging from RWE's work, General Electric (GE), together with EPRI, looked at two designs, build and possible performance testing of a large-scale ACAES plant. ${ }^{162}$ One design was to develop an ACAES plant using existing commercial GE equipment (not requiring the development of a hightemperature compressor system) or, alternatively, to design, develop, and manufacture an entirely new high-temperature compressor for application to ACAES.

Other emerging technologies include isothermal or near-isothermal CAES (ICAES), which also offer the potential for increased efficiencies over DCAES and ACAES/AACAES (see Figure 
$8 d)$. The process requires the continual removal of heat from the air during the compression cycle (interstage cooling) and its continuous addition during expansion to maintain an isothermal process. To date, technology testing has generally involved above ground processes, including storage. ${ }^{156}$ However, General Compression (GC) completed the design and installation of a General Compression Advanced Energy Storage (GCCAES ${ }^{\mathrm{TM}}$ ) plant, integrated with a 2 MW Gamesa G97 wind turbine, a pre-existing former fuel storage salt cavern, a surface brine pond (for thermal storage) and connection to the Lea County Electric Cooperative electrical grid (see Figure 8d). ${ }^{166,167}$ Such configurations do not require gas line connections, or produce air pollutants, including coal ash, $\mathrm{CO}_{2}$ emissions or other risks and would be ideally suited to areas remote from conventional power plants and associated transmission lines, or where conventional power projects would not gain approval. Commissioned in late 2012, the plant operated until ceasing operation in $2016,{ }^{168}$ but results will prove invaluable in moving the technology forward.

Further efficiencies would be possible if, instead of using energy derived from fossil fuels during compression, the compression is achieved using renewable energy sources (excess wind or PV, see section 3.7). Other studies aimed at increasing efficiencies and lowering costs, include high-temperature ACAES, where prior to compression the air is pre-heated, which could be linked to PV, or low-medium grade waste heat. ${ }^{169}$ To date, however, DCAES remains the only commercially implemented system.

\subsection{Geological Storage Options}

The following sections review briefly the main geological storage options, together with indications of costs and possible issues during storage. Underground gas storages operate by compressing gas during injection and which, on withdrawal, decompresses. The gas storages operate between maximum and minimum pressures and set pressure rate changes. This is in order to maintain the geomechanical stability of reservoir to avoid overpressuring and fracturing, or underpressuring and collapse. Rock strength and storage depths (equating to lithostatic pressure - the pressure or stress imposed on a layer of rock by the weight of overlying rock) determine the operational pressure ranges. The gas 
between the minimum and maximum pressures is the working gas volume, whilst the amount of unrecoverable gas that must remain in storage is known as cushion gas.

\subsubsection{Solution-mined Salt Caverns}

Thick, deeply buried (>250 m) bedded or domal halite/rocksalt ('salt', NaCl) deposits exist in many countries ${ }^{170}$ and provide the host to the two commercial CAES facilities. The favourable physical properties of halite means that the construction and operation of very large unlined caverns is possible, which offer highly flexible, inexpensive storage in comparison to other geological storage options (see Table 2). They are not only stable for very long periods of time, but halite is gas tight with no cavern pressure losses over often extended periods of storage (months), and are also inert with respect to liquid and gaseous hydrocarbons, as well as to oxygen and hydrogen. ${ }^{171}$ Salt caverns are constructed by a process known as solution-mining: water is pumped via cased boreholes into salt deposits deep underground, dissolving the salt to create a cavity and brine as a by-product. The brine is extracted, with the process continuing until the cavern is the required size and shape. The brine produced maybe either used for industrial applications, or is disposed of at sea or by injection into saline aquifers. The latter is often the case in many USA gas and hydrocarbon storage operations. Globally, salt caverns rank third in terms of natural gas storages, accounting for $6 \%$ of facilities as at $2014^{171}$ and represent the cheapest main storage option (see Table 2).

(insert Table 2 around here)

To date, the two operational commercial CAES systems both use solution-mined salt caverns. Huntorf operates with two air caverns (140000 and $\left.170000 \mathrm{~m}^{3}\right)$ and one gas storage cavern, ${ }^{151,173}$ whilst Mclntosh has one cavern $\left(566000 \mathrm{~m}^{3}\right) .{ }^{174}$ At Gaines in Texas, Texas Dispatchable Wind, LLC (a subsidiary of General Compression) commissioned and briefly operated a small-scale near-isothermal $2 \mathrm{MW}$ plant using a reconditioned former liquid hydrocarbon storage cavern (c. $31100 \mathrm{~m}^{3}$ or 265000 barrels) between late 2012 and 2016 (see Figure 6). ${ }^{166,167}$ The proposed ADELE adiabatic CAES demonstration plant in Germany was scheduled for completion in 2016 but has not progressed further. ${ }^{165}$ Other salt cavern sites assessed CAES around the world include ones in Israel, Canada and the UK 
(see Figure 6), with Gaelectric's current application to construct a 200-300MW plant near Larne in Northern Ireland ${ }^{175}$ and Haughey. ${ }^{176}$

\subsubsection{Porous Rock - Saline Aquifers and Depleted Fields}

Dependent upon the existence of a suitable caprock and trapping structure, porous rock formations with sufficient porosity and permeability offer potential for storage, with many gas storage facilities constructed using both depleted hydrocarbon reservoirs and aquifers (water-filled reservoirs). In the porous-medium storage concept, injection of air through a borehole displaces the water, creating an air 'bubble' within the pore space in the near-well region, creating a 'gas cap'.

Globally, with a proportion of 81 and $13 \%$ respectively, for stored natural gas, depleted field and aquifer structures represent the first and second most important storage types e.g.147,171. EPRI suggest that aquifer storage is the least-expensive geological storage option (see Table 2). However, a number of things require taking into account when considering CAES aquifer storage and that add to the costs of developing an aquifer storage. Firstly, geological and physical characteristics of aquifer formation, such as suitable trapping structure plus caprock and adequate porosity/permeability are not known ahead of time and significant investment has to go into investigating these and evaluating the aquifer's suitability for gas storage. The same would be true for CAES, with air also representing a lower energy density and value compared to natural gas or hydrogen. Secondly, all of the associated infrastructure may have to be developed, including installation of wells, extraction equipment, pipelines, dehydration facilities and specialised equipment near the wellhead, and possibly compression equipment. This increases the development costs compared to depleted reservoir sites. The aquifer initially contains water with no naturally occurring hydrocarbon gases (or air) in the formation and of the gas injected, a significant portion will be physically unrecoverable. Consequently, aquifer storage typically requires significantly more cushion gas than depleted reservoirs: up to $80 \%$ of the total gas volume. Thus, developing an aquifer storage facility for gas storage is usually time consuming and expensive, making it the least desirable type of natural gas storage facility. 
With depleted fields, proven porosity, permeability and trapping structure exist, but some potential technical challenges and problems arise when considering CAES. Firstly, residual hydrocarbons remain in the reservoir after production ceases. The injection of air can lead to co-mingling with the gas and give rise to the formation of ignitable gas mixtures during the withdrawal phase. Formation damage may also have occurred during production due to the de-pressuring and collapse of the reservoir. In a similar fashion, the caprock may have suffered fracturing during pressure decrease and its integrity may need consideration. Further risks arise with potential reactions between oxygen and the mineral constituents of the reservoir rock, which can lead to oxygen depletion and the potential for bacterial/microorganism growth due to the introduction of warm air/oxygen to the reservoir.

CAES in depleted fields has been, and is currently being, assessed with a number of these located in the US (see Figures 6 \& 7). As part of the 2009 ARRA Energy Smart Grid Demonstrations Program and storage demonstrations, PG\&E together with EPRI have considered projects in California for an advanced $300 \mathrm{MW}, 10$-hour storage CAES plant using a depleted gas reservoir. ${ }^{177}$ Borehole tests at candidate sites have been undertaken but, to date, there have been no test plants developed.

Potential benefits with aquifers may include enhanced deliverability rates if an active water drive exists (the natural, regional flow in an aquifer, or as water in the aquifer expands during hydrocarbon production), which supports the storage reservoir pressure through the injection and production cycles. However, the reservoirs have not previously been pressurised to the levels likely to occur during storage and reached when conditioning the reservoir - the aquifer contains only water and to begin displacing the pore water and replacing it with natural gas or air, high injection pressures are required. Water coning could occur, where water infiltrates the near wellbore region and is produced instead of hydrocarbons (or air). In addition, once injected, a certain amount of natural gas/air is physically unrecoverable, being trapped in the pore spaces. Since aquifers are naturally full of water (and not gas), cushion gas requirements may be as high as $80 \%$ of the total 'gas' volume. This results in less flexibility in injecting and withdrawing the stored gases and greater costs. 
Testing of aquifer storage sites has taken place (see Figures $6 \& 7$ ). Much early aquifer assessment took place in Illinois, USA, with the Pittsfield structure tested (c. $200 \mathrm{~m}$ below ground level) ${ }^{148,160}$ and which demonstrated the feasibility of daily cycling of compressed

air. ${ }^{148,160,161}$ However, reservoir pressures were lower than expected with 'fingering' of air within the aquifer found (the unequal movement of air in the porous rock, producing uneven or 'fingered' profile), both of which affect growth of the air bubble. Also, over longer storage periods, oxygen depletion occurred, related to the oxidation of minerals, particularly iron sulfides (pyrite).

Another early aquifer storage assessment was a $25 \mathrm{MW}$ test facility at Sesta (Italy), which ran between 1987 and $1991 .{ }^{178}$ Again, the project encountered less than ideal reservoir conditions and a 'geothermal anomaly', and was shutdown. The most recent aquifer storage assessment was the innovative $270 \mathrm{MW}$ Dallas Centre CAES project, coupled with wind generation near Des Moines, lowa, USA (c. $890 \mathrm{~m}$ below ground level). ${ }^{179}$ The project ceased following eight years of study and development due to geological limitations, including reservoir heterogeneity (thickness, permeability and porosity) and high sulfate concentrations in water.

Thus, despite a large US government research programme over 30 years ago, more recent testing of an aquifer site in lowa and modelling studies that suggest aquifer CAES is very feasible, fundamental questions remain regarding the hydrological and energetic performance of CAES in porous media. ${ }^{17}$

\subsubsection{Mined Voids - Abandoned Mines and Hard/Competent Rock Caverns (Unlined)}

This category includes two main types of unlined rock caverns (cavities) which are generally conventionally-mined (excavated) in competent rock formations: abandoned mines and specifically mined caverns for storage, both of which have been used as gas storages. Some rock masses are gas tight, but generally the host rock, whilst stable, has fractures and joints and is not tight with respect to liquids and gases. Hydrostatic pressure of the water in the overlying rock mass provides containment: groundwater above the storage percolates 
through the cracks and into the storage, preventing the gas from leaking outwards and upwards. The water collects in sumps at the base of the cavern, to be pumped to the surface. Water curtains are sometimes constructed, comprising a system of holes drilled above the storage and into which water is pumped to increase the hydrostatic pressure.

Gas storage has been undertaken in abandoned coalmines at Anderlues and Peronnes in Belgium ${ }^{181}$ and at Leyden in the USA. ${ }^{182}$ However, due to leakage the storages closed after a short period of operation. Liquid hydrocarbons have been stored in specifically mined unlined rock caverns in the USA and Europe since the 1950s. One former salt mine located at Burggraf-Bernsdorf in Germany is currently operating as a natural gas storage. ${ }^{171}$ The feasibility of storing wind energy as compressed air in the Lyons Salt Mine in Kansas was investigated in $2009^{183}$ but never progressed. Investigations took place into constructing a 2 $700 \mathrm{MW}$ CAES plant in a former limestone mine $\left(10\right.$ million $\left.\mathrm{m}^{3}\right)$ at Norton, Ohio, USA. ${ }^{158}$ Interest started in 2001, but the project stalled and now seems to have been abandoned. ${ }^{151}$

The construction of rock caverns is associated with a higher level of risk and accident compared to salt caverns and porous storages due to excavation of the caverns by mining techniques (drilling, blasting and clearing the fallen rock). Cost-wise, unlined rock caverns have the highest initial capital costs for geological storage options and these would be increased if the construction of water curtains were needed to provide containment. Although there have not yet been commercial compressed air storages, small unlined caverns, operated at air pressures around 0.8 MPa (116 psi/8 bar) were used from 1936 to support electricity supply in Finnish mine operations (including the Pyhäsalmi Zinc Mine ${ }^{184}$ ). Compressed air cushion surge chambers attached to hydropower plants use unlined rock caverns as part of power generation operations at Fosdalen and Rausand in Norway. ${ }^{185}$ Elsewhere, in Japan, a series of borehole tests were conducted for CAES potential in unlined caverns in a range of rock types during the 1980s, although no sites were developed (see Figure 6). ${ }^{186-188}$

\subsubsection{Lined Rock Caverns}


Lined rock caverns (LRC) are a variation on the mined void storage type, with rock caverns constructed and lined with an artificial, gas-tight barrier, generally comprising concrete and stainless steel sheet. The technology was proved for gas storage following the construction and testing of a pilot plant between 1988 and 1993 at Grängesberg in south-central Sweden and the opening of a demonstration cavern $\left(40000 \mathrm{~m}^{3}\right)$ at Skallen near Halmstad in southwestern Sweden. ${ }^{\text {e.g.189 }}$ Construction of several small CAES test facilities using LRC took place in former mine tunnels in Korea and Japan during the 1980s (see Figure 6). ${ }^{190,191}$ Tests were successful, but in general short and no facility was developed.

Investigations into the feasibility and stability of shallow CAES LRCs in cavities and tunnels is ongoing, with studies on the coupled thermodynamic, geomechanical behaviour and stability of lined caverns located at 60-120 m depth. ${ }^{189,192,193}$ Maximum air pressures of $20 \mathrm{MPa}$ may be possible, depending on the geotechnical conditions.

Although smaller volume and higher cost than other storage options (see Table 2), LRCs offer a number of distinct advantages over existing conventional underground storage types. They have greater geological flexibility, are a technology that provides adequate degrees of tightness and high storage pressures, even at relatively shallow depths, and have a capability for high-frequency cyclic operations. They thus can create conditions for the storage of large volumes of 'gas' in regions where more favourable rock types do not exist, or those present are unsuitable for geological CAES storage. As such, this storage concept is particularly well suited where the challenge for energy systems will be the management of electricity, because the major sources of renewable energy such as wind or solar do not always occur in regions with favourable geology.

Costs are the highest of all geological storage operations due to mining operations and the construction of the cavern lining. Capital expenditure (CAPEX) of the Skallen storage was $€ 27$ million, or $€ 675$ million. ${ }^{3,194}$

\subsection{Operational Modes of CAES 'Reservoirs'}


The operational nature of cavern and porous media storage differs. For salt caverns and mined voids, two operational modes generally considered, with compressed air in both systems stored at up to $70-80$ bar pressure, are (see Figures $8 \& 9$ ):

1. Fixed volume, variable pressure system (isochoric) - the most common mode, with a cavity or cavern of fixed volume operated over an appropriate pressure range, increasing as air is pumped in, and vice versa. Both Huntorf and McIntosh facilities operate in this mode and require throttling to maintain constant turbine inlet pressures

2. Constant pressure but variable volume storage cavity (isobaric) - the underground storage cavity is linked to a water (or brine) reservoir at the surface; as compressed air is pumped in, water is displaced from the cavity (brine compensation mode). The pressure in the cavern remains almost constant, despite the increase in volume of the air, which represents a more efficient system than the constant volume method. ${ }^{195}$ Examples of liquid hydrocarbon (propane) salt cavern storages operating by brine displacement are found on Teesside in the UK. ${ }^{196}$

(insert Figure 9 around here)

The two modes present different environmental considerations (see below). Recent publications ${ }^{\text {e.g.197 }}$ suggest the operational window for CAES salt caverns lies between 500 to $1300 \mathrm{~m}$ (see Figure 8), based upon operating pressures being directly dependent on depth and power-plant components. However, breakthroughs in compressor and turbine technology could enable CAES deployment to greater depths than previously possible, with $1500 \mathrm{~m}$ considered at Larne in Northern Ireland (Haughey ${ }^{176}$ ). To maintain the mechanical stability and integrity of salt caverns, they operate within a minimum and maximum pressure range and pressure change rate during injection or withdrawal. These limits are set by the mechanical properties of the salt and the depth of storage, and are generally between 30 and $80 \%$ of lithostatic pressure. However, CAES caverns may occasionally require lowering to atmospheric pressure during maintenance periods, although the lower pressures should be for the minimum time possible. ${ }^{151}$ 
Porous media storage presents different conditions and problems from those of salt cavern or mined voids, with significant differences existing between an open cavern and the distributed pore space in an aquifer (or depleted field), and how energy is stored (spatially). Pressure evolution in a cavern shows nearly uniform pressure throughout the cavern because in an open cavern there is very little resistance to air flow, permitting very rapid pressure propagation. In contrast, the aquifer rock provides a large resistance to airflow, which results in pervasive pressure gradients established by the injection of air. In an aquifer, reservoir pressure increases during initial fill period and then oscillates during each production, recharge, shut-in and production period, with much of the variation occurring in and near to the well. This is due to the reservoir itself, which limits the flow of air and thus the extent to which injection-related pressure propagates over time. ${ }^{17}$ Whilst aquifer storage may exhibit water compensation mode over the long term, it acts as a constant volume-variable pressure system for short- term cycling, ${ }^{160,198}$ with pressure gradients remaining throughout the injection period. ${ }^{18}$ During shut in, the gradient tends to diminish but does not disappear entirely in the reservoir and thus variable pressure (pressure gradients) rather than single pressure values dominate energy storage in an aquifer. Added to these physical constraints are the facts that system efficiencies and dynamics are affected by large loss of heat to the formation found through the wellbore, and the loss of oxygen in the stored air, probably due to oxidation reactions with minerals in the formation.

Other considerations may include aquifer water drive arising from regional flow and unconfined, or confined aquifers due to structural compartmentalisation. The latter, together with poor permeabilities, could lead to isolated pressure regimes, such that water drive does not exist, or is much reduced and. These issues may lead to both overpressuring during charging, or underpressuring during air withdrawal, as the influx of water to replace the air is not possible. Both situations may lead to loss of reservoir performance and permanent aquifer/reservoir damage. Gas storage experience in aquifers suggests that maximum charging pressures should not exceed c. $80 \%$ of lithostatic pressure, whilst maximum reservoir storage pressure should not exceed $50 \%$ of lithostatic pressure. ${ }^{160}$ Pore pressures exceeding lithostatic pressure could lead to fracturing or parting along bedding planes in the reservoir and overburden rocks, with the possibility of air loss, displacement of ground water and damage to surface structures. Depleted reservoirs may act in a similar 
fashion, but experience from production will assist the understanding of reservoir recharge and management.

\subsection{UK Potential for Deployment of CAES}

Shell and the Gas Board assessed CAES potential in the UK the late 1980s and 1990s. ${ }^{199,200}$ $\mathrm{ICI}$ (now Ineos) have looked at CAES prospects for their salt field in Cheshire and although the salt beds have been proved for gas storage caverns, no CAES project has been progressed. Interest has once again returned with sites under consideration in Northern Ireland and in England, both part-funded by EU programmes.

Following lengthy investigations, in 2015 Gaelectric submitted planning application documents for a deep (c. $1500 \mathrm{~m}$ ) salt cavern hosted CAES facility in the Larne area of Northern Ireland (Haughey ${ }^{176}$ ). Storelectric was planning a $40 \mathrm{MW}, 800 \mathrm{MWh}$ pilot plant using a salt cavern air store in NW England, ${ }^{162}$ although little information is available regarding progress.

\subsection{Planning and Regulatory Environment for CAES}

In the UK, halite beds occur only onshore in England and Northern Ireland (NI) and currently, salt cavern storages seem the most likely for a CAES facility. To date, no planning applications for CAES have been submitted in England, with the only one in the UK being for the Gaelectric project-CAES Larne, NI projectNI, submitted in $2015 .{ }^{201} \mathrm{NI}$ legislation differs in some details from that in England (The Planning Act 2008) and the separate planning legislation for Wales and Scotland. However, it provides evidence of the status of such a project in terms of national planning policies and applicable legislation. Thus, together with underground gas storage applications in England, in which similar storage technologies are employed, and existing oil and gas legislation, it is possible to highlight the main legislation and regulations that will likely be applicable to applications relating to large-scale energy infrastructure such as CAES in England (see Figure 10). 
The following overview attempts to place a CAES application in context with what is a complex EU and UK legislative and regulatory environment likely to affect CAES development in the UK (see Figure 10). It is necessarily brief and cannot address all issues. A number of Competent Authorities (CA) will be involved in the process, including the relevant environmental regulator, the Health \& Safety Executive (HSE) and, for some operations in offshore areas, the Maritime Agency (MA). The differing storage types will likely come under different areas of legislation/regulation, particularly in the offshore areas.

For the Gaelectric Project-CAES Larne, NI proposal, the Planning Act (Northern Ireland) 2011 is the primary planning legislation and is equivalent of the Planning Act 2008 (plus amendments) in England. This gives the NI Government responsibility for regional planning policy, the determination of regionally significant and called-in applications, and planning legislation. The EU Trans-European Energy Infrastructure (TEN-E) Regulation (347/2013 EU) sets out rules for the timely development of energy infrastructure across Europe and streamlining the permitting processes for major energy infrastructure projects (designated projects of common interest [PCI]) that contribute to European energy networks amongst Member States. $\mathrm{PCl}$ status demonstrates that projects conform to a range of criteria, including having significant benefits to at least two Member States, contributing to market integration and further competition, enhancing security of supply and reducing $\mathrm{CO}_{2}$ emissions. In October 2013, Project-CAES Larne, NI was designated a PCI and in July 2015 the Strategic Planning Division of the Department of the Environment confirmed it as a “Development of Regional Significance" under the new Planning (NI) 2011 Act and 2015 (Development Management) (DM) Regulations. The Department thus holds jurisdiction over the proposed development and the planning application.

This established the precedent in the remaining UK onshore areas for a CAES application to proceed through the main national Planning Act 2008 (as amended by the Marine and Coastal Access Act 2009, the Localism Act 2011 and the Growth and Infrastructure Act 2013). Offshore CAES will be subject to different legislation and probably will follow that around gas storage and CCS. 
The Planning Act 2008 and relevant national policy statements (NPS), as well as any other matters that are considered both important and relevant, established that large, nationally significant infrastructure projects (NSIPs) are now considered separately by the Planning Inspectorate (originally the Infrastructure Planning Commission, IPC). The Act created a new Development Consent regime (with the application for, and issue of, Development Consent Orders, DCOs) for NSIPs in the sectors of energy, transport, water, waste water, and waste (see Figure 10). It includes associated developments, which in the case of underground gas storage facilities comprises both surface works such as pumping/compressor stations, boreholes and pipelines to storage facilities, and monitoring boreholes.

Eleven National Policy Statements (NPSs) support this legislation, setting out Government policy on different types of national infrastructure development. Six of the NPSs are in Energy (EN-1 to En-6), all of which could have relevance to CAES, depending on the source of electricity and later generation. As Figure 10 suggests, other legislative and policy areas lie behind and provide reference during the DCO application process. This includes the National Planning Policy Framework (NPPF), which establishes policy for local planning authorities in various areas, including Mineral Planning and the sustainable use of minerals, to the preparation of Environmental Impact reports, adherence to water and borehole regulations and HSE requirements. The EA and HSE are statutory consultees in the process. A number of undergound gas storage projects have now successfully obtained a DCO, including the Preesall (2014) and Keuper Gas Storage (2016) applications, both constructing salt caverns. Preesall was subject to EA requirements and obtaining a consent to discharge trade effluent (brine), which at the time in England fell under the Water resources Act 1991 (as amended in the Environment Act $1995^{202}$ ). Applications today would also need to consider the Water Environment Regulations (2017) and National Planning Policy for Waste, the latter including waste (brine or rock) generated during the construction of mined voids.

(insert Figure 10 around here)

Additional legislation would likely apply for porous rock CAES storage where depleted hydrocarbon fields are considered. For onshore areas, alongside the Planning Act legislation, it is likely that certain other regulations applying to the water and oil and gas industry (O\&G) 
will apply to proposed developments. This is because any air injected to storage will likely co-mingle with residual gas and be produced together with the air during withdrawal cycles. The two important areas of legislation are the Petroleum Act 1998 (which vests all rights to the nation's petroleum resources in The Crown, including the offshore continental shelf area) and the Energy Act 2008. The Oil and Gas Authority (OGA), on behalf of BEIS and The Crown, grant a 'Petroleum Exploration and Development Licence' (PEDL) that confers exclusive rights to 'search and bore for and get' petroleum in a defined area. Northern Ireland issues its own licences to cover its onshore area independently of the OGA. The EA has issued guidance on the environmental permits required for onshore oil and gas (O\&G) operations in England. ${ }^{203}$

Use of aquifers for CAES, both on- and offshore, would be subject to legislation and a number of EA regulations relating to both surface and sub-surface infrastructure or operations, many of which are applicable to oil and gas activity. ${ }^{204}$ The primary aim of the EA is the prevention of pollution of groundwater and protection of it as a resource. But it is also to manage water supply, which might be required during the construction of salt caverns, either by abstraction from rivers, aquifers or the near-offshore area. Regulations would apply to the disposal of the brine in such operations. As part of aquifer protection, any boreholes drilled to develop and support the project would fall under the Borehole Sites and Operations Regulations (1995), which require boreholes to be properly completed to avoid communication and contamination between formations.

Offshore, CAES applications are likely to face slightly different legislation due to rights relating to minerals, the seabed and subsurface space invested in The Crown. Again, there is no experience relating to CAES and that of the offshore gas storage and CCS industries provides guidance. The Energy Act 2008 covers a number of areas, with the following likely to be applicable to offshore CAES: offshore gas infrastructure, carbon dioxide storage, Renewables Obligation, decommissioning of energy installations (nuclear, offshore renewables, and offshore oil \& gas) and offshore transmission. In terms of natural gas storage, anyone who wants to explore for, drill for or use a site in the UK's offshore area for that purpose must hold a licence issued by the OGA under Section 4 of the Energy Act 2008. In addition, for storage activities in all offshore areas, including the territorial sea, a lease is 
required from The Crown Estate (TCE), as Section 1 of the Energy Act 2008 vests all rights to store gas in the offshore area in The Crown. Northern Ireland's offshore waters are subject to the same licensing system as the rest of the UK continental shelf area (UKCS). The lease and licence provide the framework for regulatory consent for the physical activities at the site, e.g. intrusive drilling and the subsequent submission of a Gas Storage Development Plan (GSDP) for OGA approval. If it is intended to store gas in a petroleum reservoir (whether fully or partially depleted) the law requires a petroleum Production Licence (PL) because native gas will inevitably be produced from the reservoir when gas is recovered for use.

Storing gas in a non-petroleum related geological feature such as a salt beds or dome, requires no PL and only an application for a Gas Storage Development Licence is required. Aquifer storage would likely have to refer to legislation relevant to $\mathrm{CO}_{2}$ storage, which requires safeguarding of the aquifer and preparation of a GSDP. As such, the use of the subsurface storage space for CAES would likely fall under this legislation.

Should gas pipelines be required at a CAES site, then offshore oil and gas pipeline consents are also the responsibility of the Secretary of State for BEIS and are issued in accordance with the Petroleum Act 1998. Any CAES assessment is also likely to reference relevant British and European Standards on the construction and operation of underground (gas) storage facilities (BS EN 1918-1 to 5:2016) and the HSE SPC/ENFORCEMENT/185 document. ${ }^{205}$

Projects may lie across on- and offshore areas and thus more than one consenting jurisdiction and specifically across two main consenting regimes, which have overlapping regulations on EIA and HRA (Habitats Report Assessment) that apply, respectively. ProjectCAES Larne, NI falls within this category. ${ }^{201}$ In a similar manner, the Preesall Gas Storage development in NW England involved on-and offshore components, the latter requiring marine consents issued under Part 4 of the Marine and Coastal Access Act 2009. ${ }^{202}$ 


\subsection{Environmental Performance, Emissions, Sustainability \& Economics of CAES Systems}

A series of papers have reviewed the environmental performance, applications, outlook, potential and costs of various EES in power system operations. ${ }^{16,19,40,42,206}$ Clearly, no single EES technology can meet the requirements for all power system applications. However, CAES is recognised as an important technology with which to compensate for the intermittency and fluctuations that occur with renewable sources and thereby increase the penetration of renewables (wind power and PV). CAES requires suitable geology and has site-specific technological requirements, which when combined with a lack of grid-scale adoption, means a lack of data relating to the economic performance of sites. CAES, generally regarded as a storage technology to assist in reducing emissions, is also not a 'pure' storage system. It requires fuel for combustion in the turbine during the generation phase, which both increases operating costs and is associated with GHG emissions, though less so than normal gas-turbine generators. ${ }^{16}$ These factors further hamper the assessment and comparison of CAES with other EES technologies for grid operators, power suppliers, energy system analysts and policy makers developing regulation strategies. ${ }^{42}$ Many past environmental assessments have looked at diabatic CAES. Increasingly, research on the performance of ACAES systems ${ }^{207}$ and linking CAES with electricity production from wind power (which was discussed as early as $1976^{208}$ ) and using other fuels such as biogas as substitutes to further reduce the environmental impacts are under consideration. ${ }^{209}$ There is now a growing literature on the economic and environmental performance and benefits of ESS technologies and co-locating renewable generation and CAES as well as those relating to increased grid stability. ${ }^{9,15,16,210-212}$

\subsubsection{Economics of CAES - Capital Costs}

Costs of EES are discussed in the literature (see Table 1). ${ }^{14,40,207,213}$ Capital cost is one of the most important factors for the industrial take-up of EES ${ }^{14}$. However, a comparison of the merits and costs of the various technologies is not entirely straightforward. Levels of uncertainty and complexity hamper estimations and comparisons of the cost of large-scale EES systems: apart from PHS, their deployment is scarce, they are in differing stages of development, storage sizes can be different for the same power rating technical diversity, 
differences in application exist and the economic performance of existing sites is not widely reported. CAES has only two long-term commercial plants and the need to cost in the value of gas with all its market and supply variations further complicates assessments. That said, in general, EES technologies include two main sections: power conversion system (PCS, which may consist of two separated units for charging and discharging, with different characteristics) and energy storage section (that containing the storage medium, e.g. the cavern in $\mathrm{CAES}^{42}$ ).

Various studies have shown CAES and PHS to have certain economic advantages in terms of capital costs and construction energy requirements over other EES technologies (see Tables 1-3). In terms of construction, salt solution-mining for a CAES cavern is relatively low in energy intensity compared to building structures to house battery components and electrolytes. In addition, air and water CAES and PHS represent very cheap energy storage media when compared to batteries, which require intensive mining, refining and manufacture. ${ }^{16}$

The power and energy densities of different EES technologies play a significant role in determining the applicability and cost effectiveness of EES and supply. For a given amount of energy, the higher the power and energy densities are, the smaller the volume of the required energy storage system is. ${ }^{40} \mathrm{PHS}$ and CAES have low densities, requiring large reservoirs and are thus most suitable for use mainly in stationary, bulk (utility)-scale facilities, with discharge times of 10 hours or greater. ${ }^{40}$

(insert Table 3 around here)

Also important in determining the economic performance are cycle (round trip) efficiencies, ${ }^{40}$ with CAES having low cycle efficiency $(<60 \%)$, which improved from Huntorf (42\%) to the McIntosh plant (54\%). The next generation of ACAES plants promise greater efficiencies (c. 70\%). Lifetime and cycling times affect the overall investment cost, with low lifetime and low cycling times increasing the cost of maintenance and replacement. 
A growing literature exists on the levelised cost of electricity (LCOE) and levelised cost of storage (LCOS) of CAES and other EES technologies in three main applications: energy arbitrage, transmission and distribution (T\&D) support and frequency regulation. Typically, two main approaches exist when assessing the cost of EES technologies ${ }^{42}$ : calculating total capital costs (TCC, $€ / € / \$)$, or life-cycle costs (LCC; cost per kW). The majority of studies report the costs of CAES as TCC. ${ }^{42}$

TCC evaluates all costs to covering the purchase, installation and delivery of an EES unit, generally expressed in terms of the cost per kW [power], cost per kWh [energy] and cost per kWh per cycle. TCC costs comprise two main areas: firstly, above-ground equipment, and secondly, the cost of developing the below-ground energy storage (solution-mining of cavern, preparation and conditioning of a porous storage, or conventional mining of a hard rock cavern). Above-ground includes costs of the power conversion system (PCS, associated with the interface connecting the storage to the utility [typically cost per kW]) and balance of power [BOP] costs (including costs for project engineering, grid connection interface and integration facilities [e.g. transformers] and construction management that includes cost of land and accessibility).

Inexpensive storage media (air and water) mean that CAES and PHS have low energy costs, which for CAES where components have long lifetimes and do not require frequent replacement, reduces total storage costs. ${ }^{214}$ Capital costs for EES technologies show that in terms of the bulk, utility-scale storage unit, underground CAES (all geological options) represents the lowest costs in comparison with all systems, other than metal-air batteries ${ }^{14,40,214}$; calculated power and energy capital costs for CAES range typically between $\$ 400$ and $\$ 800$ per kW, or 2 - 50 kWh respectively (see Table 1). Calculated capital costs per cycle kWh of PHS and CAES show they are among the lowest of all storage technologies, at 0.1-1.4 and 2-4 c/kWh-per cycle, respectively. ${ }^{14}$ Elsewhere, 18 storage technologies were reviewed ${ }^{42}$ with calculated average TCCS of CAES being the lowest at $€ 893 \mathrm{~kW}$, or $€ 92 \mathrm{kWh}$ (see Table 3). However, the costs of CAES plants are themselves strongly influenced by the geology of the storage, ${ }^{157,215}$ with energy costs ranging from $\$ 1-5 / \mathrm{kWh}$ for solution-mined salt caverns, to $\$ 30 / \mathrm{kWh}$ for excavated hard rock caverns (see Table 2). Due to their low construction costs and widespread availability, many regard aquifers as suitable sites for 
compressed air storage. ${ }^{148,160}$ However, plant siting is critical to the success of a CAES plant construction effort: the Mclntosh plant spent less than \$10 million (in 2010 \$) to develop a $566000 \mathrm{~m}^{3}$ salt cavern. ${ }^{216}$ Interest rate (\%), energy cost $(\$ / \mathrm{kWh})$ and power cost $(\$ / \mathrm{kW})$ are the top-three factors affecting the total storage costs. ${ }^{214}$

\subsubsection{Economic of CAES - Life-cycle Costs}

LCC analyses, which may be annualised (ALCC; cost per kW-yr), consider investment and operational costs over the entire life-cycle of electricity storage (fixed operation and maintenance $[O \& M]$, variable $O \& M$, replacement, disposal and recycling, in addition to TCC). It depends directly on the characteristics of the service (e.g. number of cycles per year), the power market (interest rates, price of power) and technological features. The method enables a broad overview of different technologies with different system designs and various operation modes, permitting evaluation and comparison of technologies with different cost structures. Commonly used parameters in economic evaluations of electricity storage, expressed as cost $(€ / £ / \$)$ per kWh of electricity output, are the LCOE and the levelised cost of electricity storage (LCOS or LCOES).

The following summarises briefly recent LCC analyses of differing CAES configurations undertaken in various studies. LCOS values of 18 EES technologies were calculated by including all capital and operational expenses, discounted to today's values. ${ }^{42}$ The main conclusions were that both PSH and CAES have the lowest LCOS of all technologies for energy arbitrage (up to 8 hours) at 54 and $71 € / \mathrm{MWh}$ respectively (see Table 3 ). The data for bulk EES show the LCOE delivered by PHS as the most cost-efficient technology (120 $€ / M W h)$, with CAES second at $134 € / M W h$. In terms of the ALCC of EES systems applicable to bulk energy storage (energy arbitrage), PHS offers the minimum cost (c. $240 € / \mathrm{kW}$-yr), whilst for CAES, the cheapest technology in terms of capital costs, the costs of fuel and emissions decrease its profitability (c. $270 € / \mathrm{kW}-\mathrm{yr}){ }^{42}$

A US DoE survey calculated LCOS for PSH, CAES and a number of battery technologies for the US market with differing plant designs and cycles. The results were 150-220 \$/MWh for 
PHS, 120-210\$/MWh for CAES and between 60 and $6000 \$ / M W h$ for battery technologies. ${ }^{217}$

The LCOS for PSH, CAES and five battery technologies in 11 operational modes were compared to selected fossil alternatives. ${ }^{218}$ The results illustrated that CAES, with an LCOS of 192 \$/MWh, and PSH, with an LCOS of 188-274 \$/MWh, are near cost-competitive with gasturbines (165-218 $\$ / M W h)$. All studies show that big increases in LCOS occur with decreasing amounts of yearly discharged energy (longer storage times), due to the same CAPEX and operational expenditure (OPEX) costs relative to a smaller amount of discharged energy. ${ }^{219}$

CAES and PHS technologies use conventional machinery, with the lifetime of the plant and its operational economics largely determined by the mechanical components. The long lifetimes and numbers of cycles possible with both PHS and CAES plants, the latter of which can operate for 40 years or more with many thousands of cycles, means that PHS and CAES represent the lowest costs per cycle kWh among all the EES technologies. ${ }^{14}$ CAES, with low replacement needs compares well in terms of the LCC of those EES systems subject to significant replacement costs during the lifetime, which are more sensitive to interest rates. $^{42,214}$

Long-term storage costs of PHS and both conventional DCAES and ACAES/AACAES systems have been assessed, ${ }^{219}$ with the author concluding that for a storage charged and discharged once per year (one cycle per year), PHS is the most cost-efficient technology (between 93 and $185 € c t / k W h$ [euro cent]). The LCOS of DCAES at one cycle per year is significantly higher at above $2 € / \mathrm{kWh}$. For short-term storage operated almost daily, with $c$. 150 GWh of energy discharged per year, the PSH systems show the lowest cost with 5-9 $€ \mathrm{ct} / \mathrm{kWh}$. The LCOS of ACAES and DCAES systems are similar at 7-11 €ct/kWh (ACAES) and 10-12 €ct/kWh (DCAES). However, the differing cost structures of these two technologies, suggests the ACAES system has lower cost at a higher number of cycles, while the DCAES system is more competitive in the range of less full-load hours. A large share of the LCOS of DCAES arises due to the need for fuel, with the cost of the technology depending heavily on the cost and stability of natural gas prices. While DCAES has a high gas cost, the ACAES 
system has a high insurance cost. The estimated costs of the heat storage for ACAES are in the range of $25 \%$ of the total CAPEX. ${ }^{219}$

LCOS for a number of systems, including both PSH and ACAES, have been calculated. ${ }^{220}$ PSH was found to have the lowest LCOS of $2.5 € c t / \mathrm{kWh}$, excluding cost of charged electricity, but ACAES can operate at $5.3 € c t / k W h$. An LCOE assessment of various utility-scale EES technologies including PHS and CAES was undertaken, using a simple-cycle combustion turbine (SCCT) as the baseline technology for comparison and against which EES must compete. ${ }^{221}$ SCCT LCOE values were $86-126 \$ / M W h$, which compares to the mean LCOE for PHS and CAES of 46 and 55 \$/MWh, respectively. However, LCOE values for storage systems are very sensitive to costs associated with reservoir types and siting needs. These are increased by costly 'scrubbing' equipment required to clean the air of gases picked up during storage in depleted reservoirs, including potentially harmful $\mathrm{H}_{2} \mathrm{~S}$.

Regarding the electricity source, for the UK, the levelised cost of generating electricity from wind farms is higher than that of fossil fuel, which in part is linked to the costs of ensuring standby generation during periods of little wind or sun. ${ }^{222}$ An assessment of the Danish electricity system suggests that whilst CAES is technically capable of increasing VRES penetration, even in energy systems with very high shares of wind power and combined heat and power production (CHP) the investment in CAES systems cannot be justified and must be combined with other functions. ${ }^{223} \mathrm{~A}$ profitability analysis for PSH and CAES for the UK market suggests that neither of them is profitable without subsidy. ${ }^{222}$

\subsubsection{Environmental Performance and Safety of CAES}

The application of EES promises to reduce the curtailment of renewable electricity sources and the need for fossil power, providing clear global benefits. However, depending on the storage type, negative net effects on the environment may arise during the life-cycle of electricity storage. The use of energy storage with electricity generation increases the input energy required to produce electricity, as well as the total GHGs. ${ }^{16,207}$ The issues are numerous and this review can only provide an outline of the chief environmental issues when considering the development of the technology. Many of the environmental concerns 
are also engineering, operational and economic. ${ }^{148}$ General considerations are discussed, followed by more specific issues associated with specific CAES storage types.

\subsubsection{General}

DCAES, based on conventional gas-turbine technology, involves combustion of fossil fuels, a consequence of which is that DCAES has considerably higher emissions during operation than the other storage-only technologies. ${ }^{16}$ Total GHG emissions, excluding primary electricity generation have been calculated at c.288 tonnes $\mathrm{CO}_{2} \mathrm{e} / \mathrm{GWh}$ (see Table 4), most of the direct emissions arising during operation from the combustion and transportation of natural gas to the CAES site.

Using life-cycle assessment (LCA) methodology, often involving LCC analyses, a number of studies have assessed the environmental performance of electricity storage technologies and, in particular, grid applications. ${ }^{16,211}$ The 'cradle-to-grave' approach takes into account all energy and emissions related to an energy plant, including the raw material extraction, construction, processing, manufacturing, distribution, use phase, repairs and maintenance, and decommissioning (disposal/end of life and/or recycling of materials). The life-cycle greenhouse gas (GHG) emissions from electricity delivered by an energy storage facility originate from three major sources: generation of electricity to be stored, storage plant operations and construction of the energy storage facility. ${ }^{16}$ These authors report GHG emissions in terms of tonnes $\mathrm{CO}_{2}$ equivalent $\left(\mathrm{CO}_{2} \mathrm{e}\right)$ emissions and included non- $\mathrm{CO}_{2}$ greenhouse gasses, such as methane, sulfur and nitrogen oxides.

(insert Table 4 around here)

However, emissions from primary electricity generation vary considerably, being dominated by the primary electricity generation emissions, particularly when the generation energy source is fossil. If net emissions of EES technologies are considered, then DCAES can perform more favorably. Nuclear and most renewable technologies have low life-cycle $\mathrm{CO}_{2}$ emissions (typically in the range of $10-100$ tonnes $\mathrm{CO}_{2} \mathrm{e} / \mathrm{GWh}$ ), whilst fossil generation produces between 475 and 1300 tonnes $\mathrm{CO}_{2} \mathrm{e} / \mathrm{GWh}^{224}$ - considerably higher than the 288 tonnes $\mathrm{CO}_{2} \mathrm{e} / \mathrm{GWh}$ for DCAES. 
CAES, requiring natural gas combustion, exhibits higher GHG emissions than PHS or BES when coupled with low GHG electricity generation. However, as emissions from primary electricity generation increase, DCAES becomes more competitive; when coupled with fossil fuel generation (gas, oil or coal), CAES is associated with significantly lower life-cycle GHG emissions than PHS or BES. The effect of this 'fuel switching' in the DCAES system thus makes it the preferred technology to store electricity generated from coal. ${ }^{16}$ The performance of the storage systems is reportedly tied to the electricity 'feedstocks' used, with the use of renewable energies decreasing the combustion of fossil fuels and hence reducing CAESs impact on the environment. ${ }^{211}$

Conventional DCAES is now a mature technology and its limiting factor is its dependency on natural gas. Major improvements in either reduced energy input or efficiency of these systems in the near future are unlikely. Use of renewable energy sources such as carbonneutral biomass fuels during generation would lead to significant GHG emission reductions from the DCAES systems. ${ }^{209}$

ACAES or AACAES, with predicted increased efficiencies of $70-75 \%$, promise to help reduce direct emissions further, possibly to near zero. Considering both LCOES and life-cycle GHG emissions, AACAES has relatively low life-cycle Greenhouse Gas (GHG) emissions and, together with PHS, shows the best performance for large systems. ${ }^{207}$ However, its development has not occurred although a test facility is currently operational in Switzerland (see section 3.3.2).

Development of isothermal CAES systems would lead to major reductions in direct emissions. The GCAES test facility at Gaines linked to a wind turbine, operated for about three years, supplying electricity back to the electricity grid using heat stored from compression in a pond at the surface. There was no link to fossil fuels. ${ }^{166,167}$

Using LCA, the environmental impacts associated with both CAES and ACAES systems as a means of balancing the electricity output of an offshore wind farm are addressed. ${ }^{212}$ For the CAES system, wind power production and natural gas combustion are main contributors to the assessed life-cycle environmental impacts. CAES increased acidification, particulate 
matter, photochemical oxidant formation and climate impacts significantly, but saw decreases in eutrophication, toxicity and mineral resource-depletion impacts. Significant contributors for the ACAES system were wind power production and thermal energy storage, with moderate increases in environmental impacts found across all assessed impact categories, which are sensitive to the required capacity of the thermal energy storage.

More general and indirect environmental benefits of EES and CAES include:

- Storage may lead to the integration of more renewable energy into the electricity grid;

- Reduced use of less efficient fossil-fueled power stations with relatively high air emissions per kWh, reducing air emissions from central generation;

- Time-shifting of electric energy from intermittent renewable generation makes renewables more viable alternatives to fossil-fueled generation. Depending on how it is used and where it is located, electricity storage could reduce the need for additional generation, transmission or distribution facilities, and the land on which they are built. Furthermore, if storage is located at or near loads, then reductions in energy losses associated with T\&D could be achieved.

- Reduced need for generation to provide spinning reserve and load following;

- Assist generation facilities to operate at optimal levels, reducing the use of less efficient generating units that would otherwise only run at peak time;

- Added capacity provided by electricity storage can delay or alleviate the need to build additional power plants or transmission lines.

\subsubsection{Specific Issues Relating to Geological Storage}

Early studies of CAES in the US during the mid- to late-1970s and early 1980s identified the areas of main environmental concern, which remain and are perhaps more relevant today in terms of environmental and climate change issues. At the time, many areas were poorly understood, but have subsequently been considered and reported on during development of the operational CAES plants and by the underground gas and fuel-storage industry. Investigations into $\mathrm{CO}_{2}$ disposal in porous strata (saline aquifers) continue to inform some areas. A problem determining and quantifying problems is that they are also site-specific. 
This section can only provide a short review of very differing storage environments (see section 3.3) and results of differing construction methods and generated waste products. The following areas are among the main factors when considering CAES deployment:

- Air quality and climate - pollutant emissions and meteorological impacts;

- Water quality - consumption, discharge and hydrological impacts;

- Geological structure and seismicity;

- Land requirements - both at site and for disposal of wastes;

- Fuel requirements - including required pipelines for gas or water/brine;

- Noise and safety;

- Aesthetic - including the impact of multiple surface facilities and collection/supply lines.

Of interest in the lowa investigations was the negative public perception to a CAES plant. As a result, the project name was changed from "lowa Stored Energy Plant" to "Iowa Stored Energy Park", and the project website appearance and text were revised from an engineering, power-plant orientation to conform with the various important environmental reliability and energy-security messages identified in the research as important to community members. ${ }^{179}$

\subsection{Salt Caverns}

Environmental issues for the development of salt cavern storages exist and are different from those posed by porous rock storages. During solution-mining, significant volumes of low salinity water are required, abstracted from local rivers or from the sea. Abstractions from a river can adversely impact the river system and the associated flora/fauna. Early considerations of CAES using salt caverns considered that the operational mode would be uncompensated (isochoric), as excavation costs are low and brine-compensation operation has significant design and environmental issues. ${ }^{148}$ 
During cavern creation, if no use exists for the produced brine (e.g. as a chemical feedstock in the petrochemicals industry), then it becomes a waste product, the disposal of which requires careful consideration.

Apart from the Portland gas storage project, where storage of some brine during storage operations was considered in a deep saline aquifer, ${ }^{225}$ there have been no plans to inject brine from solution-mining into porous rocks. During construction of gas storage caverns at sites close to the shore, the brine has been disposed of offshore, as at Hornsea and Aldbrough in East Yorkshire, ${ }^{225}$ as would be the case at Preesall and Portland. The EIA requires modelling of the brine plume and dispersion, plus the impacts on the local seabed and communities. At King Street in Cheshire, no local water supply or brine use was available and construction of a $61 \mathrm{~km}$ twin pipeline from the Cheshire Basin to an outflow point in the Mersey Estuary was proposed. This was to both bring in seawater and take away brine from the solution-mining of the caverns and required additional environmental analyses regarding the pipeline route. ${ }^{227}$ Such operations raise questions over the sustainable use of a mineral resource. But in all cases, the examining authorities recognised that no markets existed in the UK or indeed internationally, effectively deeming the brine a waste product. e.g. $228^{2}$

Cavern storage operations using brine compensated (isobaric) mode would partially reduce the sustainability issue, as brine would be recycled to a degree. However, it may pose environmental risk as a large surface shuttle pond/reservoir is required for the brine, which must be secure from leakage and or failure. The deep (c. $2.2 \mathrm{~km}$ ) Portland gas storage project was to operate caverns in brine-compensated mode, for which the surface storage of brine would not be practicable. Instead, brine produced during gas injection mode was to be pumped via a pipeline and injected into a deep underground aquifer some $18 \mathrm{~km}$ to the north. ${ }^{225}$ The environmental issues of both pipeline and aquifer storage had to be considered by the Council Planning officers during the application.

\subsection{Porous Rock Storage (Aquifers and Depleted Hydrocarbon Fields)}

Porous rock storage presents a complex series of problems and environmental concerns. The first is ensuring no contamination of an aquifer system. The injection of air above 
ambient temperature may affect in situ subsurface conditions, both mechanically, geochemically and also biologically. Local aquifer flows might be perturbed and, in the presence of fluids, geochemical changes leading to hydrolytic and oxidation reactions, mineral dissolution and transport, which could all lead to permeability changes, weakening and increased corrosion. In addition, oxidation could lead to depletion of oxygen in withdrawn air, which could result in impaired combustion efficiency in the gas turbines. ${ }^{229}$ Similarly, gypsum scale could be precipitated during oxidation, occluding porosity and impairing CAES performance.

The drilling of boreholes requires completions that prevent leakage of air or water between aquifers that may led to pollution of water supplies. In addition, injection of air to form a bubble within the aquifer may affect local aquifer pressures, water production and adjacent groundwaters. Water levels in existing wells may fluctuate due to long-term formation pressurisation that can occur several years after operations begin. This could lead to limiting the use of aquifers due to sensitivities of the operation to drawdown. Additionally, CAES systems themselves maybe adversely affected by unscheduled or scheduled withdrawals of water from other wells. Storage pressures would have to be determined to prevent the increased pressures in the storage reservoir causing increased pore pressures in fault zones in contact with the reservoir and which may cause movement.

Injection into depleted hydrocarbon sites will carry health and environmental risks different from aquifer storages. Injection into depleted hydrocarbon sites will require a number of considerations. Firstly, caprock integrity and possible damage will require assessment. During production the reservoir pressure declines, which may lead to settling of the caprock and overburden, causing fracturing. Upon re-pressuring of the reservoir, the opening of fractures may result, permitting the escape of either native gas or air that might migrate to the top of the reservoir. This could lead to fugitive gases finding their way, not only into overlying strata with potential aquifers, but also eventually to surface. In both scenarios, potential future hazards exist.

Furthermore, oil and gas production does not lead to the removal of all the hydrocarbons and remnant oil and/or gas (methane, but possibly $\mathrm{CO}_{2}$ and $\mathrm{H}_{2} \mathrm{~S}$ ) is present in the reservoir, 
with which the injected air will co-mingle. Consequently, during withdrawal cycles, the air will contain some native gases, which will require separation and subsequent disposal. In the case of gas, there is a real danger of explosion, whilst $\mathrm{H}_{2} \mathrm{~S}$ poses major health risks.

Well-bore desaturation and reversible air-water interface movements provide potential for geochemical reactions and the generation, transport and deposition of fine particulate matter. Particulates generated around the wellbore could be carried in the airflow to the CAES turbomachinery, where they might damage the turbine blades and other sensitive equipment. Airflow rates mean that the CAES air stream would be able to pick up particles of nearly any size generated within a few feet of the wellbore. ${ }^{229}$

Despite the potential problems associated with porous rock storage, reviews of the proposed lowa Stored Energy Park project concluded that investigations into the aquifer storage site suggested it represented a well-researched and planned "environmentally safe project". ${ }^{179}$

\subsection{Mined Voids - Lined and Unlined}

The main impacts of this form of storage relate to the production of waste rock and its use or disposal, be it at site (waste piles) or elsewhere. If local, then leaching of the waste piles can lead to contamination of surface water bodies. Dust emissions may be significant if transport is required. If water enters the storage during operations, as is the case in some fuel storages, where containment partly provided by hydrostatic pressure then produced waters may represent a risk in terms of pollution. This could be due to having dissolved material on its way to the storage, but also within the storage, with the potential for picking up gases from mineral breakdown, bacterial growth or contaminants from former coalmines.

In summary, DCAES may be of limited environmental and economic value in future energy systems, where electricity storage will increasingly be required, whereas ACAES/AACAES and ICAES may reach storage efficiencies of more than $70 \%$ for practical applications and if reductions in costs are possible, provide a better alternative to conventional CAES. ACAES is 
a promising technology for off-grid applications as it is capable of operating without the need for fossil fuels. With a demonstration plant now operating (from August 2015) in the PollegioLoderio Tunnel ALACAES project, ${ }^{165}$ this technology may prove itself to be a realistic choice for support of future hybrid systems.

\subsection{Safety Record of CAES and Some Potential Risks (Human and Environmental)}

It should be stressed that gas storage, and CAES in particular, has a good safety record. However, despite nearly 40 years operational experience, with only two commercial CAES facilities, there has been little chance for serious problems to develop during CAES operations. Health and safety hazards associated with compression of air on this scale will be similar to those associated with natural gas or carbon capture and storage, i.e. related to high pressures, the integrity of pipelines, storage structures and the associated electrical and mechanical equipment. However, stored compressed air in salt caverns does not have any hazardous toxic or asphyxiant properties, which is a significant advantage over some other stored energy concepts. This may not be true if porous rock storages are considered, particularly depleted gas fields, where the production of native gases with the withdrawn air might be possible.

At Huntorf, serious problems occurred during testing and commissioning of the plant, when human error led to overpressuring of the compressor unit, causing a 3.5 month shutdown and costly maintenance and repairs. ${ }^{231}$ Also at Huntorf, after 20 years of problem-free operations, some sections of the fibreglass reinforced plastic (FRP) production strings developed material problems, with the partial destruction of some that required replacement. ${ }^{151}$ Potential exists for salt and other corrosive or abrasive materials from the storage cavern to enter the airshaft and be carried into the turbine, where damage to the blades and associated equipment in a CAES plant might occur. ${ }^{232}$

Elsewhere, a water-compensated, $11000 \mathrm{~m}^{3}$ rock cavern air-storage system, which operated for over 30 years at Trollhättan in Sweden as part of a vehicle test facility, developed a serious problem with major consequences at the surface. ${ }^{233}$ Around 1960 , the system was overcharged and a large air-bubble entered the water shaft, blowing the fluid up to the surface and destroying the building on top of the shaft. 
Unlined rock caverns storing compressed air as part of a power-generation plant operate in Norway as air cushion surge chambers attached to hydropower plants. They have suffered leakages. ${ }^{234}$ Problems of containment have also occurred in hydraulic compressed air storages in Finland. At the Pyhäsalmi Mine extensive shotcreting (spraying of concrete at high speed as a construction and strengthening technique) and coating with an elastic bitumen was required to gain air-tightness around the void. ${ }^{184}$ The dramatic blowout event at the Kanopolis salt mine in Kansas, USA, ${ }^{235}, 236$ was not related to storage, but highlights the problems of increased air pressures underground without proper identification and sealing of old shafts.

Depleted natural gas reservoirs present a possible safety issue resulting from residual hydrocarbons remaining in the depleted formation. Additionally, some salt beds and storage caverns produce gas, as is well documented in the Strategic Petroleum Reserve (SPR) in the USA. ${ }^{237}$ Oxygen does not occur in the subsurface in the volumes required for major ignition and explosion. However, compressed air storage would provide sufficient oxygen and therefore in the presence of hydrocarbons in a depleted reservoir, the potential for ignition exists, with possible sources including heat of compression, piezoelectricity, static from the build-up of charge on dust particles caused by filling/emptying of the underground storage facility, lightning or friction and fracturing arising from earthquakes. ${ }^{238}$ The authors discuss mitigation and safety measures for storage in depleted reservoirs.

\section{Acknowledgements}

The authors are grateful to David A Jones (Natural Resources Wales) and Bob Schulte (Sandia National Laboratories) for discussions and information on aspects of environment and legislation. We also thank Drs. A Bloodworth, J Mankelow, A Hughes, Wei He and Prof. Ron Hester, all of whose comments improved earlier versions of the manuscript. DJE \& GF publish by permission of the Director, British Geological Survey. DJE acknowledges funding from the EPSRC Grand Challenge for Grid Storage IMAGES project. GC thanks M O'Brien for helpful discussions on PHS. 


\section{References}

1. EC, 2013. 2020 climate and energy package. European Commission (EC) Climate Change and Targets policy documentation. https://ec.europa.eu/clima/policies/strategies/2020 en

2. IRENA, 2017. Electricity Storage and Renewables: Costs and Markets to 2030. International Renewable Energy Agency, Abu Dhabi. International Renewable Energy Agency (IRENA) Report, October 20017, 132 pp.

3. Energy Trends, Department for Energy, Business and Industrial Strategy, London, 2017

4. Carbon Brief website article, https://www.carbonbrief.org/uk-low-carbon-generatedmore-than-fossil-fuels-in-2017, (accessed April 2018).

5. UK Government energy statistics homepage, https://www.gov.uk/government/collections/renewables-statistics, (accessed April 2018).

6. Smart Power, National Infrastructure Commission, 2016.

7. United States Department of Energy Global Energy Storage Database, http://www.energystorageexchange.org/, (accessed Dec 2017).

8. The benefits of pumped storage hydro to the UK, Scottish Renewables, Glasgow, 2016.

9. C. Bullough, C. Gatzen, C. Jakiel, M. Koller, A. Nowi and S. Zunft, 2004. Advanced Adiabatic Compressed Air Energy Storage for the Integration of Wind Energy. Proceedings of the European Wind Energy Conference (EWEC), London, UK, 22-25- November 2004, 8 pp.

10. ERP, 2011. The future role for energy storage in the UK: Main Report. June 2011 Energy Research Partnership (ERP) Technology Report, 48 pp. http://erpuk.org/wpcontent/uploads/2014/10/52990-ERP-Energy-Storage-Report-v3.pdf

11. F. Díaz-González, A. Sumper, O. Gomis-Bellmunt and R. Villafáfila-Robles, 2012. A review of energy storage technologies for wind power applications. Renewable and Sustainable Energy Reviews, 16, 2154-2171.

12. G. Salgi and H. Lund, 2008. System behaviour of compressed-air energy-storage in Denmark with a high penetration of renewable energy sources. Applied Energy, 85, 182189.

13. E. Fertig and J. Apt, 2011. Economics of compressed air energy storage to integrate wind power: A case study in ERCOT. Energy Policy, 39, 2330-2342.

14. H. Chen, T.N. Cong, W. Yang, C. Li Y. Tan and Y. Ding, 2009. Progress in electrical energy storage system: a critical review. Progress in Natural Science, 19, 291-312.

http://dx.doi.org/10.1016/j.pnsc.2008.07.014

15. P. Denholm and G.L. Kulcinski, 2003. Net energy balance and greenhouse gas emissions from renewable energy storage systems. Energy Centre of Wisconsin Report, June 2003, ECW Report Number 223-1, 55 pp. http://fti.neep.wisc.edu/pdf/fdm1261.pdf

16. P. Denholm and G.L. Kulcinski, 2004. Life cycle energy requirements and greenhouse gas emissions from large scale energy storage systems. Energy Conversion and Management, 45, 2153-2172.

17. P. Denholm and T. Holloway, 2005. Improved Accounting of Emissions from Utility Energy Storage System Operation. Environmental Science and Technology, 39, 90169022. https://pubarchive.Ibl.gov/islandora/object/ir\%3A159061

18. C. Oldenburg and L. Pan, 2012. Porous Media Compressed-Air Energy Storage (PMCAES): Theory and Simulation of the Coupled Wellbore-Reservoir System. Transport in Porous Media, 97(2), Report Number LBNL-6529E, 201-221. doi:DOI:10.1007/s11242012-0118-6 
19. H. Ibrahim, A. Ilinca and J. Perron, 2008. Energy storage systems-characteristics and comparisons. Renewable and Sustainable Energy Reviews, 12(5), 1221-1250.

20. R.B. Schainker, N. Nakhamkin, P. Kulkarni and T. Key, 2008. New Utility Scale CAES Technology: Performance and Benefits (Including CO2 Benefits). Electric Power Research Institute (EPRI) paper, EPRI 3420 Hillview Avenue, Palo Alto, California 94304, 6 pp. http://www.espcinc.com/library/EPRI Paper on CAES Technology.pdf

21. A. Pimm, S.D. Garvey and M. de Jong, 2011. Design and testing of Energy Bags for underwater compressed air energy storage. Energy, 66, 496-508.

22. P.Y. Li, E. Loth, T.W. Simon, J.D. Van de Ven and S.E. Crane, 2011. Compressed Air Energy Storage for Offshore Wind Turbines. IFPE Staff Paper, $7 \mathrm{pp}$.

23. M. Saadat and P.Y. Li, 2012. Modeling and Control of a Novel Compressed Air Energy Storage System for Offshore Wind Turbine. 2012 American Control Conference Fairmont Queen Elizabeth, Montréal, Canada, June 27-June 29, 2012, 6 pp.

24. A. Assis, J.P. Paul, A.E. Joseph and P.G. Scholar, 2015. Energy storage system for floating wind turbines. International Journal of Advanced Computing and Electronics Technology (IJACET), 2, 2394-3416.

25. S.D. Garvey, 2015.Integrating Energy Storage with Renewable Energy Generation. Wind Engineering, 39, 129-140.

26. D.A. Katsaprakakis, D.G. Christakis, E.A. Zervos, D. Papantonis and S. Voutsinas, 2008. Pumped storage systems introduction in isolated power production systems. Renewable Energy, 33, 467-90.

27. S. Rehman, M. Luai, L.M. Al-Hadhrami \& Md.M. Alam, 2015. Pumped hydro energy storage system: A technological review. Renewable and Sustainable Energy Reviews, 44, 586-598.

28. Petrescu \& Petrescu, 2015. Hydropower And Pumped Storage. Altenergymag, online article, 17 pp. https://www.altenergymag.com/article/2015/11/hydropower-and-pumpedstorage/22104

29. B. Stefen, 2012. Prospects for pumped-hydro storage in Germany. Energy Policy, 45, 420-429.

30. PSM, 1930. A ten-mile storage battery. Popular Science Monthly (PSM), July 1930, p.60. https://books.google.co.uk/books?id=sigDAAAAMBAJ\&pg=PA60\&dq=1930+plane+\%22P opular\&hl=en\&ei=zxiVTtztJ-

PrOgGvtu2kBw\&sa=X\&oi=book result\&ct=result\&redir esc=y\#v=onepage\&q=1930\%20p lane\%20\%22Popular\& $\mathrm{f}=$ true

31. M. Lempriere, 2017. Dinorwig: A unique power plant in the north of Wales. Power Technology online article, 28 March 2017. https://www.power-

technology.com/features/featuredinorwig-a-unique-power-plant-in-the-north-of-wales$\underline{5773187 /}$

32. Snowdonia Pumped Hydro: Glyn Rhonwy scheme homepage, http://www.snowdoniapumpedhydro.com/index.php/en/glyn-rhonwy, (accessed April 2018).

33. La Región 2011. La Xunta se desvincula del proyecto de Iberdrola en el Sil. La Región online article, 13/09/2011. http://www.laregion.es/articulo/ourense/xunta-desvinculaproyecto-iberdrola-sil/20110914082529164794.html

34. R.D. Allen, T.J. Doherty, L.D. Kannberg, 1984. Underground Pumped Hydroelectric Storage. Pacific Northwest Laboratory prepared for the U.S. Department of Energy, Report Number PNL-5142, 78 pp. 
35. B. Cassell, 2014. FERC issues permit for 1,500-MW pumped storage project in Ohio: Developer gets three years to study project feasibility. GenerationHub online article, 10/16/2014, 2 pp.http://generationhub.com/2014/10/16/ferc-issues-permit-for-1500mw-pumped-storage-proj

36. ECE, 2016. Comments of Eagle Crest Energy on the CAISO Draft 2015-2016 Transmission Plan, March 3rd, 2016. Eagle Crest Energy (ECE) response document, March 2016, 4 pp. https://www.caiso.com/Documents/EagleCrestEnergyCommentsDraft20152016Transmi ssionPlan.pdf

37. US Dol, 2013. Columbia Basin Project. Us Department of the Interior (US Dol), Bureau of reclamation. Reclamation: Managing Water in the West.

38. JCLD, 2001. Seawater pumped-storage power plant Japan Commission on Large Dams. Japan Commission on Large Dams (JCLD) online article.

https://web.archive.org/web/20020708041342/http://www.jcold.or.jp/Eng/Seawater/Seaw ater.htm

39. Japanupdate 2016. Experimental power plant in Kunigami dismantled. Japan Update online article, http://www.japanupdate.com/2016/07/experimental-power-plant-inkunigami-dismantled/

40. X. Luo, J. Wang, M. Dooner and J. Clarke, 2015. Overview of current development in electrical energy storage technologies and the application potential in power system operation. Applied Energy, 137, 511-536.

41. Generation of electricity and district heating, energy storage and energy carrier generation and conversion: technology data for energy plants. Danish Energy Agency, Denmark, 2012.

42. B. Zakeri and S. Syri, 2015. Electrical energy storage systems: a comparative life cycle cost analysis. Renewable and Sustainable Energy Reviews, 42, 569-596.

43. Renewable energy technologies: cost analysis series Vol. 1 Hydropower, International Renewable Energy Agency, 2012.

44. E. Barbour, I.A. Grant-Wilson, J. Radcliffe, Y. Ding, and Y. Li. Renewable and Sustainable Energy Reviews Vol. 61, 2016, p. 421.

45. Engie: understanding the capacity market article. http://business.engie.co.uk/wpcontent/uploads/2016/07/capacitymarketguide.pdf, (accessed April 2018)

46. Carbon Brief: Understanding the Capacity Market article, https://www.carbonbrief.org/guest-post-understanding-governments-capacity-market, (accessed April 2018).

47. OFGEM: Cap and Floor brochure, https://www.ofgem.gov.uk/system/files/docs/2016/05/cap and floor brochure.pdf, (accessed April 2018).

48. First Hydro website: Dinorwig station, https://www.fhc.co.uk/en/powerstations/dinorwig-power-station/, (accessed April 2018).

49. First Hydro website: Ffestiniog station https://www.fhc.co.uk/en/powerstations/ffestiniog-power-station/,(accessed April 2018).

50. Cruachan station homepage, https://www.visitcruachan.co.uk/, (accessed April 2018).

51. SSE Foyers station homepage, http://sse.com/whatwedo/ourprojectsandassets/renewables/foyers/, (accessed April 2018).

52. M. Gimeno-Gutiérrez, R. Lacal-Arántegui, Assessment of the European potential for pumped hydropower energy storage - A GIS-based assessment of pumped hydropower 
storage potential, Joint Research Centre Institute for Energy and Transport, European Commission, 2013.

53. O. Edberg, C. Naish, Energy Storage and Management Study, AEA Report for Scottish Government, 2010.

54. Scottish and Southern Energy: Coire Glas pumped hydroelectric storage scheme, http://sse.com/whatwedo/ourprojectsandassets/renewables/CoireGlas/, (accessed April 2018).

55. Glenmuckloch Pumped Storage Hydro Ltd - EIA Non-Technical Summary, https://www.buccleuch.com/wp-content/uploads/2015/12/Glenmuckloch-NonTechnical-Summary 2015 low-resolution.pdf, (accessed April 2018).

56. Scottish Power: Cruachan pumped hydroelectric storage scheme, https://www.visitcruachan.co.uk/, (accessed April 2018).

57. Renewable Energy World news article, http://www.renewableenergyworld.com/articles/2010/10/sse-to-develop-sloy-pumpedstorage-hydro-plant.html, (accessed April 2018).

58. BBC News Article, http://www.bbc.co.uk/news/uk-scotland-highlands-islands-43712533, (accessed April 2018)

59. VOA News article, https://www.voanews.com/a/tunnel-collapse-closes-ethiopias-newhydropower-project-84054397/159768.html, (accessed April 2018)

60. Thanhnien News Article, http://www.thanhniennews.com/society/vietnam-tunnelcollapse-highlights-safety-management-of-hydropower-projects-36607.html, (accessed April 2018)

61. Energy Live News Article, https://www.energylivenews.com/2013/08/13/four-die-inchinese-hydropower-tunnel-collapse/, (accessed April 2018)

62. Article: http://blogs.worldwatch.org/revolt/pump-up-that-seawater-a-remix-topumped-storage-hydro/, (accessed April 2018).

63. Hydropower Good Practices: Environmental Mitigation Measures and Benefits Case study 01-01: Biological Diversity - Okinawa Seawater Pumped Storage Power Plant, Japan, International Energy Agency, 2006.

64. News article, https://www.energy-storage.news/news/energyaustralia-ponders-worldslargest-seawater-pumped-hydro-energy-storage, (accessed April 2018).

65. News article, https://www.hydroworld.com/articles/2015/01/ferc-receives-permitapplication-for-seawater-powered-hawaii-pumped-storage.html, (accessed April 2016).

66. E McLean and D Kearney, Energy Procedia Vol.46, 2014, p.152.

67. European Commission Environmental Impact Assessment homepage, http://ec.europa.eu/environment/eia/eia-legalcontext.htm, (accessed April 2018).

68. Legislation.gov.uk website - Town \& Town and Country Planning (Environmental Impact Assessment) Regulations 1999 (as amended), https://www.legislation.gov.uk/uksi/1999/293/contents/made, (accessed April 2018).

69. UK Government guidance on Environmental Impact Assessment (England), https://www.gov.uk/guidance/environmental-impact-assessment, (accessed April 2018).

70. Scottish Government guidance on Environmental Impact Assessment, http://www.gov.scot/Topics/Built-Environment/planning/Roles/ScottishGovernment/Enviromental-Assessment/EIA, (accessed April 2018).

71. Welsh Government guidance on Environmental Impact Assessment, http://gov.wales/topics/planning/developcontrol/environmental-impactassessment/?lang=en, (accessed April 2018). 
72. Northern Ireland Department of Agriculture, Environment and Rural Affairs, guidance on Environmental Impact Assessment, https://www.daera-

ni.gov.uk/articles/environmental-impact-assessment-eia, (accessed April 2018).

73. Environmental Impact Assessment Guide to Delivering Quality Development, Institute for Environmental Management and Assessment, Lincoln, 2016.

74. The Town and Country Planning (Environmental Impact Assessment) Regulations 2017, Statutory Instruments 2017 No. 571 Town and Country Planning.

75. UK Government guidance: Water Management - Abstract or impound water, https://www.gov.uk/guidance/water-management-abstract-or-impound-water, (accessed April 2018).

76. Natural Resources Wales Information about applying for an abstraction or impoundment licence, http://naturalresourceswales.gov.uk/permits-and-permissions/waterabstraction-and-impoundment/?lang=en, (accessed April 2018).

77. Scottish Environment Protection Agency: Water regulations in Scotland, https://www.sepa.org.uk/regulations/water/, (accessed April 2018).

78. Northern Ireland Department of Agriculture, Environment and Rural Affairs, https://www.daera-ni.gov.uk/articles/abstraction-and-impoundment-licensingrequirements, (accessed April 2018).

79. European Commission Water Framework Directive homepage, http://ec.europa.eu/environment/water/water-framework/index en.html, (accessed April 2018).

80. Legislation.gov.uk website - The Water Environment (Water Framework Directive) (England and Wales) Regulations 2003, http://www.legislation.gov.uk/uksi/2003/3242/contents/made, (accessed April 2018).

81. Legislation.gov.uk website - Water Environment and Water Services (Scotland) Act 2003, https://www.legislation.gov.uk/asp/2003/3/contents, (accessed April 2018).

82. Legislation.gov.uk website - The Water Environment (Water Framework Directive) Regulations (Northern Ireland) 2003 (as amended), http://www.legislation.gov.uk/nisr/2003/544/contents/made, (accessed April 2018).

83. Guidance document on Article 6(4) of the 'Habitats Directive' 92/43/EEC, European Commission, 2007.

84. European Commission Invasive Alien Species homepage, http://ec.europa.eu/environment/nature/invasivealien/index en.htm, (accessed April 2018).

85. D. Bradley, D. Cadman and N. J. Milner, Ecological indicators of the effects of abstraction and optimisation of flow releases from reservoirs WFD21d Final Report, Scotland and Northern Ireland Forum for Environmental Research (Sniffer), 2012.

86. B. D. Smith, P. S. Maitland and S. M. Pennock, Biological Conservation, 1987, Volume 39, p. 291.

87. B. D. Smith, P. S. Maitland, M. R. Young and M. J. Carr, Monographiae Biologicae, 1981, Volume 44, p.155.

88. B.D. Smith, The ecology of Cruachan pumped-storage reservoir in relation to Loch Awe, Scotland, Institute for Terrestrial Ecology Report to NSHEB, Penicuik, Midlothian, 1980.

89. C. Mc Parland and O. Barratt, Hydromorphological Literature Reviews for Lakes - Science report: SC060043/SR1, Environment Agency, Bristol, 2009.

90. Common Standards Monitoring Guidance for freshwater lakes, Joint Nature Conservation Committee, Peterborough, 2015. 
91. The Water Environment (Controlled Activities) (Scotland) Regulations 2011 (as amended) A Practical Guide Version 8.2, Scottish Environment Protection Agency, 2018.

92. R. Boak and D. Johnston, Hydrogeological impact appraisal for dewatering abstractions Science Report - SC040020/SR1, Environment Agency, Bristol, 2007.

93. UK Government guidance: Reservoirs - owner and operator requirements (England), https://www.gov.uk/guidance/reservoirs-owner-and-operator-requirements, (accessed April 2018).

94. Scottish Environment Protection Agency: Reservoir Safety in Scotland homepage, https://www.sepa.org.uk/regulations/water/reservoirs/, (accessed April 2018).

95. Natural Resources Wales: Reservoir safety homepage, http://www.naturalresources.wales/ReservoirSafety/?lang=en, (accessed April 2018).

96. Northern Ireland Department for Infrastructure: Regulating reservoir safety in Northern Ireland homepage, https://www.infrastructure-ni.gov.uk/articles/what-reservoirs-billnorthern-ireland, (accessed April 2018).

97. A M. Folkard, North West Geography, 2008, Volume 8, p.42

98. H. Austin, D. Bradley, I. Stewart-Russon, and N. Milner, Literature review of the influence of large impoundments on downstream temperature, water quality and ecology, with reference to the Water Framework Directive, Scottish Environment Protection Agency, 2015.

99. G. E. Petts, (1986) Progress in Physical Geography, 1986, Volume 10, p. 492.

100. F. Bunea, G. D. Ciocan, G. Oprina, G. Băran and C. A. Băbuţanu, Environmental engineering and management journal, 2010, Volume 9, p. 1459

101. F. Bunea, D. M. Bucur, G. E. Dumitran and G. D. Ciocan, Ecological Water Quality Water Treatment and Reuse, 2012, p391.

102. Joint Nature Conservation Committee: Protected sites homepage, http://jncc.defra.gov.uk/default.aspx?page=4, (accessed April 2018).

103. European Commission Habitats Directive homepage, http://ec.europa.eu/environment/nature/legislation/habitatsdirective/index en.htm, (accessed April 2018).

104. Legislation.gov.uk website - Conservation (Natural Habitats) Regulations 1994 (as amended), http://www.legislation.gov.uk/uksi/1994/2716/contents/made, (accessed April 2018).

105. European Commission Habitats Directive homepage, http://ec.europa.eu/environment/nature/legislation/birdsdirective/index en.htm, (accessed April 2018).

106. Ramsar homepage, https://www.ramsar.org/, (accessed April 2018).

107. Legislation.gov.uk website - Wildlife and Countryside Act 1981, https://www.legislation.gov.uk/ukpga/1981/69, (accessed April 2018).

108. Joint Nature Conservation Committee: Wildlife and Countryside Act 1981, http://jncc.defra.gov.uk/page-1377, (accessed April 2018).

109. Legislation.gov.uk website - The Countryside and Rights of Way Act 2000, https://www.legislation.gov.uk/ukpga/2000/37/contents, (accessed April 2018).

110. Legislation.gov.uk website - Nature Conservation (Scotland) Act 2004, https://www.legislation.gov.uk/asp/2004/6/contents, (accessed April 2018).

111. Legislation.gov.uk website - Wildlife and Natural Environment (Scotland) Act 2010, http://www.legislation.gov.uk/asp/2011/6/contents/enacted, (accessed April 2018). 
112. Legislation.gov.uk website - Nature Conservation and Amenity Lands (Northern Ireland) 1985, https://www.legislation.gov.uk/nisi/1985/170/contents, (accessed April 2018).

113. Legislation.gov.uk website - Environment (Northern Ireland) Order 2002, https://www.legislation.gov.uk/nisi/2002/3153/contents, (accessed April 2018).

114. Joint Nature Conservation Committee: UK Biodiversity Action Plan, http://jncc.defra.gov.uk/ukbap, (accessed April 2018).

115. Legislation.gov.uk website - Natural Environment and Rural Communities (NERC) Act 2006, https://www.legislation.gov.uk/ukpga/2006/16/contents, (accessed April 2018).

116. Legislation.gov.uk website - Environment (Wales) Act 2016, http://www.legislation.gov.uk/anaw/2016/3/contents/enacted, (accessed April 2018).

117. Welsh Government - Environment (Wales) Act 2016, http://gov.wales/topics/environmentcountryside/consmanagement/natural-resourcesmanagement/environment-act/?lang=en, (accessed April 2018).

118. Legislation.gov.uk website - Wildlife and Natural Environment Act (Northern Ireland) 2011, https://www.legislation.gov.uk/nia/2011/15/contents, (accessed April 2018).

119. Joint Nature Conservation Committee: Country Biodiversity Strategies, http://incc.defra.gov.uk/default.aspx?page=5701, (accessed April 2018).

120. Welsh Government Natural Resources Policy homepage, http://gov.wales/topics/environmentcountryside/consmanagement/natural-resourcesmanagement/natural-resources-policy/?lang=en, (accessed April 2018).

121. European Law and Publications webpage: ECJ Case C-127/02 (Waddenzee), https://eur-lex.europa.eu/legal-content/EN/TXT/?uri=CELEX\%3A62002CJ0127, (accessed April 2018).

122. Guidance document on Article 6(4) of the Habitats Directive 92/43/EEC, European Commission, 2007.

123. Guidelines for ecological impact assessment in the UK and Ireland: Terrestrial, Freshwater and Coastal $2^{\text {nd }}$ Edition, Chartered Institute of Ecology and Environmental Management, Winchester, 2016.

124. Literature review and analysis of the effectiveness of mitigation measures to address environmental impacts of linear transport infrastructure on protected species and habitats, Report NECR132, Natural England, Peterborough, 2013.

125. I.F.G. McLean, 2003. A Habitats Translocation Policy for Britain, Joint Nature Conservation Committee, Peterborough.

126. Interim Advice Note 183/14 Environmental Management Plans, Highways England, 2014

127. NetRegs: Environmental guidance for Scotland and Northern Ireland for the Construction sector, http://www.netregs.org.uk/business-sectors/construction/, (accessed April 2018).

128. Control of Water Pollution from Construction Sites - Guidance for consultants and contractors C532, CIRIA, London 2001.

129. Environmental Permitting Guidance - Core guidance for the Environmental Permitting (England and Wales) Regulations 2010, DEFRA, London, 2013.

130. Guide to hydropower construction best practice Version 2, Joint publication by Scottish Environment Protection Agency, Scottish Natural Heritage and Scottish Renewables, 2015. 
131. P. Stone and J. Shanahan, Sediment Matters - A practical guide to sediment and its impact in UK rivers, Environment Agency, Bristol, 2011.

132. Engineering in the Water Environment Good Practice Guide - Temporary Construction Methods, Scottish Environment Protection Agency, 2009

133. NetRegs: Environmental guidance for Scotland and Northern Ireland on oil storage, http://www.netregs.org.uk/environmental-topics/materials-fuels-and-equipment/oilstorage/, (accessed April 2018).

134. UK Government guidance on oil storage regulations for business, https://www.gov.uk/guidance/storing-oil-at-a-home-or-business, (accessed April 2018).

135. UK Government guidance on waste legislation and regulations, https://www.gov.uk/guidance/waste-legislation-and-regulations, (accessed April 2018).

136. Natural Resources Wales guidance on waste management, https://naturalresources.wales/guidance-and-advice/environmental-topics/wastemanagement/?lang=en, (accessed April 2018).

137. NetRegs: Environmental guidance for Scotland and Northern Ireland guidance on waste, http://www.netregs.org.uk/environmental-topics/waste/, (accessed April 2018).

138. Good practice during wind farm construction Version 3, Joint Publication by Scottish Renewables, Scottish Natural Heritage, Scottish Environment Protection Agency, Forestry Commission Scotland, Historic Environment Scotland, 2015.

139. GB Non-Native Species Secretariat homepage,

(http://www.nonnativespecies.org/home/index.cfm, (accessed April 2018).

140. Biosecurity Guidance, Forestry Commission, 2012.

141. Scottish Natural Heritage Peatland action, https://www.nature.scot/climatechange/taking-action/carbon-management/restoring-scotlands-peatlands/peatlandaction-2018-2019, (accessed April 2018).

142. Developments on peatland: guidance on the assessment of peat volumes, reuse of excavated peat and the minimisation of waste, Joint publication by Scottish Renewables and Scottish Environment Protection Agency, 2012.

143. General Electric, 1976. Economic and Technical Feasibility Study of Compressed Air Storage. General Electric final report prepared for the US Energy Research and Development Administration Office of Conservation. Report number COO-2559-1, March 1976, 399 pp.

144. R.F. Legget, 1979. 75-year old underground compressed air plant still in use in Canada. Underground Space, 4, 29-31.

145. N. Tollinsky, 2013. Prof aims to revive Ragged Chute technology. In: Technology, online article, August 13, 2013. http://www.sudburyminingsolutions.com/prof-aims-torevive-ragged-chute-technology.html

146. FW. Gay, 1948. Means for storing fluids for power generation; 2,433,896; 1948.

147. D.J. Evans, 2009. A review of underground fuel storage problems and putting risk into perspective with other areas of the energy supply chain: In: D.J. Evans and R. A. Chadwick (eds) Underground gas storage: worldwide experiences and future development in the UK and Europe. Geological Society of London Special Publication, 313, 173-216.

148. R.D. Allen, T.J. Doherty and L.D. Kannberg, 1985. Summary of selected compressed air energy storage sites. Report prepared by Pacific Northwest Laboratory for Battelle and the U.S. Department of Energy under contract DE-AC06-76RLO 1830. Report number PNL-5091, $112 \mathrm{pp}$. 
149. D.W. Boyd, O.E. Buckley and C.E. Clark Jr, 1983. Assessment of Market Potential of Compressed Air Energy Storage Systems. Journal of Energy, 7, 549-556.

150. M. Budt, D. Wolf, R. Span and J. Yan, 2016. Compressed air energy storage - an option for medium to large scale electrical energy storage. Energy Procedia, 88, 698-702.

151. F. Crotogino, K.-U. Mohmeyer and D.R. Scharf, 2001. Huntorf CAES: More than 20 years of successful operation. Spring 2001 Meeting Orlando, Florida, USA.

152. P. Radgen, 2008. 30 years compressed air energy storage plant Huntorfexperiences and outlook. In: 3rd International Renewable Energy Storage Conference, Berlin, p. 18.

153. PowerSouth, 2017. Compressed Air Energy Storage. Mclntosh Powerplant, Mclntosh, Alabama. PowerSouth Energy Cooperative Brochure, available online, $3 \mathrm{pp}$.

http://www.powersouth.com/wp-content/uploads/2017/07/CAES-Brochure-FINAL.pdf

154. S. Zavattoni, M. Barbato, L. Geissbühler, A. Haselbacher, G. Zanganeh and A.

Steinfeld, 2014. CFD modeling and experimental validation of the TES system exploited in the Pollegio AA-CAES pilot plant. Swiss Competence Centers for Energy Research, Heat and Electricity Storage $-5^{\circ}$ Symposium, 1 pp. http://repository.supsi.ch/7878/1/SCCER5th-symposium-PSI-A1.pdf

155. J. Deign, 2017. ALACAES seeks CAES partners. Online article, March 22, 2017, 4 pp. http://energystoragereport.info/alacaes-seeks-partners-caesquest/\#sthash.sf9E7kfC.dpbs

156. M. Budt, D. Wolf, R. Span and J. Yan, 2016. A review on compressed air energy storage: Basic principles, past milestones and recent developments. Applied Energy, 170, 250-268.

157. EPRI, 2003. EPRI-DOE Handbook of Energy Storage for Transmission and Distribution Applications: Electricity Energy Storage Technology Options. Electric Power Research Institute (EPRI), Palo Alto, CA, and the U.S. Department of Energy (DoE), Washington, DC. EPRI Report, $516 \mathrm{pp}$.

158. S. van der Linden, 2010. Chapter 18 - Wind Power: Integrating Wind Turbine Generators (WTG's) with Energy Storage. In: Muyeen S.M. (Ed.) Wind Power, 415-436. http://www.intechopen.com/books/wind-power/wind-power-integrating-wind-turbinegenerators-wtg-s-withenergy-storage

159. R.D. Allen, T.J. Doherty and R.L. Thorns, 1982. Geotechnical Factors and Guidelines for Storage of Compressed Air in Solution Mined Salt Cavities. Report prepared by Pacific Northwest Laboratory for Battelle and the U.S. Department of Energy under contract DEAC06-76RLO 1830. Report number PNL-4242, 105 pp.

160. R.D. Allen, T.J. Doherty, R.L. Erikson and L.E. Wiles, 1983. Factors Affecting Storage of Compressed Air in Porous Rock Reservoirs. Report prepared by Pacific Northwest Laboratory for Battelle and the U.S. Department of Energy under contract DE-AC0676RLO 1830. Report number PNL-4707, 157 pp.

161. EPRI, 2011. Compressed Air Energy Storage Demonstration Newsletter. Electric Power Research Institute (EPRI), Palo Alto, CA., October 2011, 10 pp.

162. EPRI, 2013. CAES Projects: Development/Progress Status. Compressed Air Energy Storage Demonstration Newsletter. Electric Power Research Institute (EPRI), Palo Alto, CA., July 2013, 8 pp.

163. EPRI, 2014. Molten Salt Provides Thermal Energy Storage for ACAES. Compressed Air Energy Storage Demonstration Newsletter. Electric Power Research Institute (EPRI), Palo Alto, CA., September 2014, 8 pp. 
164. J. Wang, L. Kunpeng, L. Ma, J. Wang, M. Dooner, S. Miao, J. Li and D. Wang, 2017. Overview of compressed air energy storage and technology development. Energies, 10, 991-1013. http://wrap.warwick.ac.uk/91858/7/WRAP-overview-compressed-air-energy-storagetechnology-development-Wang-2017.pdf

165. S. Zunft, V. Dreißigacker and M. Krüger, 2016. Electricity storage with adiabatic compressed air energy storage: Results of the BMWi-project ADELE-ING. International ETG Congress, 28.-29. Bonn, Germany.

166. D. Marcus, 2011. Fuel-Free Geologic Compressed Air Energy Storage From Renewable Power. General Compression Task \#1 Deliverable Report for New Technology Implementation Grant Program 582---11---13126---3225. October 24, 2011, 9 pp. https://www.tceq.texas.gov/assets/public/implementation/air/terp/ntig/prog rpts/GC Task1.pdf

167. R.J. Lyman, 2014. Fuel-Free Geologic Compressed Air Energy Storage From Renewable Power. General Compression Task \#7 Deliverable Report for New Technology Implementation Grant Program 582---11---13126---3225. March25, 2014, Resubmitted April 30, 2014, 20 pp.

http://tceq.com/assets/public/implementation/air/terp/ntig/prog rpts/2014 GC Task7 . $\mathrm{pdf}$

168. T. Wilson and U. Turaga, 2016. Oil Majors Pursue Energy Storage. ADI Analytics online article, July 29, 2016. http://adi-analytics.com/2016/07/29/oil-majors-pursue-energystorage-technology/

169. B. Cárdenas, A.J. Pimm, B.M. Kantharaj, C. Simpson, J.A. Garvey and S.D. Garvey, 2015. Lowering the cost of large-scale energy storage: High temperature adiabatic compressed air energy storage. Propulsion and Power Research, 6, 126-133.

170. A. Gillhaus, F. Crotogino, D. Albes and L. van Sambeek, 2006. Compilation and evaluation of bedded salt deposit and bedded salt cavern characteristics important to successful cavern sealing and abandonment. SMRI Research Report No. 2006-2-SMRI, Clarks Summit (PA), USA, 2006, 118 pp.

171. F. Crotogino, G-S. Schneider and D.J. Evans, 2017. Renewable energy storage in geological formations. Proceedings IMechE Part A: Journal Power and Energy, 232, 100114.

172. EPRI, 2010. Electricity Energy Storage Technology Options: A White Paper Primer on Applications, Costs, and Benefits. Electric Power Research Institute (EPRI), Technical Update, December 2010, 170 pp.

173. P. Quast and Crotogino, F. 1979. Initial Experience with the Compressed-Air Energy Storage (CAES) - Project of Nordwestdeutsche Kraftwerke AG (NWK) at Huntorf/ West Germany. Erdöl-Erdgas-Zeitschrift, 95, 310-314.

174. S. Serata and B. Mehta, 1993. Design and Stability of Salt Caverns for Compressed Air Energy Storage (CAES). Elsevier Science Publishers B.V., Amsterdam Seventh Symposium on Salt, Vol. I, 395-402.

175. S. Aherne and J. Kelly, 2013. Project CAES Larne - An exploration program for compressed air energy storage in Northern Ireland. Solution Mining Research Institute (SMRI) Fall 2013 Technical Conference, Avignon, France, 30 September-1 October 2013, $11 \mathrm{pp}$.

176. Gaelectric, 2015. Gaelectric energy storage: The missing link. Company newsletter available on line. http://www.gaelectric.ie/wpx/wpcontent/uploads/2015/09/Gaelectric-Supplement-June-2015.pdf 
177. US DoE, 2014. Final Environmental Assessment for the Pacific Gas and Electric Company (PG\&E) Compressed Air Energy Storage (CAES) compression testing phase project, San Joaquin County, California. U.S. Department of Energy (US DoE), National Energy Technology Laboratory, Report DOE/EA-1752, 74 pp.

178. A. Ter-Gazarian, 1994. Chapter 7: Compressed air energy storage. Energy Storage for Power Systems. Peter Peregrinus Ltd., on behalf of the Institution of Electrical Engineers, London, UK. Redwood Books, Trowbridge Wiltshire, $197 \mathrm{pp}$.

https://books.google.co.uk/books?id=5VMotgCfJmACandpg=PA118andlpg=PA118anddq $=$ compressed+air+sesta+italyandsource=blandots=XLXOU7exRXandsig=Q3 46bb17tTmK c610bwnJ8sHKHQandhl=enandsa=Xandei=vPSrVle5B6Le7AbAloGwDwandved=0CCoQ6A EWAQ\#v=onepageandq=compressed\%20air\%20sesta\%20italyandf=false

179. R.H. Schulte, N. Critelli Jr., K. Holst and G. Huff, 2012. Lessons from lowa:

Development of a 270 Megawatt Compressed Air Energy Storage Project in Midwest Independent System Operator: A Study for the DOE Energy Storage Systems Program. Sandia Report, January 2012, Report number SAND2012-0388, 97 pp.

180. Hydrodynamics, 2011. lowa Stored Energy Plant Agency Compressed-Air Energy Storage Project: Final Project Report Dallas Center Mt. Simon Structure CAES System Performance Analysis. Report prepared for: lowa Storage Energy Plant Agency Des Moines, lowa, July 22, 2011, 52 pp.

181. K. Piessens, and M. Dusar, 2003. $\mathrm{CO}_{2}$ sequestration in abandoned coalmines. Proceedings of the International Coal bed Methane Symposium, May 5-9, Tuscaloosa, Alabama. Paper No. 346.

182. K. Schultz, 1998. Gas storage at the abandoned Leyden coal mine near Denver, Colorado. EPA report, contract 68-W5-0018, prepared by Raven Ridge Resources Inc., $12 \mathrm{p}$.

183. W.S. Keith, 2011. Surrebuttal testimony before the Public Service Commission of Missouri, Case NO. ER-2011-0004. April 2011, 23 pp.

https://www.efis.psc.mo.gov/mpsc/commoncomponents/viewdocument.asp?Docld=93 5587378

184. R. Matikainen, 1977. Structure and operation of underground hydraulic compressed air reservoirs in Finland. In: M. Bergman (ed), Storage in Excavated Rock Caverns: Rockstore 77. Proceedings of the First International Symposium, Stockholm, 5-8 September 1977, Pergamon Press, Vol. 3, 705-710.

185. E. Grøv, 2007. Chapter 4.2: Geological requirements and challenges for underground hydrocarbon storage. Underground Constructions for the Norwegian Oil and Gas Industry. Norwegian Tunnelling Society Publication No. 16, 27-33.

186. K. Nakagawa, T. Shidahara and T. Ohyama, 1991. Field tests on air tightness of rock for compressed air storage. Proceedings 7th International Society for Rock Mechanics (ISRM) Congress, A. A. Balkemea, Vol. I, 135-138.

187. T. Shidahara, T. Oyama and K. Nakagawa, 1993. The hydrogeology of granitic rocks in deep boreholes used for compressed air storage. Engineering Geology, 35, 125-135.

188. T. Shidahara, T. Oyama, K. Nakagawa, Kaneko, K, and Nozaki, A. 2000. Geotechnical evaluation of a conglomerate for compressed air energy storage: the influence of the sedimentary cycle and filling minerals in the rock matrix. Engineering Geology, 56, 207213.

189. J. Rutqvist, H.M. Kim, D.W. Ryu, J.H. Synn and W.K. Song, 2012. Modeling of coupled thermodynamic and geomechanical performance of underground compressed air 
energy storage in lined rock caverns. International Journal of Rock Mechanics and Mining Sciences, 52, 71-81.

190. M. Hayashi, 1991. Rock mechanics of compressed air energy storage and super magnetic energy storage in Japan. In: Rock mechanics in Japan. Japanese Committee for ISRM, Tokyo, pp 50-57

191. T. Ishihata, 1997. Underground compressed air storage facility for CAES-G/T power plant utilizing an airtight lining. International Society Rock Mechanics, 5, 17-21.

192. H.M. Kim, J. Rutqvist, D.W. Ryu, B.H. Choi, C. Sunwoo and W.K. Song, 2012. Exploring the concept of compressed air energy storage (CAES) in lined rock caverns at shallow depth: a modeling study of air tightness and energy balance. Applied Energy, 92, 653667.

193. P. Perazzelli and G. Anagnostou, 2016. Design issues for compressed air energy storage in sealed underground cavities. Journal of Rock Mechanics and Geotechnical Engineering, 8, 314-328.

194. O. Kruck, F. Crotogino, R. Prelicz and T. Rudolph, 2013. Overview on all Known Underground Storage Technologies for Hydrogen. In: Assessment of the potential, the actors and relevant business cases for large scale and seasonal storage of renewable electricity by hydrogen underground storage in Europe. HyUnder Report for Deliverable No. 31, 94 pp.

195. C. Braester and J. Bear, 1984. Some hydrodynamic aspects of compressed-air energy storage in aquifers. Journal of Hydrology, 73, 201-225.

196. E. Passaris and R. Noden, 2011. Geomechanical Parametric Studies for a Propane Storage Cavern in North Tees Salt Field in the UK. Solution Mining Research Institute (SMRI) Fall 2011 Technical Conference, 3-4 October 2011, York, United Kingdom, 10 pp.

197. J. Kepplinger, F. Crotogino, S. Donadei and M. Wohlers, 2011. Present Trends in Compressed Air Energy and Hydrogen Storage in Germany. SMRI Fall 2011 Technical Conference 3-4 October 2011 York, United Kingdom, 13pp.

198. T.J. Doherty, 1981. Air Storage Systems. In Proceedings of International Conference on Seasonal Thermal Energy Storage and Compressed Air Energy Storage, Vol. 2, CONF811066 Technical Information Service, Springfield, Virginia, 455-468.

199. R.A. Edwards, A.J.J. Goode and J.G. Rees, 1987. Preliminary Geological Assessment of compressed air energy storage (CAES) sites. British Geological Survey commercial in confidence report, WZ/87/04.

200. S.T. Horseman, S. Holloway, P.J. Hooker and J.G. Rees, 1992. Geological Assessment of Potential Sites for Compressed Air Storage. British Geological Survey commercial in confidence report, WE/92/6C.

201. Gaelectric, 2015. Project-CAES Larne, NI Section 3: Planning and Development Context. Gaelectric Environmental Statement report, December 2015, 24 pp.

202. Hyder, 2011. Environmental Impact Assessment Scoping Report. Halite Energy Group. Preesall Underground Gas Storage Facility DCO document, 128 pp.

203. EA, 2016. Onshore Oil and Gas Sector Guidance. Environment Agency (EA), Version 1, 17 August 2016, 64 pp.

204. EA, 2017. The Environment Agency's approach to groundwater protection. Environment Agency (EA), March 2017, Version 1.0, 55 pp.

205. HSE, 2016. Natural Gas Salt Cavity Storage -Guidance to Inspectors on Borehole and Cavern Design, Cavern Leaching and Operation of the Borehole and Cavern. Health and 
Safety Executive (HSE) document: SPC/ENFORCEMENT/185, 14 pp.

http://www.hse.gov.uk/foi/internalops/hid circs/enforcement/spc185.pdf

206. M. Beaudin, H. Zareipour, A. Schellenberglabe and W. Rosehart, 2010. Energy storage for mitigating the variability of renewable electricity sources: An updated review. Energy for Sustainable Development, 14, 302-314.

207. A. Abdon, X. Zhang, D. Parra, M.K. Patel, C. Bauer and J. Worlitschek, 2017. Technoeconomic and environmental assessment of stationary electricity storage technologies for different time scales. Energy, 139, 1173-1187.

208. F.R. Eldridge, 1976. Wind energy conversion systems using compressed air storage. Virginia: McLean; 1976.

209. P. Denholm, 2006. Improving the technical, environmental and social performance of wind energy systems using biomass-based energy storage. Renewable Energy, 31, 13551370.

210. P. Denholm and R. Sioshansi, 2009. The value of compressed air energy storage with wind in transmission- constrained electric power systems. Energy Policy, 37, 3149-3158.

211. L. Oliveira, M. Messagie, J. Mertens, H. Laget, T. Coosemans and J. Van Mierlo, 2015. Environmental performance of electricity storage systems for grid applications, a life cycle approach. Energy Conversion and Management, 101, 326-335.

212. E.A. Bouman, M.M. Øberg and E.G. Hertwich, 2016. Environmental impacts of balancing offshore wind power with compressed air energy storage (CAES). Energy, 95, 91-98.

213. D.O. Akinyele and R.K. Rayudu, 2014. Review of energy storage technologies for sustainable power networks. Sustainable Energy Technologies Assessments, 8, 74-91.

214. S. Sundararagavan and E. Baker, 2012. Evaluating energy storage technologies for wind power integration. Solar Energy, 86, 2707-2717.

215. S. Succar, and R. Williams, 2008. Compressed air energy storage: theory, resources, and applications for wind power. Technical report Princeton Environmental Institute, 81 pp.

216. EPRI, 2012. EPRI Report Analyzes CAES Plant Reference Design and Costs. Compressed Air Energy Storage Demonstration Newsletter. Electric Power Research Institute (EPRI), Palo Alto, CA., January 2012, 9 pp.

217. A.A. Akhil, G.H. Aileen, B. Currier, B.C. Kaun, D.M. Rastler, S.B. Chen, A.L. Cotter, D.T. Bradshaw and W.D. Gauntlett, 2015. DOE/EPRI Electricity Storage Handbook in Collaboration with NRECA. Sandia National Laboratories, Sandia Report, SAND2015-XXX, $347 \mathrm{pp}$.

218. LAZARD, 2015. Lazard's Levelized Cost of Storage Analysis - Version 1.0; 2015, 30 pp.

219. V. Jülch, 2016. Comparison of electricity storage options using levelized cost of storage (LCOS) method. Applied Energy, 183, 1594-1606.

220. T. Weiss, J. Meyer, M. Plenz and D. Schulz, 2016. Dynamische Berechnung der Stromgestehungskosten von Energiespeichern für die Energiesystemmodellierung und einsatzplanung. Z Energiewirtsch, 40, 1-14.

221. M. Obi, S.M. Jensen, J.B. Ferris and R.B. Bass, 2017. Calculation of levelized costs of electricity for various electrical energy storage systems. Renewable and Sustainable Energy Reviews, 67, 908-920.

222. G. Locatelli, E. Palerma and M. Mancini, 2015. Assessing the economics of large Energy Storage Plants with an optimisation methodology. Energy, 83, 15-28. 
223. H. Lund, and G. Salgi, 2009. The role of compressed air energy storage (caes) in future sustainable energy systems. Energy Conversion Management, 50(5), 1172-1179.

224. L. Gagnon, C. Bélanger and Y. Uchiyama, 2002. Life-cycle assessment of electricity generation options: The status of research in year 2001. Energy Policy, 30, 1267-1278.

225. D. Langham, 2007. The proposed Isle of Portland natural gas storage facility and Mappowder to Portland gas pipeline project: 2. Project Description, Text, $191 \mathrm{pp}$.

226. F. Dean, 1978. Salt cavity storage. Gas Engineering and Management, Sept 1978, 291-304.

227. E. Passaris, A. Dornan and M. O'Brien, 2011. King Street Energy gas storage scheme in the UK. Solution Mining Research Institute (SMRI) Fall 2011 Technical Conference, York, United Kingdom, 3-4 October 2011, 12 pp.

228. E.A. Simpson, 2007. Town \& Country Planning Act 1990 Planning (hazardous substances) Act 1990 Lancashire County Council: Appeals by Canatxx Gas Storage Limited. Report by the Planning Inspectorate to the Secretary of State for Communities and Local Government. Report date 30 March 2007, 318 pp.

229. S. Succar and R.H. Williams, 2008. Compressed Air Energy Storage: Theory, Resources, and Applications for Wind Power. Report prepared by Princeton Environmental Institute, Princeton University, 8 April 2008, 81 pp.

230. EPRI, 2002. Compressed-Air Energy Storage Preliminary Design and Site Development Program in an Aquifer. Electric Power Research Institute (EPRI), EM-2351, November 1982.

231. H.C. Herbst, H. Hoffeins and Z.S. Stys, 1979. Huntorf 290 MW Air Storage System Energy Transfer (ASSET) Plant Design, Construction and Commissioning. In: Proceedings of the 1978 Compressed Air Energy Storage Symposium, Vol.1, 1-17.

232. W.F. Adolfson, J.S. Mahan, E.M. Schmid and K.D. Weinstein, 1979. Geologic issues related to underground pumped hydroelectric and compressed air storage. $14^{\text {th }}$ Intersociety Energy Conversion Engineering Conference, 452-454.

233. J. Pellin, 1980. Actual C.A.E.S. technology in Europe. In: Energy Storage: a vital element in Mankind's quest for survival and progress. 1st International Assembly: Papers, 472-484.

234. D.C. Goodall, B. Aberg and T.L. Brekke, 1988. Fundamentals of Gas Containment in Unlined Rock Caverns. Rock Mechanics and Rock Engineering, 21, 235-258.

235. P. Bérest, B. Brouard and B. Feuga, 2003. Dry mine abandonment, Solution Mining Research Institute Technical Conference Paper, Fall 2003 Conference, 5-8 October, Chester, United Kingdom, $28 \mathrm{pp}$.

236. L. van Sambeek, 2009. Natural compressed air storage: a catastrophe at a Kansas salt mine. Proceedings 9th International Symposium on Salt, Beijing, Zuoliang Shaed, Vol. 1, 621-632.

237. B. Ehgartner, J. Neal and T. Hinkebein, 1998. Gas releases from salt. Sandia National Laboratories, Albuquerque, New Mexica, Sandia Report June 1998, report number SAND98-1354, 42 pp.

238. M.C. Grubelich, S.J. Bauer and P.W. Cooper, 2011. Potential Hazards of Compressed Air Energy Storage in Depleted Natural Gas Reservoirs. Sandia Report, number SAND2011-5930, 23 pp. 


\section{Table Captions:}

Table 1 Summary of technical and economical characteristics, and maturity level of electrical energy storage technologies (based upon ${ }^{14,40,42,157}$. Others where noted).

Table 2 CAES capital costs of storage (compiled from ${ }^{42,157,172}$ ).

Table 3 Main capital cost items and levelised costs breakdown for grid-scale EES systems competing with CAES (compiled from ${ }^{42}$ ).

Table 1 Life-cycle energy inputs and GHG emissions related to plant construction and operation (compiled from ${ }^{16}$ ).

\section{Figure Captions:}

Figure 1 Schematic of main energy storage systems by duration and power (compiled

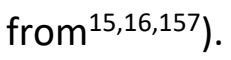

Figure 2 Location of operational and proposed PHS, hydroelectric and CAES facilities in the UK and referred to in the text.

Figure 3 Schematics of PHS schemes. a) conventional PHS with surface reservoir and discharge to lower water body, either river, lake or sea, b) underground PHS with lower reservoir created by mined void below ground.

Figure 4 Schematic to illustrate the principal EU and UK regulatory and legislative frameworks against which a PHS scheme would be assessed in the UK Figure 5 Key steps in the environmental impacts assessment process. Environmental Impact Assessment (EIA): A handbook for scoping projects, Environment Agency, 2002 (Contains public sector information licensed under the Open Government Licence v3.0)

Figure 6 Map of compressed air facilities, CAES assessments, projects and operational facilities around the world. Sample only shown for US, but including many of the more recent assessments jointly undertaken with EPRI and ARRA funding. 
Figure 7 Timeline of compressed air usage, CAES R\&D and principal industrial efforts (in part from $\left.^{156}\right)$.

Figure 8 Basic CAES configurations. a) conventional CAES (e.g. Huntorf), b) conventional CAES with recuperator (e.g. McIntosh), (c) adiabatic CAES and (d) near-isothermal CAES (refer $\left.{ }^{166,167}\right)$.

Figure 9 Schematic of operational isobaric (constant pressure) and isochoric (constant volume) pressure modes in underground storage

Figure 10 Illustration of the key EU and UK (England) legislation, regulations and regulatory bodies likely to apply to an application to develop a CAES plant. Main Planning Act (2008) and supporting policies are the likely primary legislation under which a DCO planning application would be submitted for a CAES facility onshore (highlighted). Also indicated relevant Competent Authorities involved in a DCO application and assessment, with likely applicable legislation for storage in the offshore area (Energy Act, 2008), overseen by BEIS (OGA) and The Crown Estate (TCE). 


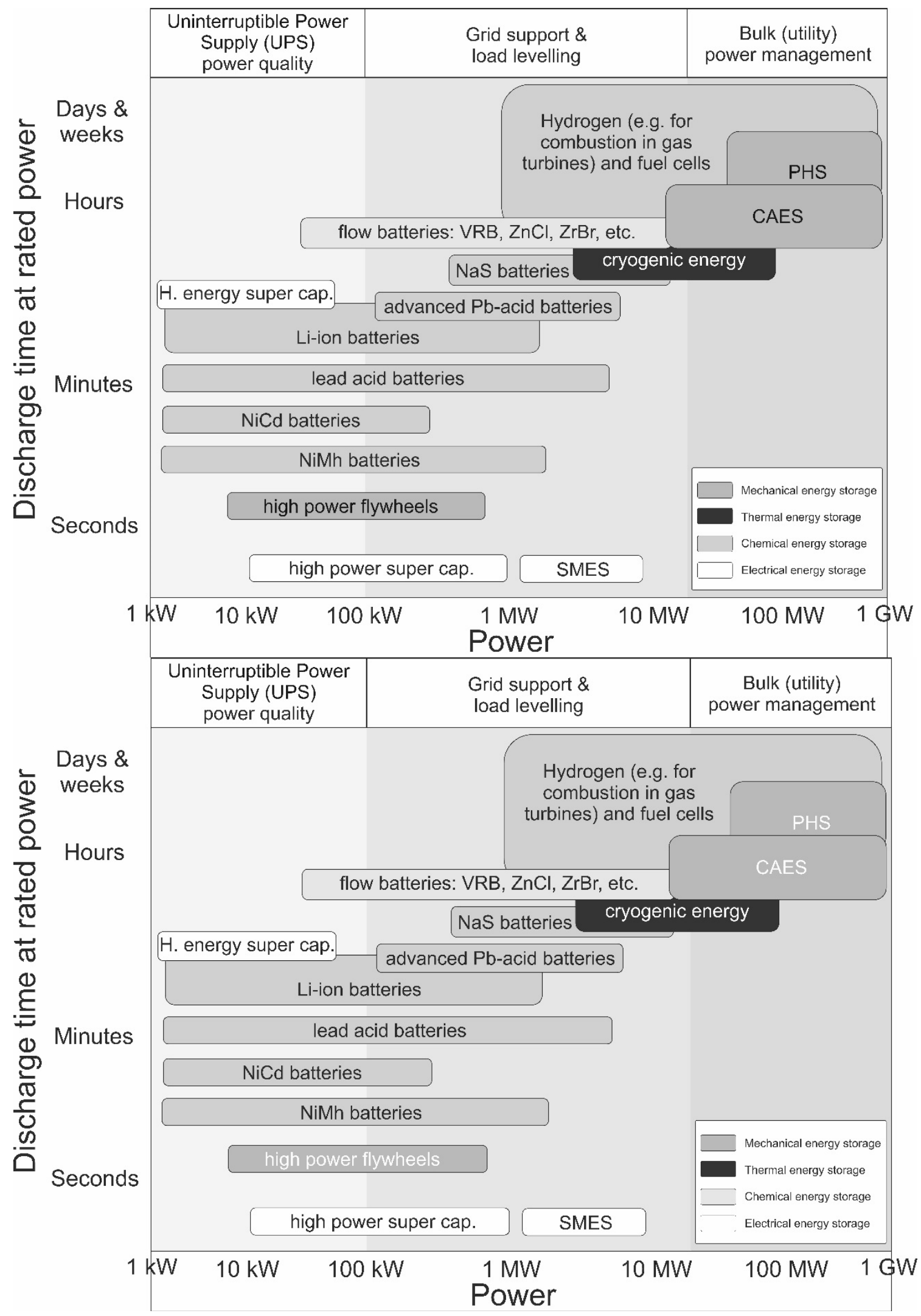

Figure 1 Schematic of main energy storage systems by duration and power (compiled from $^{15,16,157}$ ). (different text versions - for publisher to decide which is best) 


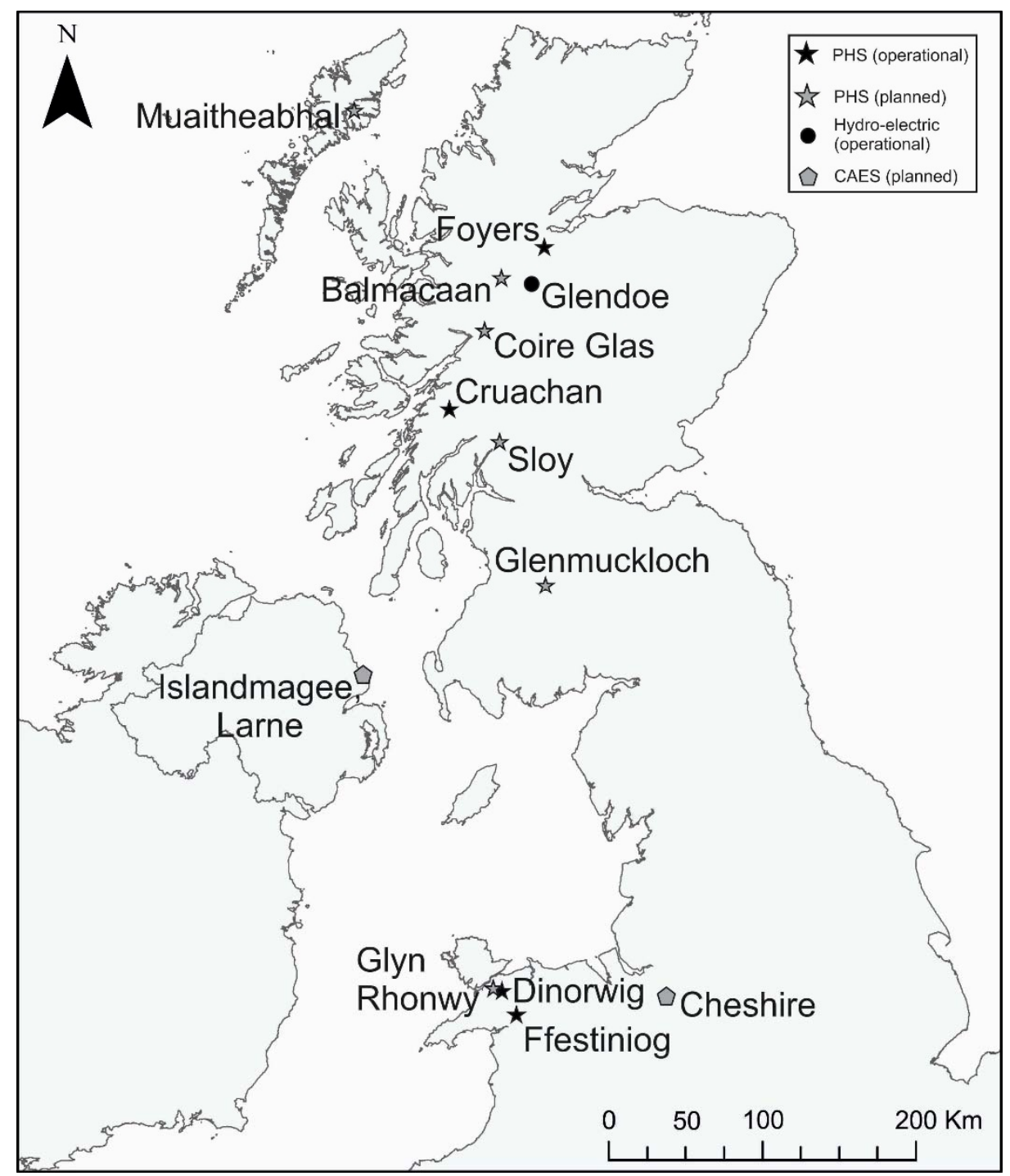

Figure 2 Location of operational and proposed PHS, hydroelectric and CAES facilities in the UK and referred to in the text. 

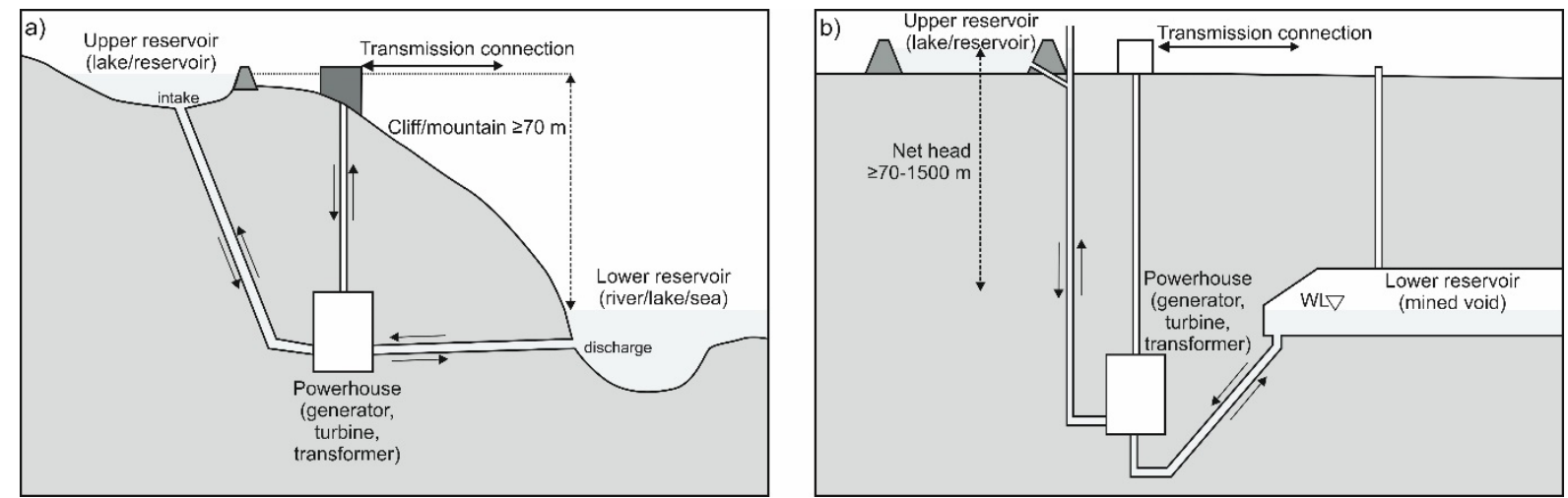

Figure 3 Schematics of PHS schemes. a) conventional PHS with surface reservoir and discharge to lower water body, either river, lake or sea, b) underground PHS with lower reservoir created by mined void below ground. 


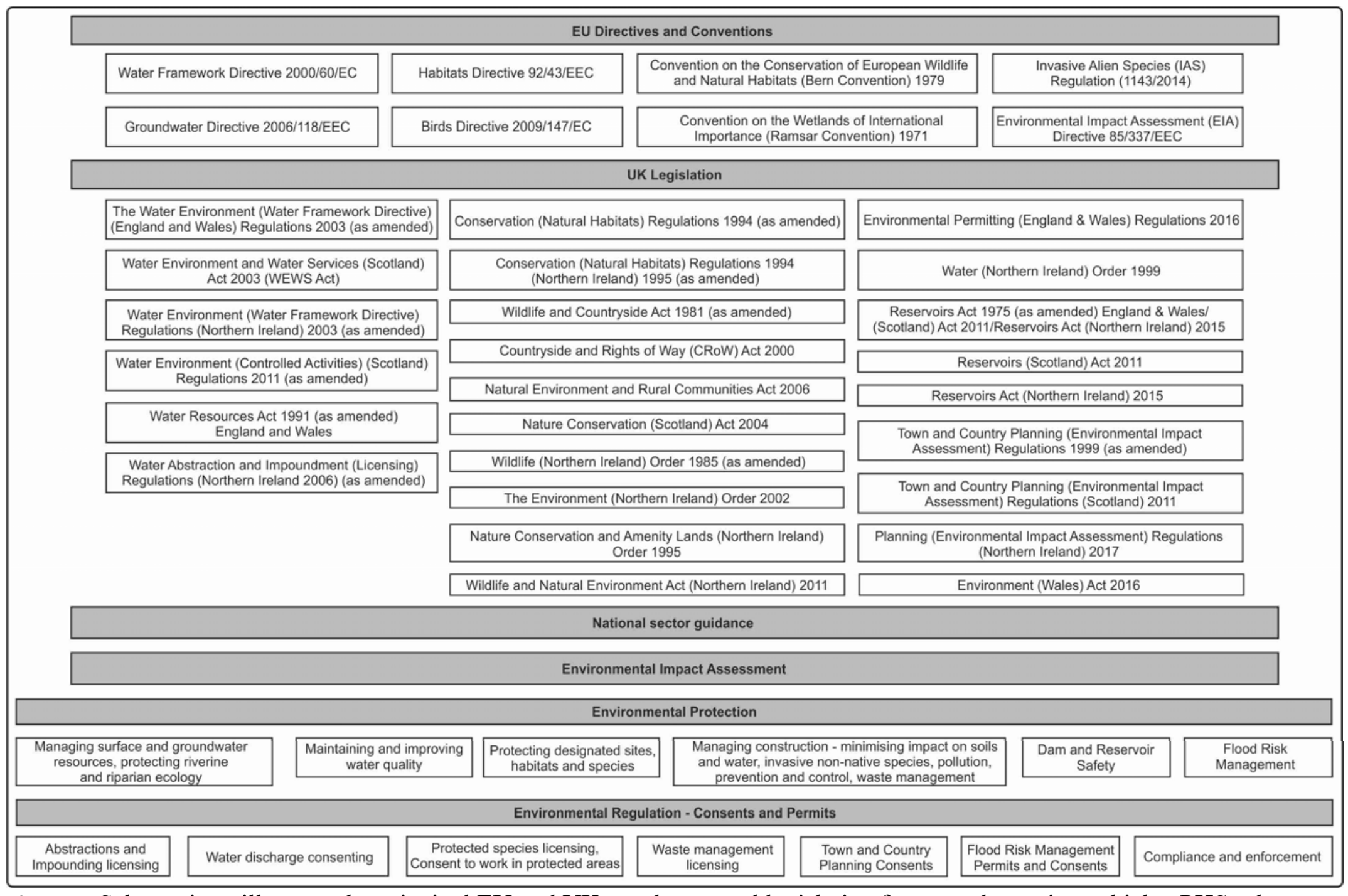

Figure 4 Schematic to illustrate the principal EU and UK regulatory and legislative frameworks against which a PHS scheme would be assessed in the UK. 


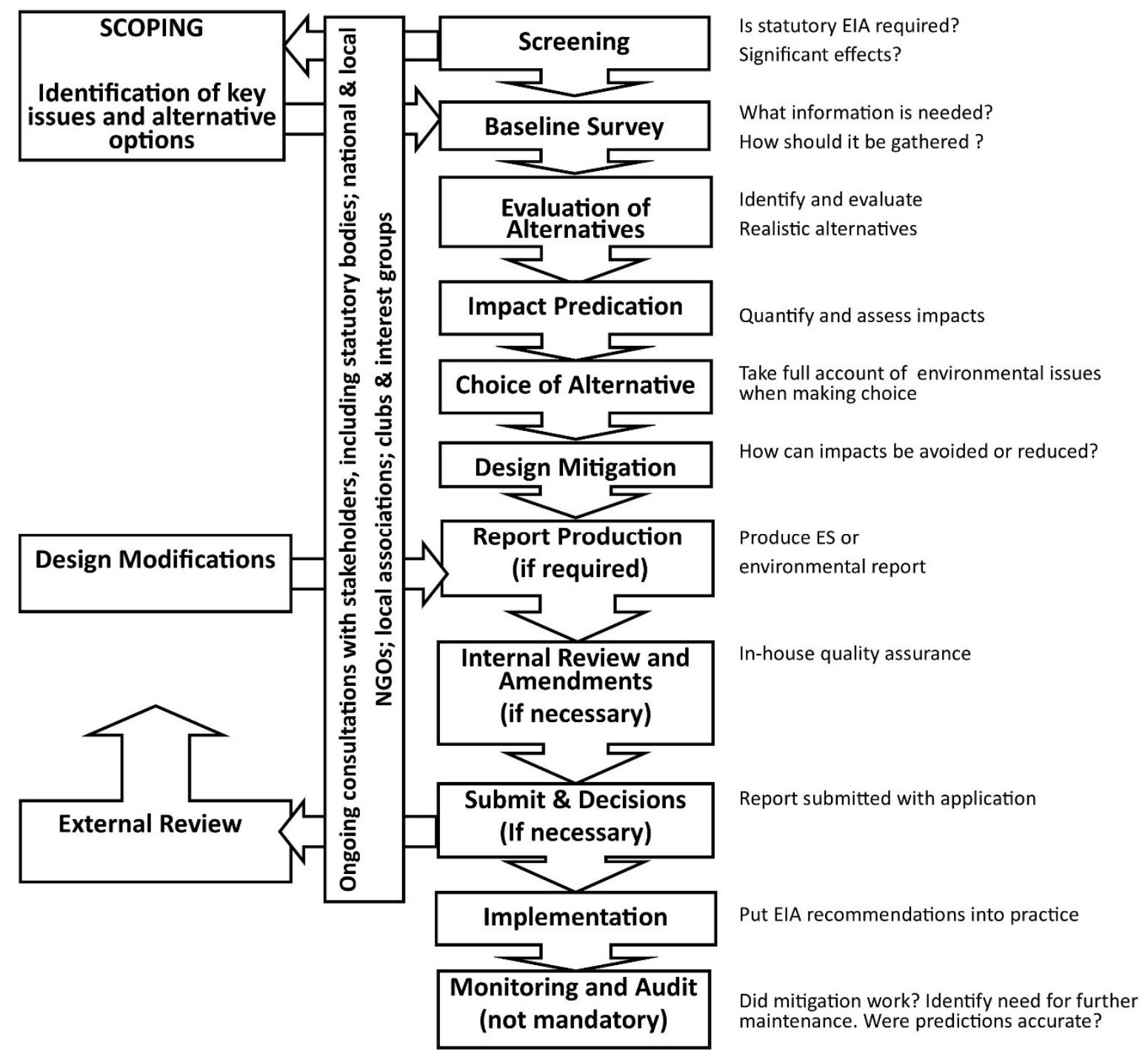

Figure 5 Key steps in the environmental impacts assessment process.

Environmental Impact Assessment (EIA): A handbook for scoping projects, Environment Agency, 2002. (Contains public sector information licensed under the Open Government Licence v3.0). 600 dpi pdf version supplied 


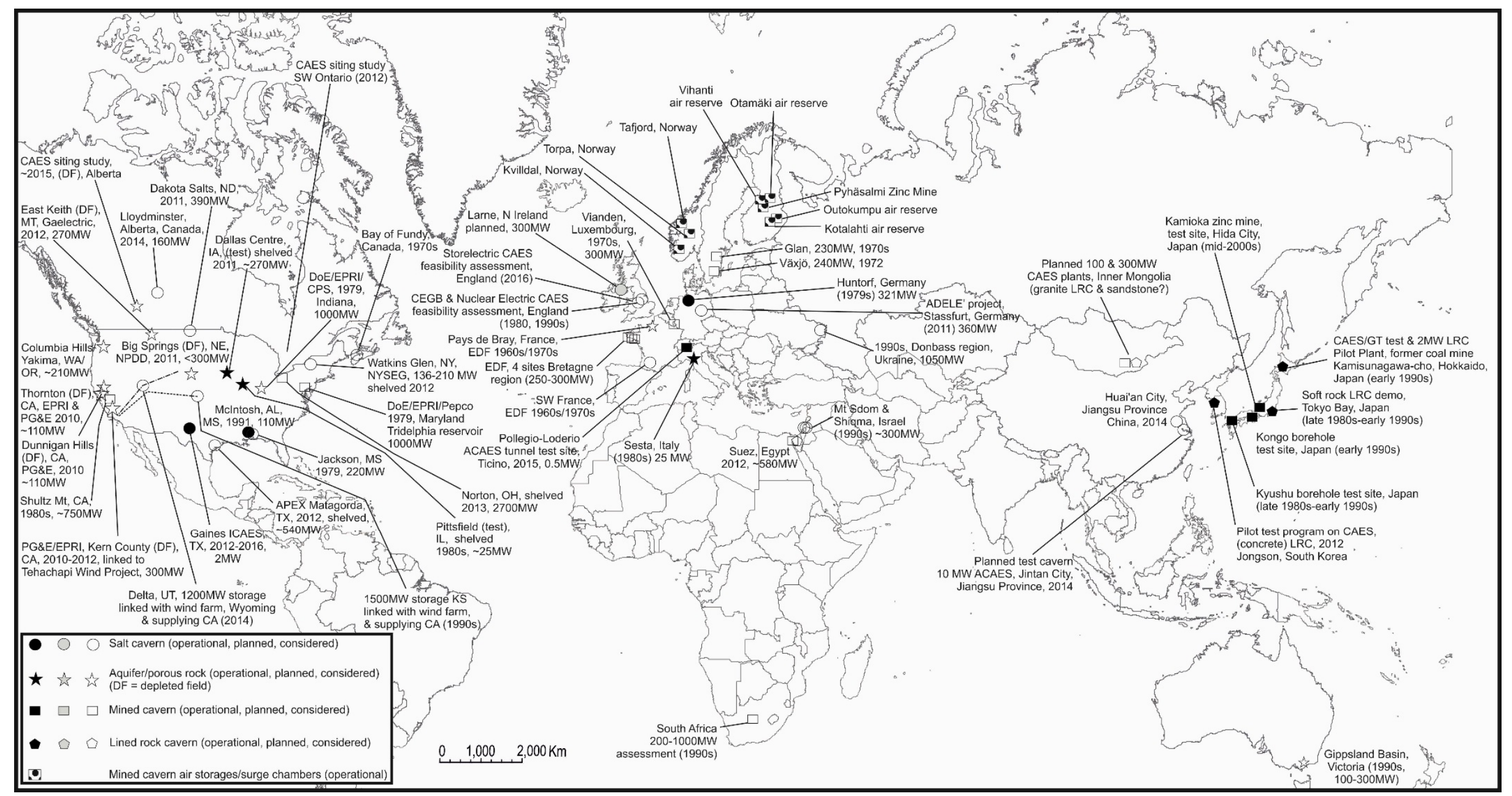

Figure 6 Map of compressed air facilities, CAES assessments, projects and operational facilities around the world. Sample only shown for US,

but including many of the more recent assessments jointly undertaken with EPRI and ARRA funding. 


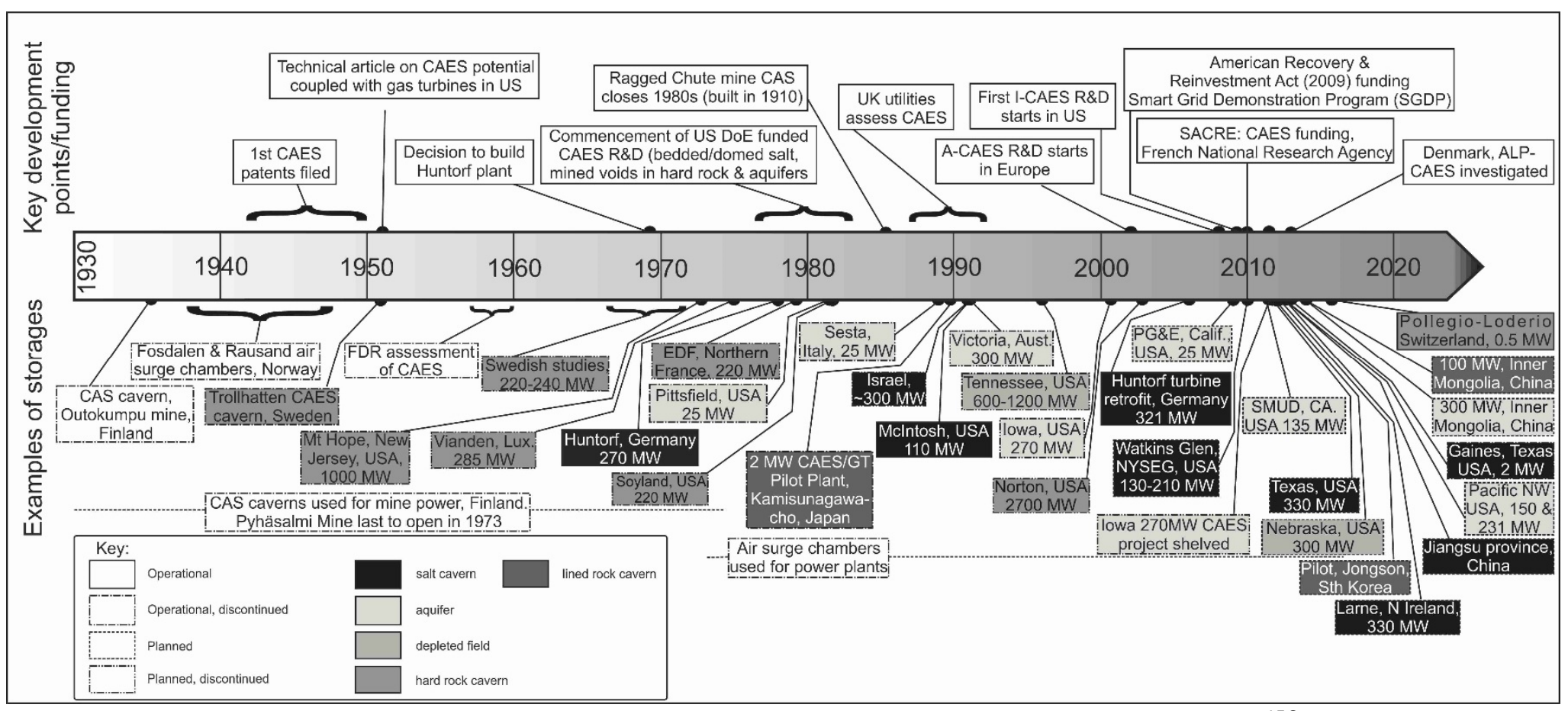

Figure 7 Timeline of compressed air usage, CAES R\&D and principal industrial efforts (in part from ${ }^{156}$ ). 


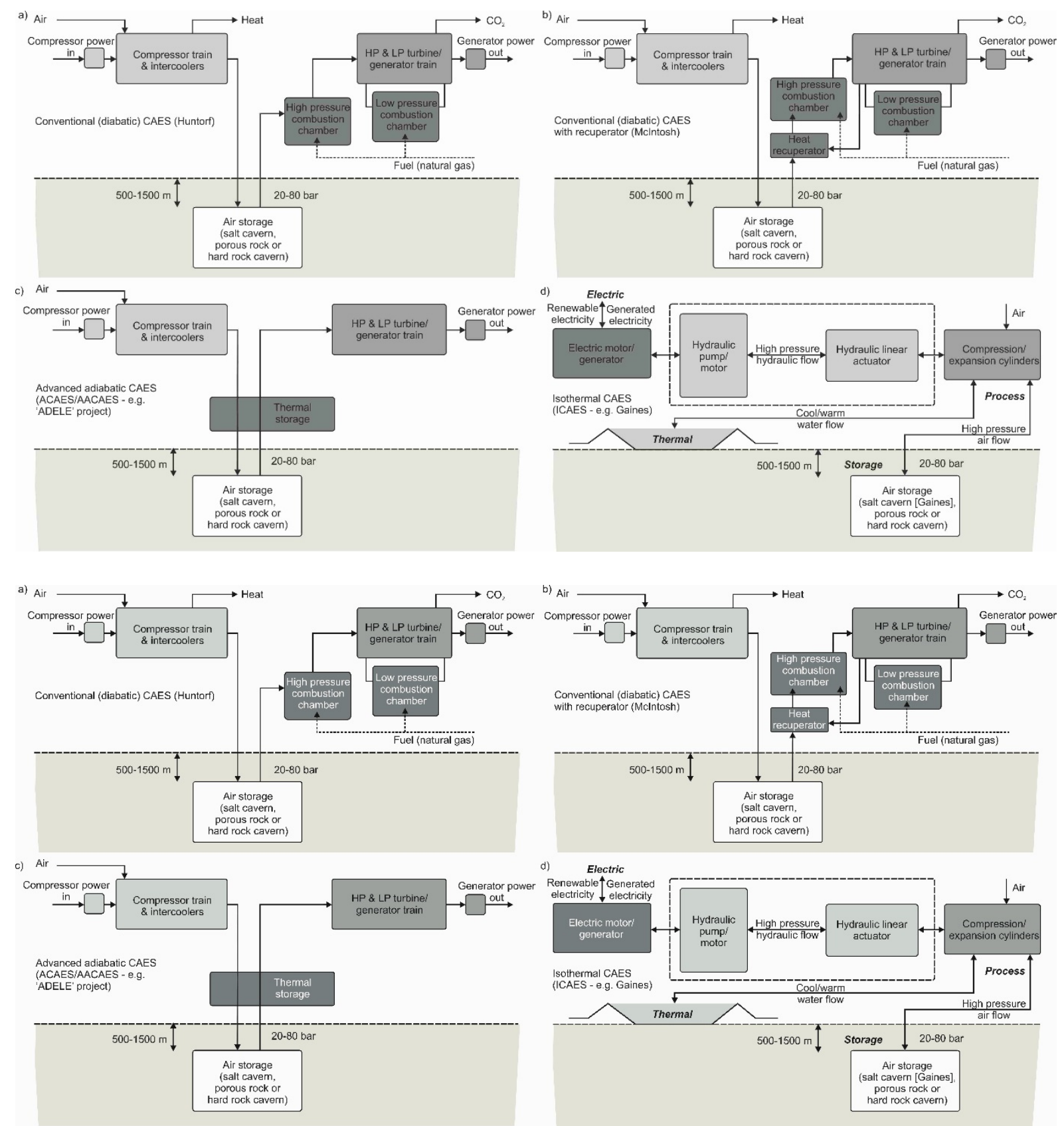

Figure 8 Basic CAES configurations. a) conventional CAES (e.g. Huntorf), b) conventional CAES with recuperator (e.g. McIntosh), (c) adiabatic CAES and (d) near-isothermal CAES (refer $\left.{ }^{166,167}\right)$. (different text versions - for publisher to decide which is best) 


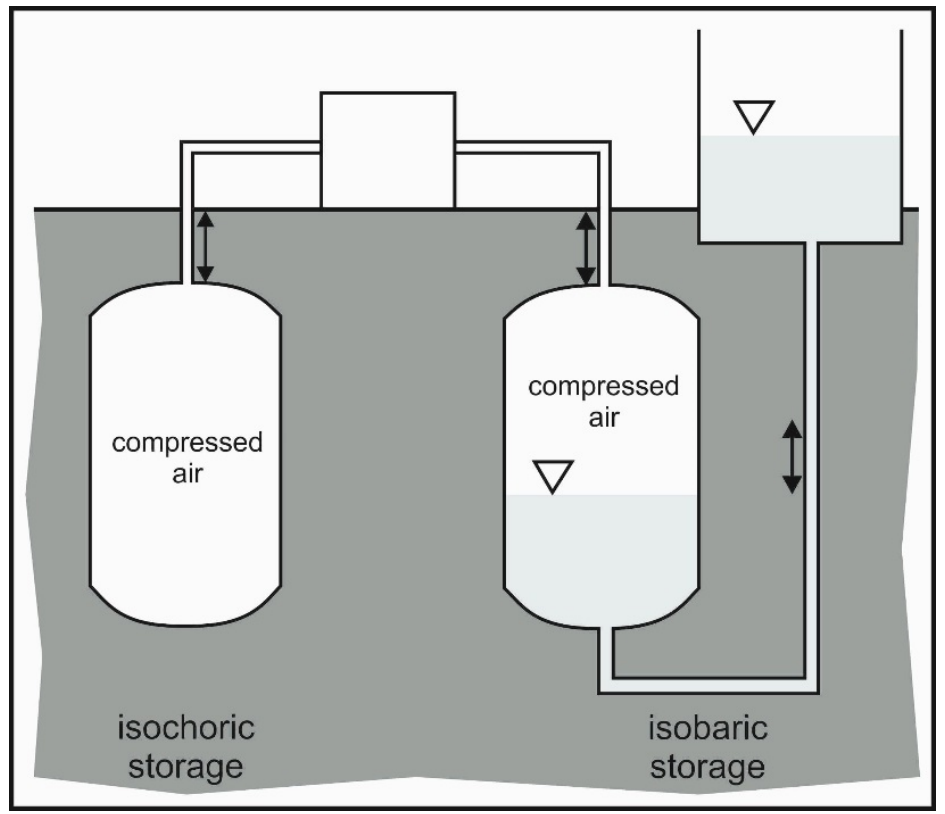

Figure 9 Schematic of operational isochoric (constant volume) and isobaric (constant pressure) pressure modes in underground storage. 


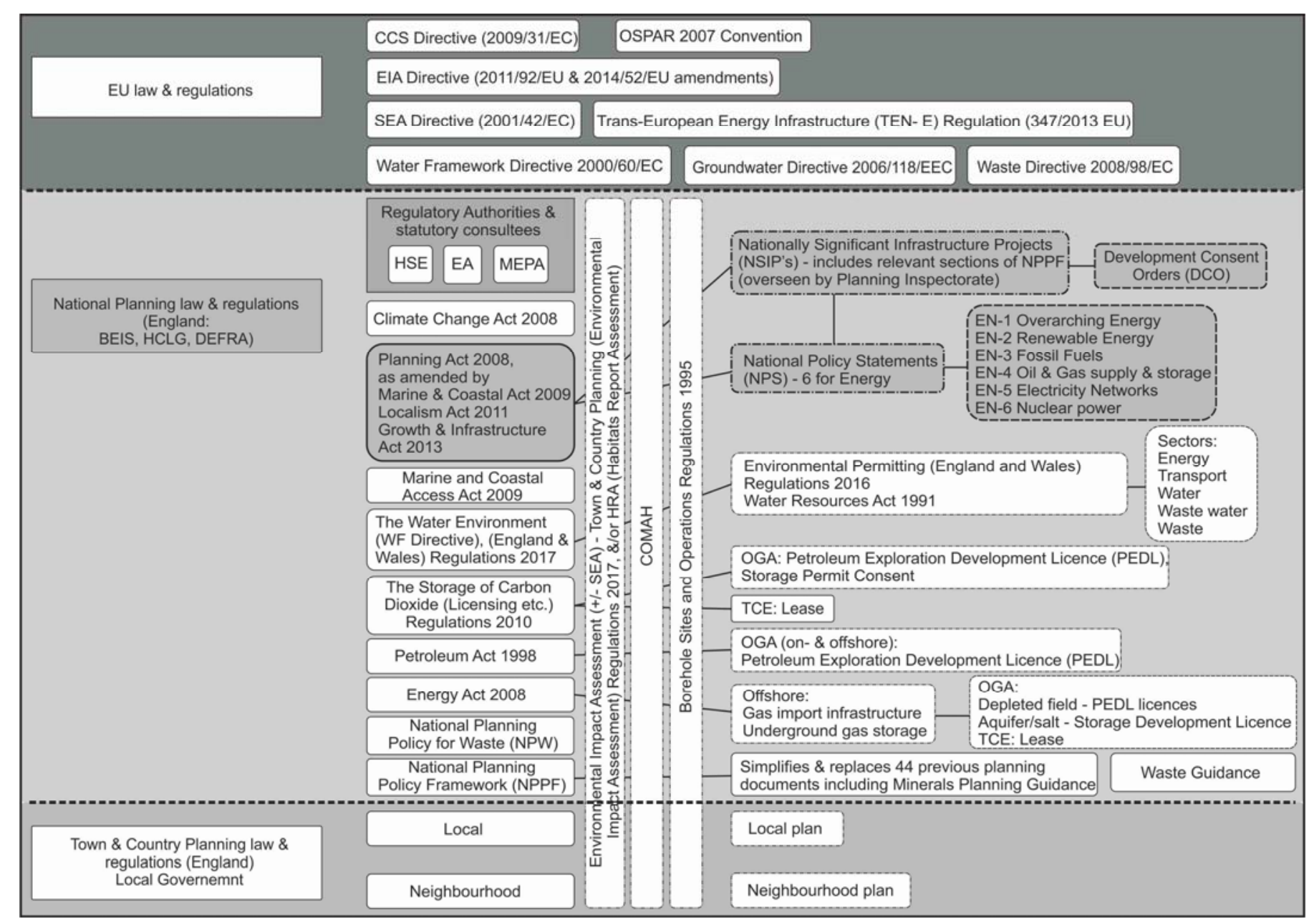

Figure 10 Illustration of the key EU and UK (England) legislation, regulations and regulatory bodies likely to apply to an application to develop a CAES plant. Main Planning Act (2008) and supporting policies are the likely primary legislation under which a DCO planning application would be submitted for a CAES facility onshore (highlighted). Also indicated relevant Competent Authorities involved in a DCO application and assessment, with likely applicable legislation for storage in the offshore area (Energy Act, 2008), overseen by BEIS (OGA) and The Crown Estate (TCE). 
Table 1 Summary of technical and economical characteristics, and maturity level of electrical energy storage technologies (based upon ${ }^{14,40,157}$. Others where noted).

\begin{tabular}{|c|c|c|c|c|c|c|c|c|}
\hline $\begin{array}{l}\text { Technology } \\
\text { (source) }\end{array}$ & $\begin{array}{c}\text { Power } \\
\text { rating } \\
\text { (MW)/ } \\
\text { Cycle } \\
\text { efficiency } \\
\text { (\%) }\end{array}$ & $\begin{array}{l}\text { General } \\
\text { storage } \\
\text { duration }\end{array}$ & $\begin{array}{l}\text { Lifetime/ } \\
\text { cycling } \\
\text { times } \\
\text { (years/ } \\
\text { cycles) }\end{array}$ & $\begin{array}{l}\text { Discharge } \\
\text { time }\end{array}$ & $\begin{array}{c}\text { Power } \\
\text { capital } \\
\text { cost } \\
(\$ / \mathrm{kW})\end{array}$ & $\begin{array}{c}\text { Energy } \\
\text { capital } \\
\text { cost } \\
\text { (\$/kW-h) }\end{array}$ & $\begin{array}{c}\text { O/M } \\
(\$ / k W / \\
\$ / k W-y r)\end{array}$ & $\begin{array}{c}\text { Technology } \\
\text { maturity level }\end{array}$ \\
\hline PHS & $\begin{array}{c}100-5000 / \\
70-85\end{array}$ & $\begin{array}{l}\text { Long term, } \\
\text { hours- } \\
\text { months }\end{array}$ & $\begin{array}{l}40-60 / \\
10000- \\
30000\end{array}$ & $1-24 h+$ & $\begin{array}{l}600- \\
4300\end{array}$ & $5-100$ & $0.004 / \sim 3$ & $\begin{array}{c}\text { Commercialised, } \\
\text { mature }\end{array}$ \\
\hline $\begin{array}{l}\text { Large-scale } \\
\text { below } \\
\text { ground CAES }\end{array}$ & $\begin{array}{l}5-300 / \\
42-54\end{array}$ & $\begin{array}{l}\text { Long term, } \\
\text { hours- } \\
\text { months }\end{array}$ & $\begin{array}{l}20-40 / \\
8000- \\
12000\end{array}$ & $1-24 h+$ & $\begin{array}{l}400- \\
1000\end{array}$ & $\begin{array}{l}2-<50 \\
\text { (?up to } \\
120 \text { ) }\end{array}$ & $\begin{array}{c}0.003 / \\
19-25\end{array}$ & $\begin{array}{c}\text { Commercialised, } \\
\text { mature }\end{array}$ \\
\hline $\begin{array}{l}\text { Above } \\
\text { ground } \\
\text { small-scale } \\
\text { CAES }\end{array}$ & $\begin{array}{c}0.003-3 \\
/-\end{array}$ & $\begin{array}{l}\text { Long term, } \\
\text { hours- } \\
\text { months }\end{array}$ & 30000+ & $30 s-3 h$ & $\begin{array}{l}517- \\
550\end{array}$ & $200-250$ & Very low & $\begin{array}{l}\text { Immature, test/ } \\
\text { development } \\
\text { stage }\end{array}$ \\
\hline $\begin{array}{l}\text { ACAES with } \\
\text { thermal salt } \\
\text { TES }^{162}\end{array}$ & $\begin{array}{l}128 / \\
60-70\end{array}$ & $\begin{array}{l}\text { Long term, } \\
\text { hours- } \\
\text { months }\end{array}$ & - & $1-10 \mathrm{~h}$ & 1720 & - & - & $\begin{array}{c}\text { Immature, test/ } \\
\text { development } \\
\text { stage }\end{array}$ \\
\hline GE ACAES ${ }^{163}$ & $\begin{array}{l}100 / \\
66-70\end{array}$ & $\begin{array}{l}\text { Long term, } \\
\text { hours }\end{array}$ & - & $1-4 \mathrm{~h}$ & $\begin{array}{l}1070- \\
1200\end{array}$ & - & - & $\begin{array}{c}\text { Immature, } \\
\text { concept }\end{array}$ \\
\hline GE ACAES ${ }^{163}$ & $\begin{array}{c}80 / \\
70-72 \\
\end{array}$ & $\begin{array}{c}\text { Long term, } \\
\text { hours }\end{array}$ & - & $1-4 \mathrm{~h}$ & $\begin{array}{l}1150- \\
2000 \\
\end{array}$ & - & - & $\begin{array}{c}\text { Immature, } \\
\text { concept }\end{array}$ \\
\hline Flywheel & $\begin{array}{l}0-0.25 / \\
90-95\end{array}$ & $\begin{array}{c}\text { Short } \\
\text { term, }<1 \mathrm{~h}\end{array}$ & $\begin{array}{l}\sim 15-20 / \\
20000- \\
21000\end{array}$ & $\begin{array}{l}\text { Millisecs- } \\
15 \mathrm{~min}\end{array}$ & $\begin{array}{l}250- \\
350\end{array}$ & $\begin{array}{l}1000- \\
5000\end{array}$ & $\begin{array}{c}0.004 / \sim 2 \\
0\end{array}$ & Early commercial \\
\hline $\begin{array}{l}\text { BES (VRB, } \\
\text { ZnBr, PSB) }\end{array}$ & $\begin{array}{c}30 \mathrm{~kW}-15 \\
\mathrm{MW} / \\
60-80\end{array}$ & $\begin{array}{l}\text { Hours- } \\
\text { months- } \\
\text { long term }\end{array}$ & $\begin{array}{c}5-20 / \\
2000+- \\
12000+\end{array}$ & Secs-10 hr & $\begin{array}{l}600- \\
2500\end{array}$ & $150-1000$ & $\sim 20-\sim 80$ & $\begin{array}{c}\text { Demo \& } \\
\text { commercialised }\end{array}$ \\
\hline
\end{tabular}

Table 2 CAES capital costs of storage (compiled from ${ }^{42,157,172}$ ).

\begin{tabular}{|c|c|c|}
\hline Geology & $\begin{array}{c}\text { Storage/reserve } \\
\text { capacity cost }(\$ / k W h)\end{array}$ & $\begin{array}{c}\text { Cost of storing air adjusted } \\
\text { figures }(€ / k W h)\end{array}$ \\
\hline Salt cavern - solution mining & $1-5$ & 1.01 \\
\hline Salt 'cavern' - dry mining & 10 & 9.71 \\
\hline
\end{tabular}




\begin{tabular}{|l|c|c|}
\hline $\begin{array}{l}\text { Porous rock - aquifer, } \\
\text { depleted field }\end{array}$ & 0.1 & 0.1 \\
\hline Hard rock - existing mine & 10 & 29.55 \\
\hline Hard rock - excavated cavern & 30 & 9.71 \\
\hline $\begin{array}{l}\text { Abandoned mine - } \\
\text { limestone, coalmine etc. }\end{array}$ & 10 & \\
\hline
\end{tabular}


Table 3 Main capital cost items and levelised costs breakdown for grid-scale EES systems competing with CAES (compiled from ${ }^{42}$ ).

\begin{tabular}{|c|c|c|c|c|c|c|c|c|c|c|}
\hline \multirow[b]{2}{*}{$\begin{array}{l}\text { Bulk } \\
\text { EES } \\
\text { type }\end{array}$} & \multicolumn{10}{|c|}{ Costs (average) } \\
\hline & $\begin{array}{l}\text { Cost of PCS } \\
\text { (€/kW) - } \\
\text { average/ } \\
\text { range }\end{array}$ & $\begin{array}{l}B O P(€ / k W) \text { - } \\
\text { average/ } \\
\text { range }\end{array}$ & $\begin{array}{l}\text { Cost of storage } \\
\text { section ( }(/ \text { /kWh) } \\
\text { - average/range }\end{array}$ & $\begin{array}{c}\text { Fixed O\&M } \\
\text { costs } \\
\text { (€/kW-yr) - } \\
\text { average/range }\end{array}$ & $\begin{array}{l}\text { Variable } \\
\text { O\&M costs } \\
\text { (€/MWh) - } \\
\text { average/ } \\
\text { range }\end{array}$ & $\begin{array}{l}T C C, \text { per } \\
\text { unit of } \\
\text { power } \\
\text { rating } \\
(€ / \mathrm{kW})\end{array}$ & $\begin{array}{l}\text { TCC, per } \\
\text { unit of } \\
\text { storage } \\
\text { capacity } \\
\text { (€/kWh) }\end{array}$ & $\begin{array}{c}\text { Annualised } \\
\text { LCC } \\
(€ / k W-y r)\end{array}$ & $\begin{array}{c}L C O E \\
\text { (delivered } \\
\text { electricity) } \\
-€ / M W h\end{array}$ & $\begin{array}{l}\text { LCOS } \\
\text { (€/MWh)- } \\
1-8 \text { hour } \\
\text { periods }\end{array}$ \\
\hline $\mathrm{NiCd}$ & $239 / 206-329 * 1$ & & 780/564-1120 & $11 / 4-24$ & NA & 1093 & 699 & 842 & 421 & $\sim 500-350$ \\
\hline $\mathrm{Fe}-\mathrm{Cr}$ & $362 / 326-523 * 1$ & & $145 / 64-156$ & $3.3 / 2.7-6.9$ & 0.4/0.1-1.0 & 1132 & 569 & 417 & 209 & $\sim 675-140$ \\
\hline VRFB & $490 / 472-527^{* 1}$ & & $467 / 433-640$ & 8.5/3.4-17.3 & $0.9 / 0.2-2.8$ & 2512 & 307 & 706 & 353 & $\sim 690-290$ \\
\hline $\mathrm{NaS}$ & $366 / 241-865^{* 1}$ & & 298/180-563 & $3.6 / 2.0-17.3$ & 1.8/0.3-5.6 & 2254 & 343 & 487 & 244 & $\sim 410-190$ \\
\hline $\begin{array}{l}\text { Lead- } \\
\text { acid }\end{array}$ & $\begin{array}{c}378 / \\
95-594\end{array}$ & $87 / 43-130$ & 618/184-847 & $\begin{array}{c}3.4 / \\
3.2-13.0\end{array}$ & $\begin{array}{c}0.37 / \\
0.15-0.52\end{array}$ & 1923 & 437 & 646 & 323 & $\sim 575-270$ \\
\hline $\begin{array}{l}\text { Fly- } \\
\text { wheel }\end{array}$ & $\begin{array}{c}287 / \\
263-470 * 1\end{array}$ & & $2815 / 865-47764$ & $\begin{array}{c}5.2 / \\
4.3-6.0\end{array}$ & $\begin{array}{c}2.0 / \\
0.2-3.8\end{array}$ & 867 & 4791 & 210 & NA & NA \\
\hline $\begin{array}{l}\text { CAES } \\
\text { (above } \\
\text { ground) }\end{array}$ & $\begin{array}{c}846 / \\
804-887\end{array}$ & NA & 109/86-131 & $2.2 / 2.2-3.7$ & 2.2/1.9-3.0 & 1315 & 263 & 319 & 159 & $\sim 355-100$ \\
\hline $\begin{array}{l}\text { CAES } \\
\text { (under } \\
\text { ground) }\end{array}$ & $\begin{array}{c}843 / \\
543-1014\end{array}$ & NA & $40 / 4-64 * 2$ & $\begin{array}{c}3.9 / \\
2.0-4.2 * 3\end{array}$ & $\begin{array}{c}3.1 / \\
2.2-2.5^{* 4}\end{array}$ & 893 & 92 & 269 & 134 & $\sim 315-71$ \\
\hline PHS & $\begin{array}{c}513 / \\
373-941 \\
\end{array}$ & $15 / 3-28$ & $68 / 8-126$ & $\begin{array}{c}4.6 / \\
2.0-9.2 \\
\end{array}$ & $\begin{array}{c}0.22 / \\
0.19-0.84 \\
\end{array}$ & 1406 & 137 & 239 & 120 & $\sim 250-54$ \\
\hline
\end{tabular}


Table 2 Life cycle energy inputs and GHG emissions related to plant construction and operation (compiled from ${ }^{16}$ ).

\begin{tabular}{|c|c|c|c|}
\hline & Component & Life cycle energy & GHG emissions \\
\hline \multirow{9}{*}{ 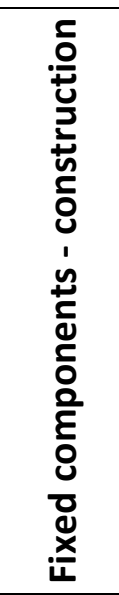 } & & $\begin{array}{c}\text { (GJt/MWh storage } \\
\text { capacity) }\end{array}$ & $\begin{array}{c}\text { (tonnes CO2e/MWh } \\
\text { storage capacity) }\end{array}$ \\
\hline & $\begin{array}{l}\text { Cavern } \\
\text { development }\end{array}$ & 16.2 & 1.2 \\
\hline & Site and buildings & 36.7 & 3 \\
\hline & Plant electrical & 65.9 & 4.7 \\
\hline & Subtotal - plant & 102.6 & 7.8 \\
\hline & Electrical T\&D & 14.2 & 1 \\
\hline & Gas infrastructure & 130.5 & 9.2 \\
\hline & Decommissioning & 2.3 & 0.2 \\
\hline & Total & 265.7 & 19.4 \\
\hline \multirow{6}{*}{ 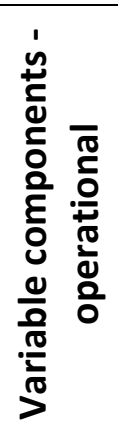 } & & (GJt/GWh) & (tonnes CO2e/GW h) \\
\hline & Fuel & 4649 & 234 \\
\hline & Fuel delivery & 518 & 51 \\
\hline & O\&M\&SCR & 42 & 3 \\
\hline & $\begin{array}{l}\text { Total variable- } \\
\text { EEop, Efop }\end{array}$ & 5210 & 288 \\
\hline & ERnet & $\begin{array}{c}0.735 \text { times primary } \\
\text { energy }\end{array}$ & $\begin{array}{c}0.735 \text { times source } \\
\text { emissions }\end{array}$ \\
\hline
\end{tabular}

